\title{
Absolute Pitch Acquisition as Memory System with Its' Musical Executive Function from Cognitive Neuropsychological Perspective
}

\author{
Irina G. Andreeva ${ }^{1}$, Maria Dymnikowa ${ }^{2,3,4}$, Elena A. Ogorodnikova ${ }^{2}$, Valentin I. Petrushin ${ }^{3,5}$. \\ ${ }^{1} \mathrm{PhD}$ in biology, Laboratory of comparative physiology of sensory systems, I. M. Sechenov Institute of Evolutionary Physiology \\ and Biochemistry, Russian Academy of Sciences, Toreza pr.44,194223 Saint-Petersburg. \\ ${ }^{2} \mathrm{PhD}$ in biology Laboratory of Psychophysiology of Speech, I. P. Pavlov Institute of Physiology, Russian Academy of Sciences, \\ Makarova nab. 6, 199034 Saint-Petersburg. \\ ${ }^{3}$ Association of Musical Psychologists and Psychotherapists, Akademika Anohina st. 38/3, 119602, Moscow. \\ ${ }^{4} \mathrm{PhD}$ in psychology, Laboratory of Music-therapy, Institute of Psychiatry and Neurology, al. Sobieskiego 1/9, 02957 Warsaw. \\ ${ }^{5}$ Prof. in music psychology, P. I. Tchaikovsky Moscow State Conservatory, Bolshaya Nikitskaya st. 13/6, 125009 Moscow. \\ Authors'Email: ig-andreeva@mail.ru,dmwl@bk.ru,elena-ogo@mail.ru,valpetr-psy@yandex.ru.
}

\begin{abstract}
Absolute (perfect) pitch is defined as the ability to identify and categorize a musical pitch - tone frequency by its name in the musical equal temperament tuning system without an external reference tone. The article presents absolute pitch process as long-term working semantic musical memory with musical executive function included in musical practical activity, with the description of similarities between music and language structure in music cognitive neuropsychology studies' evidence, as a background for cognitive neuropsychological possibilities of its generally available development. The article describes methodological assumptions' content of empirically developed aural behavioral psychological memory training method 'absolute pitch ecological practical activity' (APEPA) for childhood and youth age, based on working memory span, aural cognitive learning ability in music education and performance activity, in cognitive music neuropsychology field.
\end{abstract}

Keywords - absolute pitch, executive function, long-term working memory, music memory training.

\section{INTRODUCTION}

Absolute pitch (AP) in scientific literature is identified as cognitive music ability (i.e. skill) or process (i.e. function), concerning the musical sound (i.e. extracted from musical instruments or human voice with its' overtone structure and accurate timbre). The AP definition in music psychology studies' methodology $[10,18,30,40,63,64,107,145,174,198,214,216,248,288,292,311]$ is described as:

1. A rare ability of categorical perception of isolated music pitch tone frequency of accurate timbre and of equal tempered tuning system, with 12 chromatic semitones as chromas of octave's musical unit, with overtones' structure of each pitch frequency - i.e. in height' components with fundamental frequencies on related algorithm tuning sounding [128], where tone height is a function of auditory scene analysis, with tone chroma described as an 'information stream' [312]. Whereas timbre $[5,288]$ is the quality characteristic of the sound of a specific music instrument or voice, that is defined as an attribute that enables us to distinguish sounds of the same duration, volume, pitch and location in space, especially to distinguish musical instruments that play the same pitch frequency note. 2. With its rapid spontaneous response (i.e. AP passive form) of double naming identification:

2.1. Of pitch height's class (i.e. pitch-semitone-label from 12 literal name-labels' system) with its spatial variety (i.e. chroma from 10 octave number or name - labels) identification, with AP errors defined by Revesz [243] and Bachem [10,11], that are classified according to two established pitch dimensions: tone height and tone chroma The height is a sensation of natural pitch corresponding to linear frequency changes (e.g. from low to high), whereas the chroma refers to an octave circularity inherent in named musical pitch classes within each octave. Chroma change is specifically represented anterior to the primary auditory cortex, whereas height change is specifically represented posterior to the primary auditory cortex [312].

2.2. Or additional production (i.e. AP active form) of kinesthetic vocal vs. music instrumental reproduction of perceived pitch frequency, also the aural reproduction from its note-name form visual perception). Identification process in the AP passive form concerns additionally the variant of tonality's tonic key identification (i.e. of functional harmony classical tonality system), where the same semitones have different a harmonic function of accurate tonality (i.e. key). 3. Without using any reference tone (i.e. without relative comparative estimation with an external pattern, what is presented in relative pitch perception of musical tones, as the ability to name one pitch when given the name of another [146], i.e. the ability to identify the standard tonal intervals [274], without the possibility to recognize exact pitch frequency). 4.On the basis of musical pitch labeling (i.e. long-term pitch memory with language phoneme systems). Asian Online Journals (www.ajouronline.com) 
The article presents reliable basic scientific empiric evidence, methodological backgrounds statement, and developmental resources of AP acquisition as the cognitive musical process on the basis of memory and language with its neuropsychological organization, and as the applied executive functional statement in musical performance activity by voice or musical instrument at middle childhood or youth period - i.e. after the critical period for AP development in early childhood conception, i.e. until age $7^{\text {th }}[47,145,173,198,240,268,269,288,306$, 309], with the method of AP acquisition during learn-ability duration designed for population oriented on constant musical performance activity with its education, in cognitive music neuropsychology field.

The music facture might be organized into the single-line structure (i.e. monophonic) or multi-lines structures (i.e. homophonic vs. polyphonic) - it imposes conditions of music's listening, learning and performance, where 'clear' AP is used only for the perception of single music pitch (i.e. only in the one-voice melody). Whereas co-sound has imposed sounds (i.e. intervals of 2 and chords of $>2$ simultaneous sounds), what is called harmonic structure including relational hearing and analysis of perceived musical pitch-frequencies. In this logical knowledge analysis the method of AP testing by the key description (i.e. tonality label of musical piece with homophonic vs. polyphonic facture) is belonged firstly to relative pitch and then to absolute hearing the single components of co-sounds, thus form of AP is 'mixed' or 'complex' with relative pitch processing, presented structurally in scheme 1 .

Scheme 1. Structural forms of AP use and diagnosis.

\begin{tabular}{|c|c|c|}
\hline $\begin{array}{c}\text { CLEAR ABSOLUTE PITCH } \\
\downarrow\end{array}$ & $\begin{array}{l}\text { MIXED / COMPL } \\
\downarrow \downarrow \text { on basis }\end{array}$ & $\begin{array}{l}\text { ABSOLUTE PITCH } \\
\text { ative pitch }\end{array}$ \\
\hline $\begin{array}{l}\mathbf{1} \text { - single sounds } \\
\text { one line melody }\end{array}$ & $\begin{array}{l}2 \text { - intervals } \\
\text { co-sounds of } 2 \text { sound }\end{array}$ & $\begin{array}{l}3 \text { - chords tonal / atonal } \\
\text { co-sounds of }>2 \text { sounds }\end{array}$ \\
\hline $\begin{array}{l}\text { AP single pitch-tone identificatior } \\
\text { by: - name-label of perceived pitc } \\
\text { - reproduction on musical inst } \\
\text { - reproduction of written pitch }\end{array}$ & $\begin{array}{lr} & \text { AP } \\
\text { passive) } & \text { Egu } \\
\text { nent (active) } & \\
\text { ne-label by voice (activ }\end{array}$ & $\begin{array}{l}\text { (i.e. tonality) identification } \\
\text { Chord Identification Method } \\
\qquad[76,251]\end{array}$ \\
\hline
\end{tabular}

AP processing has bilateral brain specialization, where tone height is analyzed in right hemisphere auditory areas, while pitch class is analyzed in left auditory areas [131], what has independent empirical evidence in brain's white and gray matter data of neuropsychological studies. So neuropsychological resources of AP acquisition concern the psychological training for inter-hemispheric connectivity optimization with its' work balance improvement in the implementation of cognitive behavioral tasks on the basis of memory and language learning mechanisms, on the principle of controlled production and performance of 'stimulus - reaction' activity in human's behavior. Cognitive neuroscience is delivering the diagnostic and neuro-rehabilitation methods, that might be also effective in using it for neuropsychological training for healthy people for improving their cognitive functioning or developing specialized complex cognitive abilities, especially as the executive functions, while the limitations of the AP research conditions described below creates gaps for a deeper analysis of the overall AP nature.

Primary historical scientific description of AP in literature belonged at the end of $19^{\text {th }}$ century to Stumpf Tonpsychologie [278], with written in music psychology literature the researchers' conclusion about absence of fully understanding the cognitive mechanisms for the AP phenotype [73, 152, 235, 261, 288] with no agreed level at which an individual is considered to be with an AP (i.e. possessor) [21] including its experience-dependent effect, which is a result of musical training and altered acoustic environment. Most of the AP researches with scientific evidence concerning musical material: 1. With narrow octave range (mostly middle octaves). 2. With sound of pure tone, piano tone (with diagnostic scale - system of white and black keys' musical pitch, with labeling in the 'do-system' [287]), synthesized piano tone and voice. 3. With single studies for other musical timbres. 4. With absence of researches for whole pitch frequencies' scale of many musical instruments' timbre especially in duration of AP acquiring by people in middle childhood and youth period (as the most critical key period in developmental psychology for the conscious motivated decision of music education completing for its constant musical performance practice in the future for art and gainful activity). Additional absence of diagnostic tests and training methods for AP acquisition with the standards of psychological tests and trainings applied for music psychology duration determines pragmatic production of solutions in this range with the adaptation of only scientific knowledge for access to this ability investment, without the possibility of modeling other psychological technologies in this field. 
Most music psychology studies with empirical evidences explains the etiology of AP ability through early-learning theory, with the critical period of its acquisition in earlier childhood until the age $7^{\text {th }}[47,145,173,198$, 240, 268, 269, 288, 306], while there is no study known in which an adult acquired AP through memory training and reached the same proficiency, in terms of accuracy, speed, and effortlessness, as children in earlier childhood with AP presence [288]. At the same time in behavioral sciences' evidence anyone holds the potential to acquire AP under necessary and sufficient training conditions.

Independently there is no clear definition of accurate musical experience or proper behavioral musical training method needed for AP acquisition [18, 30, 108, 109, 173, 288, 309, 322] with the type of musical training most effective for AP development yet unidentified [324], with the evidences of specializes strategies used to encode musical pitches except for note-naming, such as notation and memorizing fingering positions on music instrument or body position on vocal organization. Primary Abraham [1] noted, that most musical experience is not conductive to the AP development. This statement was expanded by Levitin and Zatorre [174], that AP is long-term pitch memory [329] and the early musical training is not necessary for the acquisition of AP, because general musical training enhances the ability of relative pitch, whereas only the training to relate a particular auditory stimulus consistently to a certain category would train the AP ability. Latterly in single unique Ross [249] research of AP after the critical age period there is concluded, that it is possible for people to develop AP with musical training starting after the critical period, or even with little musical training at all. Additionally for proficiency measurement of AP development aspect Burns, Hulse, Takeuchi and Ward [288, 311] studies are noted about the absence of a standard method for the behavioral diagnosis of AP proficiency statement, while researchers have usually developed fresh experimental materials and scoring criteria for immediate application to their studies, what wasn't adopted for general population's psychological diagnostic procedures. That lack of consistency across studies decreases additionally the reliability of progress in the characterization of this ability impeded by non-equal comparisons between different data sets and contributing a great variability of results.

Additionally the universal nature of AP ability has been noted initially by Watt in 1917 [313], presented later by Harris [119] in 1926 that AP can be developed by memorizing tones' physical positions on the instruments, and by Oakes [206] in 1951 with the note, that anyone can develop AP under the "right" but alas unknown circumstances. Next Ward [309] conclusion noted in 1999 for absence the evidence for the learning theory of AP ability unless some technique for AP acquisition is developed that will succeed with everyone. Around of this time Levitin [2, 168, 170] suggested in 1994, that AP is not a result of 'more highly developed perceptual mechanisms' but an issue of memory and linguistic coding, where it is not developed as a result of a lack of musical training and exposure, with the evidence from 1970 of Brady [37] as the first adult achieved AP after months of practice. Baharloo et al. [19] posted in 2000, that AP can be train in any person, what was confirmed additionally in 2003 in Schellenberg [258] and Trehub [299] research, that pitch memory is a common ability and offers implicit support of a universal potential for AP, as musical skill involving the association of musical sounds with specific verbal labels. Later Sakakibara [251] AP research study noted in 2014, that AP is an ability that can be acquired through intentional training, although there is the absence of evidence of successful AP development for adults through direct training method for that ability.

Methodological research of AP nature realized by Deutsch [63, 65] in 2013 revealed description of AP genesis for its acquisition possibility. This ability was originally a linguistic ability that has been recruited for musical purposes, it has innate resources can be acquired at any time through intensive practice, and most people do have the potential to acquire it during learning process with the access to simultaneous note names presentations with exposed pitches, as a required condition of its realization. While Miyazaki, K., and Ogawa, Y. [198] earlier research in 2006 noted, that most children are able to name all 12 semitone - pitch - labels in the same manner as adults with around age $7^{\text {th }}$ or later (i.e. after to critical period of the early-learning theory of AP acquisition). It doesn't include the indispensability of musical notation learning in the case to complete the structural linguistic components of named labels presented in music notation schemes, especially in the case of the same tone - labels of different octave space (i.e. chroma's type), what may delay the age period for AP acquisition readiness. Additionally skill acquisition theory, as an alternative to critical period of early-learning theory, support the evidences for AP as an auditory skill that is developed by both short-term and long-term memory [18, 69], where people are able to develop AP ability through explicit perceptual training at any age, so also at post-critical period, what has important implications for understanding the nature of AP processing. Also fresh Hedger et. al [301] study in 2018 of training AP in adults revealed, that adult AP acquisition is possible with learning that remains stable months after explicit training has ended, with the note in the abstract, that accurate perceptual training can lead AP acquisition in some adults, that is indistinguishable to form up AP at childhood period on the behavioral level [82]. 
These scientific conditions of AP studies described above prompted to look for the AP scientific evidence through the neuroscience data of AP brain organization processing and to cognitive musical psychological methodological studies for AP as memory process. It came to the backgrounds for the empirical developed methodological solution of AP acquisition directed for the targeted population with its ergonomic and pragmatic importance in the scientific range of developing the musical brain and the human's cognitive functions resources during cognitive neuro-psychological training without cultural limitations. From the cognitive neuropsychological perspective AP as a memory system with its executive function is an example and evidence of how the interaction of a specific type of training and environmental experience can shape this specialized cognitive musical skill on the basis of income biological and psychological resources.

\section{ABSOLUTE PITCH AS MEMORY SYSTEM}

AP as complex process is conditioned by complex cognitive functions, such as memory, language and thinking. For memory process classification it concerns working memory and long-term memory in time-memory varieties, which of specifications are described below according to AP nature. Memory for time limitations processing is divided into sensorial (e.g. echoic, iconic), working, short-term and long-term type. Memory for material content might be extracted such as semantic (e.g. categorical knowledge), music (matter's material) or associative memory. Memory system refers to completed structural functioning of cognitive processing beginning from perceptual level, during semantic work-out of input information and knowledge, with completing at the executive automatic level. AP concerns working memory, associative memory and long-term memory that are described below. AP might be conceptualized in direction of the memory system as complex ability [22, 30] or musical auditory skill [124] with the note categorization performance strengthened depending on short-term and long-term memory resources, that continually influence AP performance. The frequency of regular hearing the accurate timbres, pitch classes of octaves determine the speed and accuracy of AP note identification based on specific auditory experiences [22, 196], with the possibility of AP improvement during active musical instrument playing [72, 314].

Working memory refers to a brain system that provides temporary storage and manipulation of the information necessary for complex cognitive tasks [13], is included learning, comprehension and reasoning [14]. This complex system contains the following stages [15]: encoding (i.e. registration of information), storage (i.e. maintenance of information over time, for aural receptor it concerns phonological store and articulatory rehearsal processing with two independent systems for verbal and tonal material stimuli [61, 253] with manipulation of information, and retrieval (i.e. recall or recognition). Recall and decoding of information is dependent on the hippocampal formation including the entorhinal, perirhinal and parahippocampal gyrus [39, 71, 78], where the hippocampus is inhibited during the recall of remote memories [87, 221] and tonal information [39, 71, 81, 220], involved in storing information [83, 252, 282], in the formation of relational representations, in the recall of semantic information, in encoding, recall and recognition of associative memory [27, 77, 191].

Conditional associative memory is applied in the establishment of a long-term representation for the pitch of a musical note and its pairing with a conventional name, where fundamental frequencies of a relatively large number of notes are able to be recognized form long term memory traces, i.e. representations of pitches with semitone resolution. Conditional association between an auditory stimulus and an arbitrary label happens during naming a note. The conditional associative pairing of a stimulus dimension to a label and the retrieval of this information is a universal ability which is applied specifically in the case of AP processing. This high-resolution category formation in the auditory domain is the principal feature of the AP ability.

Working memory is a basic mechanism for executive functions (where AP belongs), which is necessary for processes like attentional control, sequential planning, implementation and monitoring of intermediate results, and therefore essential for complex cognitive tasks, like language comprehension, reasoning and learning. Whereas learning and memory are defined as the abilities for acquiring new information and retain it over time [98], what can be modified and changed by the experience and by the environment [153, 192, 244], what definition is correctly described the AP ability features. It is important predictor of perceptual category learning [175] as important part of categorical perception and identification of AP units [274] during its explicit training [303]. It play a role in the process underlying musical pitch-frequency recognition, as an executive attention system to maintain and manipulate information during cognitive processing goal [16, 54]. It can be improved through training [199] and is engaged in higher-level problem solving and abstract reasoning skills. It is a structural content of fluid intelligence [151] with included: 1. Aural pitch reproduction of forward and backward (n-back) tasks with empiric evidence of possibility of learning AP categories by adults [302]. 2. Forming up effortlessly identified pitch notes' representations, with taking into account that AP training might enhance auditory digit span [67]. 
Working memory in auditory recognition, as listening effort, is relate to comprehension processing [247], where lower aural musical experience may increase listening mistakes through less precise presentations of music labeling and competing for pitch, respectively, increasing the reliance on working memory for sufficient categorization of perceptually challenging notes, with dynamic character of AP skill. Incoming signal is generally mismatched from human's internal representation [247], and auditory trace may be held in working memory with increasing the demands, i.e. improve memory capacity [7, 205], during comparing the incoming auditory signal with internal musical pitch note representations for behavioral backward interpretation, including timbre differences [305]. So in AP training listeners direct attention to pitches in a formal musical system, which kind of listening experience is directly related to the skill of identifying pitch notes from their sounds, with AP conceptualization as kind of 'second language' [68] where executive control of attention is engaged in a switching process between music pitch and speech (pitch labeling) representations.

Working memory is synonymous with attention process at the methodological level, so might be described by attention's features, such as distractors. The attention studies, investigating the influence of irrelevant noise on task performance, revealed evidence about task-irrelevant distractors can improve performance, where performance-enhancing effects can be due to modulation of attentional focus through induced by the distractors with the improvement of mild acoustic distraction [75, 207]. The performance improvement occurs as a result of the arousing nature of noise because optimum levels of arousal have been shown to enhance performance [38]. The distractors enhance attentional performance under certain conditions, as for example aural noise presence before the purposeful stimulus for estimation in AP acquisition method (APEPA), thereby improving task performance during enhancing effort allocation and implementation of attentional-control strategies [85] and enhances subsequent attentional performance [140,224]. So the preliminary preceding stimulus information enhances task-relevant processing even when it is in direct competition with task-relevant stimulus [281].

The attentional system is more activated and engaged when a stimulus is about to appear, even when it is clear that this stimulus is distracting, since people not only do not inhibit distractors prior to their presentation but, in fact, allocate more attentional resources when expecting distractors [180]. In 'programming memory' duration attentional distractors determine the resistance of the memory trace and reduced susceptibility to forgetting information in time mode after each training session, and enhance the features of focus, alertness, selectivity and focusing in extracting information from persistent memory (i.e. long-term working semantic musical memory). Rakowski and Morawska-Bungeler [239] study revealed that humans can hold pitches in short-term memory for periods as long as 5 minutes, what is the methodological background for initial requirements of AP training for the repeated presentation of accurate semitone unit with its chromas.

Long-term working memory for AP content, described in detail below, processing includes the internal template of pitch-labels activated during the analysis of perceived pitch-tones with its' independent identification of accurate location-space in the music-note system and in vocal or music-instrument. Studies of working memory for music pitch information provide compelling evidence that music perception and music memory involve cognitive process, that are relatively independent of those related to other auditory stimuli and might be influenced by training [9, 219, 259], that improves the efficiency and accuracy with which pitch information is encoded into, and recalled from both working and long-term memory.

Long-term working memory is Ericsson and Kintsch [84] memory model, as integration of cognition and expertise, extended from Chase and Ericsson's [45] skilled memory model, is covering and unifies empirical data from several domains that are normally treated separately with including expert behavior. It was introduced to explain the evidence suggested an expanded capacity in working memory that allows people (especially experts in the accurate area), to process and work with a great deal more information than it should be possible in usual, in case of that working memory capacity may get an additional boost from long term memory. So this unexpectedly big amount of actively held information may be evidence of the use of long-term memory to keep relevant information readily available and accessible to working memory. And with sufficient experience in a given domain, knowledge structures that support performance are formed up and developed in long term memory. These knowledge structures support high-speed information retrieval, where retrieval is so rapid that information seems to be held continuously in working memory when itis actually moving between working and long term memory. Information that is active in working memory might induce a retrieval cue and structure during activating the interconnected knowledge that is readily available for use in that memory level. It concerns two encoding processes allow rapid storage into long-term memory - through the elaboration of knowledge-based associations connecting items with each other or with long-term memory patterns and schemas, and through the retrieval structures. 
Here people, as an experts in various specializations of the memory content, can encode information into long-term memory quite rapidly. Although patterns and schemas can also encode new information quite quickly independently of the use of the retrieval structure, so through knowledge-based associations between items, patterns and schemas. It's the opposite proposal to Baddeley Hitch [12, 17] working memory model, which emphasize its transitory storage capacity, while here it belongs to stable storage. Methodological assumptions with empiric development conclude that cognitive processes are conditioning a sequence of stable states representing 'end products' of processing, where developed and acquired memory skills allow these 'end products' to be stored in long-term memory and kept directly accessible by means of retrieval cues belonged to working memory, as a part of short-term memory storage. The memory task is constrained of which encoding mechanism will be employed - through retrieval structures or through long-term memory elaborations. Retrieval structures are: 1. A set of retrieval cues organized in a stable structure, developed in experts' domain of specialization through practice and study. 2. Not sufficient alone and need to be completed or supplemented by the elaboration of previously stored semantic memory. The elaboration facilitates and increases the encoding of information by providing redundant cues. An articulatory loop from the working memory model stores up to three pieces of information. A common working memory span concern 3 - 4 elements [50, 51, 52, 53, 55, 84]. Patterns and schemas consist of chunks, that formed up the hierarchical structure of higher levels. The encoding into the retrieval structure is modulated by a stimulus' parameter of information. For AP processing it concerns the components of its' executive function nature, with retrieval structures based on written, aural, kinesthetic form with its internal cooperation during music performance programming activity. AP perception of accurate musical pitches makes an influence on the programming behavior for learning music performance, especially at the level of internal hearing during working with musical notes' text.

The limitation of proposed memory model was noted by Gobet [100] in case of the concept of retrieval structure not well specified to allow sufficiently precise empirical predictions, what might what may be grounded in the variety of information's matter for its searching in memory, with yet studied this model enough widely. However, Guida et al. [112] neuroimaging research of an expertise acquisition was revealed with founded consistent evidence across studies of brain region activation patterns in novice learning and expert performance that were indicative of experts' use of long term memory in working memory tasks. So it supports the evidence for long-term working memory existence with the role of long term memory knowledge structures in extending working memory capacity, where a domain-specific development of long-term working memory can overcome differences in working memory capacity.

AP by Levitin definition [171] is a cognitive ability that relies on highly developed coding perceptual self-referencing mechanism, as an internalized pitch-template, that links verbal labels with representations of categorical perceptual pitch-frequencies input - i.e. an ability to 'label the tone' [274], during possessing internal template and to mapping pitch-tone to a verbal label [168, 173] by long-term working memory mechanism [117, 118, 130]. Scientific evidence obtained about AP nature confirms, that auditory perception of pitch in people with and without AP is the same, i.e. without the difference [11, 42, 169], where the internal map is the empirical and functional evidence of long-term memory mechanisms formation and is absent during relative hearing processing. So AP is not an unusual ability in the domain of pitch perception, since it is mainly a skill in labeling as a form of long-term memory - i.e. access of tone names directly from internal template with classified categorization behavior that involving self-reference. So it's the memory's cognitive processes based on the perceptual and attentional resources with an ability of linguistic coding, what is the evidence of language structure in AP ability. Therefore, AP training is the pitch naming training that develops the pitch memory, it concerns recognition memory during hearing a pitch tone with placing it in a context included in specific label presented in the internal template (i.e. long-term semantic music memory map of pitch labels). It might be crucial to learn to associate musical note names with certain pitches to develop AP with possessing stable and precise internal-pitch template [174, 288, 306] for the automatic naming of pitches [135, 197, 320] conditioned by left planum temporale activation [329], including long-term potentiation [35]. It is a learned ability to mentally class sounds into remembered categories, that is linked to one's exposure to music and might be lost without the constant training and using [2]. The successful labeling of a pitch requires an association between a pitch stimulus and a conventional name - label (pitch class name). If a mnemonic representation of a note is not established and durable, there will not be a targeted link for a pitch - label. The probability of accessing the aural acoustical environment that facilitates the AP development is most often in musicians [20], with retaining the information in long-term memory to which can be mapped a series of labels, instrument keys. AP ability is required exceptionally stable and accurate internal pitch representations [291], where musical - pitch memory is formed up from previously presented pitch information with attention engagement. Pitch memory and pitch labeling are connected when a listener can assign a note-name to the pitch-frequency that hear, with the possibility to possess stable internal pitch memory with the knowledge of the name-labels to describe pitch information [122, 168]. 
Levitin [168] developed empirical two - component theory of AP involved two separate aural semantic abilities - pitch memory defined as 'the ability to maintain stable, long-term representations of specific pitches in memory and to access them when required' belonged to memory system, and pitch labeling defined as 'the ability to attach meaningful labels to specific pitches' belonged to language system and bound up with accurate timbre of voice or music instrument [173] formation in memory scheme qualitative features. Here different musical timbre contributes separate memory schemes with taking into account neuronal presentations of kinesthetic executive function processing, although they belong to the same music matter (i.e. on the basis of equal tempered tuning system) with biological resources for transforming memory scheme from one acoustical timbre environment to another, with requirements of stable frequent musical activity in both timbres at the same time (e.g. playing violin and viola). With including the bilateral organization of AP processing, the lack of 'interhemispheric cooperation' in the labeling of tones might prevent the AP acquisition. Since empirical evidence of a large proportion of people who develop the pitch memory but never acquired pitch labeling was observed in verification studies of that theory. This finding of memory for AP content supports independently the Massaro [182] view from Gestalt psychology direction, that memory is the product or residue of the brain process, where an auditory input produces a perceptual auditory image that contains the information in the auditory stimulus, persists beyond the stimulus presentation and preserves its acoustical information.

From the general long-term memory perspective people with AP ability have apparently internalized their pitch references and are evidently able to maintain stable representations of the pitch in long term memory [173]. Empirical studies provide evidence that people without the pitch-labeling abilities still do have long-term auditory memory resources for AP processing [62, 168, 258], therefore musical pitches notes may be learned if they are consistently presented with verbal labels [189]. So music listeners who have not learned to associate note names with specific pitches will not exhibit signs of AP [305]. Additionally researchers developed assumptions of following AP mechanisms, that completed each other and confirmed independently Levitin statement of AP matter: 1. Categorical perception processing of pitch information [238, 273]; 2. Association of the pitch - tones with its' verbal labels [273]; 3. Use of multiple coding strategies [324]; 4. Assumption of internal templates of tones, which is associated with differences in neural processes during working memory tasks for tonal material $[116,154,329]$. Totally, AP ability requires memory for specific pitch frequency (right-hemisphere processing function) and verbal label (left-hemisphere processing function) of the musical note's representation of accurate musical pitch, with the interaction between linguistic and non-linguistic information in memory for auditory stimuli [173, 322], therefore it's a bilateral ability of long term memory and linguistic coding [169].

AP processing from the moment when a note impinges upon the ear until to the moment of identification, a number of cognitive processes are engaged. The pitch must be separated and selected from the stimulus, then compared and matched to a stable and accurate mnemonic representation with sufficiently similar features, after what the association between the representation for this note and the possible response type must be retrieved, with that knowledge needed to be transformed into the appropriate response. Therefore, the external pitch height must be compared to a pitch class representation in memory. This makes the establishment of long-term working memory for that ability, where separate types of memory are activated in AP processing, such as long-term memory for the representation of the note (i.e. linguistic memory), conditional associative memory for the mapping of each note to a label, motor act or other response, and working memory which participates in the routing of the retrieved information toward areas which will transform it into an overt manifestation, with taking into account that pitch class identification and octave identification are different processes [288]. The structural analysis of music and linguistic components activated in AP processing is presented in scheme 2, with determining the intelligence type to which they have belonged.

$\mathrm{AP}$ as a memory system, is forming upon the basic and special components of intelligence, including music intelligence content. Although musical memory is the part of musical intelligence in Gardner concept [93, 94, 95, 96, 97] and is presented in several theories of musical abilities [59, 66, 266, 315], it is the basic ability classified only for aural perception ( e.g. Gordon musical audiation tests for pitch and rhythm components $[102,103,104,105,106,107])$, where other sensory receptor processing of music matter's material is described in the frame of special (professional) ability, what does not occur in psychological intelligence tests diagnosis. Thus AP diagnosis concerns general musical intelligence only in AP passive form (i.e. aural - written name - label identification of single musical pitch - tone aural perception). While special music knowledge, not educated in general common primary education but available only during additional specialized music education, is included systems of musical notation in musical clefs, musical pitch tone location in vocal or music instrument scale range, music harmony structures (intervals vs. chord with its classification labels), with its diagnostic measurement in the special music abilities direction. 
Scheme 2. Structural analogies between language and music with intelligence's type description.

[M.Dymnikowa, E.A.Ogorodnikova]

\begin{tabular}{|c|c|c|c|c|}
\hline LANGUAGE COMPONENTS & & IUSIC COMPONENTS & \multicolumn{2}{|c|}{ INTELLIGENCE TYPE } \\
\hline LINGUISTIC INTELLIGENCE & & USIC INTELLIGENCE & \multicolumn{2}{|c|}{$\mathrm{B}$ - basic, $\mathrm{S}$ - specialized } \\
\hline phonemes (aural) & $\sim$ & \multicolumn{2}{|c|}{ pitch-frequencies (i.e. music semitones) } & $\mathrm{B} / \mathrm{B}$ \\
\hline phoneme's sound aural perception & $\sim$ & \multicolumn{2}{|c|}{ pitch-frequency aural perception } & $\mathrm{B} / \mathrm{B}$ \\
\hline phoneme sound $=$ phoneme label & $\sim$ & \multicolumn{2}{|c|}{ phoneme sound $\neq$ phoneme label } & $\mathrm{B} / \mathrm{S}$ \\
\hline phoneme sound equal with naming & & \multicolumn{3}{|c|}{ musical-tone sound different from naming absolute pitch } \\
\hline phonemes' aural reproduction possible & $\sim$ & \multicolumn{3}{|c|}{$\begin{array}{l}\text { pitch-frequency aural reproduction limited } \\
\text { vocal or music instrument pitch scale - range }\end{array}$} \\
\hline letters-labels (visual) & $\sim$ & \multicolumn{2}{|l|}{ letter semitone-labels } & $\mathrm{B} / \mathrm{B}$ \\
\hline literal notation & $\sim$ & \multicolumn{2}{|c|}{ literal + musical note notation } & $\mathrm{B} / \mathrm{B}+\mathrm{S}$ \\
\hline $\begin{array}{c}\text { literal alphabet } \\
\text { double notation of aural phonemes }\end{array}$ & & \multicolumn{3}{|c|}{$\begin{array}{l}\text { literal (semitone) + music notation alphabet } \\
\text { double notation of enharmonic labels }\end{array}$} \\
\hline $\begin{array}{l}\text { words } \\
\text { aural and visual perception }\end{array}$ & $\sim$ & \multicolumn{2}{|c|}{ musical motives (phrases) } & $B / B+S$ \\
\hline sentences & $\sim$ & \multicolumn{2}{|c|}{$\begin{array}{l}\text { aural, visual and kınesthetıc perception } \\
\text { musical melodies }\end{array}$} & $\mathrm{B} / \mathrm{B}+\mathrm{S}$ \\
\hline aural and visual perception & & \multicolumn{3}{|c|}{ aural, visual and kinesthetic perception } \\
\hline different structural meaning in words & & \multicolumn{3}{|c|}{ different harmonic structure in melodies (i.e. key tonality) } \\
\hline
\end{tabular}

In total etiological analysis AP ability has flexible learnable nature, on the basis of relative pitch (especially for music harmonic facture, i.e. co-sound perception) with recourses to acquire it through use of memory and language learning - training methods, used commonly for native or foreign language learning and memory development, that should be transferred to musical pitch perception specifications and linguistic pitch label organization with taking into account the requirements of timbre acoustic environment availability for gaining experience through musical activity, what is accessible for accurate target population for its' practical use. Scientific evidences of childhood neuropsychology in the direction of general interhemispheric functional dichotomies for memory processes $[32,101,111,157,167,220,246,267]$, presented in table 1, with a set of historical neuroscientific studies, are describing the biological conditions of hemispheric organization needed taking into account in neuropsychological training of AP acquisition, with respecting its' continual activity at the executive musical performance level.

Table 1. General interhemispheric functional dichotomies.

\begin{tabular}{|c|c|c|}
\hline Author, year of data & Left-hemisphere function processing & Right- hemisphere function processing \\
\hline Weisenberg, Mak-Braid, 1935 & aural-linguistic & visual-kinesthetic \\
\hline $\begin{array}{c}\text { Milner 1958, } \\
\text { Ecaen, Azuriazerra, } 1963\end{array}$ & linguistic-verbal & music pitch-nonverbal \\
\hline $\begin{array}{c}\text { Korsakowa, Moskowicute, } \\
\text { Simernickaja, } 1979 \\
\end{array}$ & reproduction & recall \\
\hline Goldberg, Costa, 1981 & $\begin{array}{l}\text { unimodal coding system one - } \\
\text { receptor processing }\end{array}$ & $\begin{array}{l}\text { intermodal coding system multi - } \\
\text { receptor processing }\end{array}$ \\
\hline Rotenberg, Arshavsky, 1995 & $\begin{array}{c}\text { unambiguous } \\
\text { one-meaning context }\end{array}$ & $\begin{array}{c}\text { multivalued } \\
\text { multi-meaning context }\end{array}$ \\
\hline Bianki, 1985 & $\begin{array}{l}\text { inductive analysis processing } \\
\text { abstraction cue's perception } \\
\text { consistent sequential processing }\end{array}$ & $\begin{array}{l}\text { deductive synthesis processing } \\
\text { concrete precise cue's perception } \\
\text { simultaneous processing }\end{array}$ \\
\hline Griusser, Zelke, Cinda, 1995 & $\begin{array}{l}\text { naming and classification (semantic) } \\
\text { temporal (rhythm) processing }\end{array}$ & $\begin{array}{c}\text { space presentation } \\
\text { and coordination (executive) } \\
\text { spectral (pitch) processing }\end{array}$ \\
\hline $\begin{array}{c}\text { Leushina, Newskaja, } \\
\text { Pawlowskaja, } 1982\end{array}$ & $\begin{array}{l}\text { easy differentiating (very different) } \\
\text { elements, global perception }\end{array}$ & $\begin{array}{l}\text { hardly differentiating (very similar) } \\
\text { elements, concrete detail perception }\end{array}$ \\
\hline
\end{tabular}


Each selected dichotomy might be expressed in a different direction as a constant brain tendency for the form of information processing. The global scheme might determine the various profiles of human's hemispheric predispositions for specific features of the memory function, that needed to be included during AP acquisition processing on the behavioral training level manifestations. Since they are the biological backgrounds of some possible mistakes' formation, which should be reduced during accurate orientation in AP processing evaluation, as the part of correction training. All basic distinctions of a scheme of AP development in every individual human needed to connect neuropsychological and cognitive behavioral conditions for conscious controlled regulation of its' acquisition with possible moderate the training content into efficiency of the biological - neuropsychological - behavioral level. The regular executive use of AP function on musical performance activity and on working with musical note text for ergonomic effective memorizing it alone in the primary level (just with notes) contribute to the consolidation of skills acquired through the auditory and memory exercises in the phase of translating them into the path of executive practice and behavioral implementation. Conscious management of own behavior and memory processes in the use of AP as an executive function is possible only while maintaining awareness, alertness and monitoring of own cognitive processes involved in musical performance. AP as a function is supporting and facilitating professional learning of music with the control of the musical repertoire and simultaneous optimization of cognitive functioning on the background of its' brain bilateral organization.

\section{ABSOLUTE PITCH AS AN EXECUTIVE FUNCTION OF APPLIED MUSIC PSYCHOLOGY DIRECTION WITH AN INTERNAL HEARING PROCESS}

Analyzing the AP definition $[10,18,30,40,63,64,107,145,174,198,214,248,288,292,311]$ presented in music psychology literature on the issue of secondary functions involved in this process, allowed to determine its structure as music executive function for applied musical performance presented in scheme 3 . Executive function allows to plan and to perform current actions for a specific goal or task with the properties of changing the neuronal response depending on the situation, context, with selective attention directed to specific targeted incentives in the condition of stimulation [74]. Basic cognitive processes, such as attention control, cognitive inhibition, working memory and cognitive flexibility, determine basic executive functions, while complex cognitive processes, such as planning and reasoning with problem-solving, that are part of flowing intelligence, cause complex executive functions [48, 70]. An executive function [176, 204, 236] as psychological process: 1. Belongs to the flexibility and focus of behavior, planning and regulation of conscious actions of an executive nature. 2. Covers scheduling, working memory, changing settings, and braking behavior. 3. Is conditioning systematic and targeted activity against the background of reflex, automatized actions. 4. Is involved in the organization and integration of basic mental processes. Executive function includes goal setting [270], planning with errors' correction [271], flexible change of cognitive attitudes with anticipation [279], braking and inhibitory control [280], allocation of resources for selection and control of attention [178] with regulation and directionality of working memory [90], maintaining activity and suppressing the influence of interfering impacts [235]. These processes determine the organizational role of behavior and participate in a targeted behavioral act. And the very purposefulness of behavior implies the presence of its initiation to prepare up to regulation and execution.

$\mathrm{AP}$, as an executive function, is included the internal hearing, what is reading or deciphering the symbolic graphics characters in the form of musical writing (i.e. musical notation) in a specific musical key, with the activation of impressions of musical sounds for a specific timbre of a musical instrument, in their mutual temporal relation, expressed by rhythmic notation meaning. Each graphic character has the function of a strictly musical pitch frequency, i.e. of AP, which plays the role of specific letters to the analogy of the word, with a different and flexible context of harmonic and rhythmic meaning in music. It is synonymous with multitude of meanings for functions of identical letters in different words. In the musical language there is no term and no occurrence of a relative pitch frequency, which is attributed to the variation of relative hearing to the properties of the auditory music perception and of musical heights, as a subordinate function in relation to the structure of the music's matter. While absolute hearing is located etiologically in the structural level of the musical language. This etiological difference in the context of musical linguistics determines the structural differences in the processing of musical language in the brain with the absolute hearing and relative hearing systems presented in scheme 4. Relative hearing activates the functions of relational evaluation (i.e. interval calculation) between particular musical pitch frequencies, with the lack of their presentation, as independent autonomous units at the stage of brain organization of the music pitch frequency perception. It includes one or pair of output pitch frequencies in semantic memory (i.e. permanent) - which determine the identification of all other musical pitch frequencies in the interval relation. It performs superior function over the system of musical pitch frequencies, access to which is possible only through one or several permanently known pitch frequencies to a specific person. It excludes the possibility of organizing musical pitch frequencies' representations as independent and autonomous units of the auditory-letter meaning on the example of language phonemes, sounds and letters. 
Scheme 3. Applied structure of absolute pitch process as psychological - musical executive function.

1 - Input musical potential's biological and psychological resources «see - hear - perform».

Perception of musical pitch with specified timbre : \{ physiological -brain matter; physical-sensory level.

Physical level - directional and frequency selective transformation of acoustic wave by ear structures.

Receptor level - transformation of acoustic wave to activation of neural populations with tonotopic organization.

Neural level - parallel coding and processing by subcortical structures.

Perceptual level - selective activation of cortical areas and processing.

Motor level - performance

\section{$\downarrow$}

2 - Long-term working semantic musical memory. Musical: syntax, language.

Association (double) with: - letter's name - octave register's range.

\section{$\downarrow$}

3 - Musical knowledge of musical notation. Mental semantic presentations of note text.

4 - Mental musical work during musical practice.

Musical notation analysis and memorizing without the musical instrument playing.

Musical visual - aural perception in selective focused attention on note text with

internal hearing \audition of accurate musical pitch and its rhythmic duration.

Emotional regulation of intonation perception of musical notes' information.

Aesthetic musical potential (musicality).

Emotional sensitivity and responsiveness to music by musical notes' text.
5 - Musical structural analysis. Musical function of accurate pitch in harmonic system: - accurate chord, - piece's tonality.

$\downarrow$

6 - Musical performance. Musical function of location of accurate pitch on musical instrument or human voice.

- Focus of kinesthetic behavior's organization - Inhibitory kinesthetic cognitive control.

- Planning and regulation of actions (behavior) on the reflex background. - Problem solving of musical performance with cognitive flexibility. - Thinking - mental presentation of musical composition's sound.

- Visualization, anticipation, initiation of manual actions (behavior) with preparation.

- Memory control of manual studying the composition after memorizing musical composition from musical notes without its kinesthetic performance.

$\downarrow$

7 - Professional competences. Output outcomes for musical performance of musical composition.

Problem solving with supporting activity on memory and emotional musicality ergonomic state in condition of musical performance executive control for artistic live presentation of music preventing the overplayed, trapped, bored kinesthetic performance of musical composition.

Relative hearing creates the conditions for prolonged identification of musical pitch frequency. It enforces the activation of thinking (absorbing time resources) and comparative analysis of the sounds' relational identification. The identification of the name - label of musical pitch frequency is followed by way of analyzing the new notation (left-hemispheric process) without direct activation of its sound (right-hemispheric process), which is identified by the relative way to the output pith frequency in the relationship based on interval thinking. Totally hierarchical processing of relative hearing is opposite to simultaneous processing of absolute hearing. Sakakibara [251] research in 2014 about AP acquisition, on the basis of Eguchi CIM method (scheme 1) with harmonic hearing engaged, i.e. activated relative pitch processing during developing the AP mechanisms, was found to consist of the following selective AP processes: using height strategy (i.e. pitch memory of semitone labels), using chroma strategy (i.e. memory of qualitative pitch variants of selected semitone label), confusing height (semitone) and chroma (octave register) - i.e. concurrent global overall vs. partly narrow processing, identifying pitch accurately depending on both height and chroma. This evidence is a clear manifestation of AP analysis components activated during executive function processing of its acquisition. 
Scheme 4. Structural comparison of absolute and relative hearing.

\begin{tabular}{|l|l|}
\hline $\begin{array}{l}\text { Permanent (semantic aural) memory for single music pitch frequency (bilateral function) } \\
\rightarrow \text { absolute hearing, one-level parallel perceptual organization }\end{array}$ \\
\hline $\begin{array}{l}\text { pith-frequency name - label identification } \\
\text { (left-hemispheric function) }\end{array}$ & $\begin{array}{l}\text { pith-frequency name - sounding identification } \\
\text { (right-hemispheric function) }\end{array}$ \\
\begin{tabular}{|l|l|} 
Creating the internal sounding in interval \\
relation between external pitch-frequency
\end{tabular} \\
$\begin{array}{l}\text { Permanent (semantic aural) memory for specific external music pitch-frequency } \\
\text { (right-hemispheric function) } \rightarrow \text { relative hearing, dual-level hierarchical perceptual organization }\end{array}$ \\
\hline $\begin{array}{l}\text { Identification of interval relation with each musical pitch-frequency in relation to other accurate external } \\
\text { pitch-frequency with engaging musical analysis, thinking and knowledge of musical intervals' sounding. } \\
\text { (left-hemispheric function) }\end{array}$ \\
\hline
\end{tabular}

The nature of internal hearing is described by Oskina and Parnes [210] as the ability: 1. To represent music in the mind, to hear and experience it inwardly without really performing and listening to it 2. To play music from memory in the musical notes' reading process or during its' composing. Its structural components are mental representations of separate musical sounds and co-sounds, one-voice and multi-voice melodies. It allows imaging the structure of a musical piece. It can be classified according to the memory's types: basic sensorial (e.g. aural, visual, motor) and complex (e.g. aural-visual, aural-kinesthetic).

The quality of internal hearing is influenced by three factors:

1. Conditional and unconditional pitch-sound trace reflexes, which influence on the content, form and quality of internal auditory representations. The indicators of this factor are described by the:

1.1. Speed of auditory reactions.

1.2. Degree of the adequacy of the representation of pitch-sound relations to the real sounding of a musical piece with the strength of their preservation.

1.3. Arbitrariness of the reflexes' inclusion. It might be developed during trace skills of sounds' presentation. 2. The content of musical piece's representations with the coordination of its elements, what might be developed during sensitivity of sounds' coordination on the basis of musical material's internal representation.

3. The volume of musical piece's representations formed up by representations of a musical work is formed by musical memory processes (e.g. memorizing and preservation of musical information from musical notes' text) and depended on pitch-sound trace reflexes, developed by musical material capacity's increase.

Totally, the internal hearing is based on auditory perception, musical memory, conditioned and unconditional brain reflex activity. It might be developed on the basis of the perception of real music's sounding. In professional musical activity it determines the efficiency of reading musical notes from a sheet, memorizing - learning process, quality of music perception's processing and self-control on musical piece's performance. In AP processing it concerns internal processing of silence musical notes' text written perception with memorizing it and preparing initial programming of kinesthetic activity for future practice on vocal or musical instrument performance.

\section{RELATION BETWEEN SPEECH AND MUSIC IN NEUROPSYCHOLOGY ORGANIZATION FOR ABSOLUTE PITCH ACQUISITION}

Relation between speech and music are conditioned by its common brain resources and quite near mechanisms for processing the aural information. Language and music are described as characteristics of the human species [121], that have common origins [93]. This is supported by the similarities between the syntactic systems by which music and language are processed in the brain, they are both human universals in which hierarchically structured sequences are organized according to syntactic rules [155]. The overlap between language and music in the brain suggests links in processing and perception [26], so also the link between language and AP. 
Functional brain asymmetry for relation between speech and music, in studies of EEG auditory cortex sensory responses for language [162, 275, 319] and music [123, 193] processing, observed already in infants [60, 221] revealed the functional specialized dominance of: 1. Left planum temporale for speech sound processing, that is presented already in infancy, and human brain is asymmetrically organized for the processing of speech sound long before the child begins to speak with availability to understand when others are speaking [60]. 2. Auditory cortex in the left hemisphere [139] for speech processing of consonant-vowel syllables (left planum temporale) with diminishing during background noise existence in spoken words [316]; 3. Right hemisphere [31, 293] with its anterior part for musical pitch and timbre information processing $[8,142,187,195,254,256]$ and attentional control [127], with similarities of music perception and music imagination in brain activation and neural mechanism [328]; 4. Left hemisphere activity as a relatively high-frequency filter, while right hemisphere activity as a relatively low-frequency filter, in accordance of double filtering by frequency of information processing revealed by Ivry and Robertson [136]. 5. Lateral portion of Heschl's areas lying anteriorly and posteriorly to it along the superior temporal gyrus, with strongly implication in the extraction of pitch and spectral processing of complex auditory sounds founded in speech and music [110, 138, 141, 147, 195, 263, 330].

Additionally musical-linguistic researches got evidence about the role of bilaterally frontal operculum (Brodmann area 44) [327], superior temporal gyrus [177, 255, 321, 325] and interaction between frontal and temporal cortices for working memory of pitch and music-syntactic processing. These structures are also involved in language processing with evidences in auditory $[25,34,200,230,262,326]$ and visual $[144,186,272]$ stimuli studies, also for sentences comprehension process $[88,89,194]$. The parallel between language and music is due to regarding the development and use of category-based auditory perception, where acoustically variable stimulus are "abstracted" into a framework of stable mental categories. Research on development of the sensitivity structure in music shows that perception of categories within the octave and the time in which it is manifest (6-12 months) parallels the acquisition of phonemic categories in language [156]. The formation of these categories is conditioned by exposure and reflects infants' remarkable abilities for keeping track of statistical and distributional cues in the stimulus [184]. In spite of some neuropsychological researches' note about the existence of distinct, domain-specific representations for linguistic and musical syntax [215, 217] - the evidences from linguistic syntactic processing and musical harmonic processing suggests that, in both modalities, the process of bringing long-term, domain-specific knowledge into working memory is carried out by the same neural resources. It is described by Balari and Lorenzo [23] as the network, that can be characterized as a natural system of computation, based in the distinction between basal ganglia and cortical component, where Broca's area would thus be implied in these linguistic and musical sequencing operations as part of the cortical circuit providing the memory system. The neurological network devoted to music [9] exist within the human brain and make human innately predisposed to musicality the same way as human is predisposed to language learning, although the level of sophistication and awareness of these abilities differ between people [137].

Principally the processing of pitch and phonemes shares similar brain areas [126, 165], and language with music share common neurological process [172], so the same neuronal network processes musical pitch and linguistic information. Therefore as well as musical experience might implicitly train the language network, as a mechanism of linguistic alphabet phonemes forming up might be applied for musical pitch phonemes learnability in AP function. Additionally music training might improve the auditory processing (as pitch discrimination, pitch memory and rapid spectro-temporal processing) [223, 294] and language - literacy skills (as verbal memory and fluency, prosody perception, pitch processing in speech, phonological awareness, reading) [6, 24, 44, 133, 209, 277]. Since income resources of music and speech processing are intimately forming up from prenatal and infancy period [295, 300] and musical elements pave the way to linguistic capacities earlier than phonetic elements [213], where musical elements of speech play a crucial role for the language acquisition $[86,148]$ and music (as language) has syntactic and semantic dimension especially for pitch processing. Also pitch describes the high - low sounds and is involved in the interpretation of meaning in speech [218].

Mechanisms of language and AP acquisition processing concerns common structural components of its semantic content. Each language uses a unique set of around 40 distinct phonemes, as groups of non-identical sounds (i.e. phonetic units), that change the meaning of a word. The human is learning that phonemic categories before trying to acquire words depend on these elementary units [160]. The normal timeline for perceptual speech development takes first year of life [161], with processes of: discrimination of phonetic contrasts of all languages during first half age, statistical learning of distributional frequencies and language-specific perception for vowels around $6^{\text {th }}$ month, statistical learning of transitional probabilities with detection of typical stress pattern in words around $8^{\text {th }}$ month, recognition of language-specific sound combinations around $9^{\text {th }}$ month, with phoneme perception declined in foreign-language and increased in native-language around $11^{\text {th }}$ month, first words produced at $1^{\text {st }}$ age. 
Humans are able to extract regularities from an acoustic sequence such as speech from a very early stage of development. Infants are born with a pre-developed sensitivity to the prosodic aspects of language, this sensitivity seems to serve as guidance in the process of learning the fine-grained distinctions in the acoustic patterns of language [190, 203, 242]. Infants at birth are able to hear the differences between phonetic contrasts in any natural language $[158,159]$ what is additional evidence of their aural sensitivity for perception of musical elements with different timbre [222]. They show categorical perception and are especially sensitive to acoustic changes at the phonetic boundaries between categories, including those they have never heard [78, 79], with availability of discrimination of all phonetic units used in languages. Infant perception is constrained, they show heightened sensitivity to those that are important for language. The general human auditory perceptual abilities provided basic selection that influenced the choice of sound included in the phonetic repertoire [158, 159]. During infants' phoneme formation processing, they analyze the frequency distribution of sounds they hear in ambient language, as an external aural environment, and that this alters perception. This is conditioned by statistical learning early in development, where infants' ability to pick up the patterns of natural variation in language assists early phonetic learning, and they learn merely by being exposed to the right kind of auditory information [184, 250]. In musical pitch matter this natural variation is quite difficult and disrupted by repeated pitch-height components, which have sound character quite similar as applied by the overtones of primary fundamental frequency. So there is needed a special sensitivity training for improving the aural sharpness differentiation of musical tone (especially in perfect consonance relation). Also the access to that aural environment of accurate musical timbre is limited by the impossibility to produce that sound spontaneously by human (except limited pitch-height in the human's voice scale - range). The process of reproducing the phonemes by human has an analogy in musical timbre for musical pitch-heights reproduction on accurate musical instrument that required access and availability of wieldy using the instrument (i.e. possibility of reproducing all accessed instrument's pitch-heights). That means the importance of firstly learning producing all pitch-heights accessible to voice or accurate musical instrument, after which they come to be available as aural environment content during communing with them regularly. It is the conditioned limitation of aural training in AP acquisition methodology, until the aces to external musical timbre sound environment is not widely accessible for human.

The alphabet [49, 58] is the standard set of letters (i.e. written symbols as graphemes represented both vowels and consonants) of the phonemes (as basic significant sounds) represented and applied in accurate spoken language, that are used to write in the language. It is available and learnable for every healthy brain as a memory resource. According to AP musical - linguistic content nature, it might depend on a specialized network of mnemonic and perceptual systems when identifying notes $[3,36,57,114,115,135,163,166,211,225,226$, 227, 228, 229, 230, 276, 329]. It is included: 1. The parietal and posterior dorsolateral frontal cortices, involved in the retrieval and manipulation of verbal - tonal associations. 2. The left posterior dorsolateral prefrontal cortex responsible for conditional associative memory in associative transformation of pitch-frequency to pitch note-name - i.e. the association of tones and their naming labels). 3. Music and speech processing as the aural perceptual sensitivity for discrimination of musical pitch frequencies (i.e. a pitch height as a pitch audiation) and phonemic sounds of alphabet's letters (i.e. spoken language system) with its learn-ability maturity for written form of sounded matter in early childhood (what is accessed for different biological ages in foreign language learning) [207]. These are the basic primary biological genetic income (i.e. inborn) resources for auditory perception of external sound stimulus, with its further memory organization (i.e. long-term semantic mental map representation) in the case of constantly use on everyday cognitive activity. All other aspects and conditions of AP acquisition are placed in external environmental resources and mental experience with music's matter. The mature AP learnable resources are included income primary ability for both aural musical pitch perception (of accurate musical timbre of constant aural experience during practical musical activity) and visual perception of its written letter symbol presentation with its spatial location in musical notation knowledge system.

The primary structural functional differences between linguistic literal alphabet and AP alphabet are: 1. Double name-label in enharmonic meaning for 5 of 12 semitones, what doesn't exist in aural phoneme presentation, although is observed in written language (i.e. 2 literal symbols of accurate sounded phoneme). 2. Name-label structure, which has the $12^{\text {th }}$ mathematical system (instead of the decimal system) in case of 12 semitones in each octave unit (as decimal unit) with repeated letter (chroma variants) of different qualitative timbre pitch height units (octave spaces) belonged to one name-label semitone unit. 3. Mathematical algorithm tuning between musical pitch heights in case of the equal tempered tuning system order remaining in consonance - dissonance relation, which is absent for linguistic phonemes as almost unique sounds unavailable to organize all of them into ordered scale. 4. Spatial order of musical language structure organization into single sounds (i.e. unison) and harmonic sounds (i.e.co-sounds or choral vocal matter) that are absent in language order in case of impossibility to understand the 'simultaneously imposed speech' of different people. 5. Double notation system by literal and musical-notes schemes (with different clefs, i.e. C, F, G,) what doesn't exist in language notation.

Asian Online Journals (www.ajouronline.com) 
Semantic long-term musical memory for AP content is moderately stable and accurate among both musicians and non-musicians in substantial evidences [79], include an internal music pitch template - map for semantic [125, 241, 242] and recognition processing [171, 173, 308, 309] during pitch frequency identification, coded by the auditory system [33], stored in hippocampus [282, 290] with para-hippocampal gyrus engaged in memory encoding [27, 132, 304] and verbal experiences recalling [307], used during internal pitch processing by reading the music note text [134], with the right-lateralized brain structures sub-serving pitch-based learning process [179]. Musical tones are processing in the brain with tonotopy principle [26, 289, 323].

The tonotopy $[149,156,164,264,298,312]$ is the spatial arrangement of where sounds of different frequency are processed in the brain, based on physiological rules in the auditory system. It begins in the cochlea, i.e. receptor organ of hearing as the structure in the inner ear that sends information about sound to the brain. The sound-sensitive portion of the cochlea is vibrated at different sinusoidal frequencies due to variations in thickness and width along the length of the basilar membrane located in the Corti organ, so nerve fibers forming the auditory nerve transmit information from different regions of the basilar membrane and encode frequency tonotopically. This tonotopy projects through the auditory nerve to the primary auditory cortex (Heschl's gyrus) via the auditory radiation pathway. Throughout this radiation, the tonotopy organization is supported and repeatedly presented at different levels of the auditory system including cortical areas. Different frequencies of sound are represented in particular regions of the primary auditory cortex. Neurons at one end of the primary auditory cortex respond best to low frequencies, while neurons at another end of the auditory cortex respond best to high frequencies (i.e. such frequency map is the tonotopy map). Signals from low pitch sound project into the anterolateral aspect of Heschl's gyrus, while signals from high pitch sound project deeply into the lateral fissure (which houses Heschl's gyrus). Primary auditory cortex is organized with tonotopy principle (i.e. spatial representation of a stimulus), where neighboring cells in the cortex respond to accurate spatial frequencies, with identification of the fundamental elements of music including pitch. Tonotopy principle determines the memory of chromas' pitch variants. Primary and secondary auditory cortices are involved in the extraction of acoustic properties, namely of pitch height, pitch chroma, timbre, intensity, and roughness, where secondary auditory cortex, i.e. belt area, plays an important role in sound localization and analysis of complex sounds: in particular for specific human language. It also has a role in auditory memory, since the belt region helps to integrate hearing with other sensory systems.

Additionally different auditory processing of dissonance and consonance sounds of intervals' structures needed to be included in AP acquisition, as the background of pitch sound perception of equal tempered tuning system. Harmonic relationships of pitch tones in intervals are represented in the temporal discharge patterns of auditory nerve fibers, with revealed scientific evidence of impairments in consonance perception following auditory cortex lesions, as a result of pitch perception deficits [297]. Consonant intervals evoke auditory nerve fiber activity with responses contains strong representations of harmonically related pitches implied by the interval in addition to the pitches of notes actually present in the interval, while dissonant intervals evoke auditory nerve fiber activity that does not contain strong representations of constituent notes [296].

People process musical pitch tones in the same way as speech sounds and assign them to particular categories, what is defined as the categorical perception of tones. Therefore people with AP ability: 1. Without musical labels' knowledge (at very early childhood) might process the notes later on and associate them with memory information about musical pitch frequencies. 2. With musical labels' knowledge (at later childhood) might categorize the note already at a very early stage of sound processing. So the AP acquisition is different for these childhood age conditions, with including the different musical pitch spatial processing in case of aural frequencies' tonotopic organization. It is available and accessible by biological resources of brain plasticity during musical memory training activity. The brain plasticity is a consequence of synaptic plasticity and an ability to adapt to the environment or to be shaped by experience and underlie learning, what include mind-training [41], where neural correlates are changed after the training of WM processes, such as AP acquisition processing. Intensive learning abilities in musicians playing different instruments with engaging the memory processes, is accompanied by the ability of plastic reorganization, indicating 'meta-plasticity' in musicians - i.e. anatomical and functional cerebral differences changes as a result of musical training [4, 80, 202, 213, 235]. Thus, a very specific environment seems to lead to very specific changes in the brain. Practicing and performing music entails increased somatosensory and auditory input [211, 212, 237, 244], with providing the brain plasticity state [201, 260]. Including the necessity of initial learning the musical notation, with genetic predisposition of musical pitch audiation presence (i.e. with the absence of this condition in amusia state) the nature of AP acquisition, as cognitive musical executive function based on bilateral brain organization, is coming more accessible for human, but useful only for population with constant musical activity. 


\section{METHODOLOGICAL CONCLUSION}

$\mathrm{AP}$ as the process of labeling the pitch-frequencies - concern semantic cognitive processes, including intentional attentional perception, working memory processing of perceived aural stimulus with engaging linguistic semantic memory of labeling map. It is formed up by long-term working memory processing based on semantic knowledge of pitch - labeling with its presentation in musical notation (analogous to language notation) and vocal or music instrumental location as semantic presentation of aural sounding, visual written and kinesthetic manual space receptor forms. The manifestations of this process in different perceptual level and pragmatic use are conditioned its music executive function, with conscious programming behavior in contact and dealing with the music as semantic matter in case its mathematical structure in pitch organization in equal-tempered tuning system of pitch frequencies. Most scientific researches about AP evidence belongs to an early-learning theory with a critical period in early childhood (until age $7^{\text {th }}$ for acquiring this function by methods working in younger human development period [47, 145, 173, 198, 240, 268, 269, 288, 306, 309]. It describes the conditions of Asian educational system (from $4^{\text {th }}$ age with a keyboard lesson in public school), with improving better predisposing for memory of white keys in case of started learning on the diatonic scale C major (i.e. with white keys' firstly activation in playing). Researches behind Asian culture, as for AP improvement in adults or people older from $7^{\text {th }}$ age, belongs to very rare evidence without replication in other countries, in case of statement of this function as non-required obligatory even in music professional population. Independent evidence of an early-learning theory of acquiring the AP brings importance of significant difference in nature of AP of adults and children older than $7^{\text {th }}$, what is not yet discovered enough without presence of generally available methods or principles for acquiring and developing this function latterly.

The nature of AP as memory system based on linguistic labeling coding, i.e. pitch alphabet acoustical phonemes of musical language system, with the practical kinesthetic presentation in pitch-space of voice or music instrumental scale-range (what is not presented in language alphabet systems), is conditioned by access to this ability for professional musicians (during study or work) in musical practical activity (professional or amateur) with instrumental or vocal performance processing on everyday life style. The musical pitch labeling process is analogous to label the linguistic phonemes of original or foreign language alphabet, with difference of access to this musical matter. Since linguistic units might be reproduced by every human, while musical pitch units might be excavated often only by limited human voice scale-range, and very rarely by the musical instruments except the piano as most popular. Including official practical scientific evidence of cognitive learning ability for mastering the foreign language (even with different symbolic alphabet system) by humans with different age period, especially older adults after $50^{\text {th }}$, based on long-term memory system with active using it in everyday existence the musical pitch language processing in specific timbre of voice or of musical instrument in the population of with constant musical activity can be acquired on the same memory mechanisms as it concern any foreign language with specific alphabet - phonemes' system. The process of losing acquired foreign language in the case of stopping using it on everyday activity, conditioned by memory mechanisms and forgetting function, is the same analogous for AP ability in condition of not use it on everyday vocal or musical instrument practicing. This nature has an opposite property to an early-learning theory for AP acquiring in the case of its more often or accessible learning and forgetting, as the language alphabet system. AP for this duration, as helpful pragmatic function for musicians, seems to be accessible with its specifications of nature of musical interests' development. It comes in a wide childhood age, even in the later period, including the fact of beginning period by studying playing on different musical instruments (e.g. brass or woodwind groups). Many countries offer music education system only from middle school or at the university level after maturity completion. Additional musical education on musical instruments in earlier age has other developmental function, where the maturity period for conscious choice the professional musical activity comes elder than age $7^{\text {th }}$. Final crystallization of personal interests for art studies and art professions comes usually in late childhood or early youth. This period is also optimal for conscious motivated choice of studying the foreign language for professional use in work or other everyday activities.

Biological evidence of language phonemes formation process until $1^{\text {st }}$ year brings the basis for possibilities of acoustical musical pitch formation process at the infancy level [203], including the fact that musical pitch frequencies belonged to the range space of the human hearing system. It is conditioned aural musical experience by perceptual listening or active dealing with the music by singing or playing the instruments at the game level. This is formed up the aural musical abilities, such as audition for music sound's characteristics except the loudness (i.e. pitch, rhythm, timbre, harmony, agogic). Including the principles of aural musical abilities crystalized around age $9^{\text {th }}$, and of cognitive maturity for school learning in wide early childhood period for reading, writing and counting readiness the minimal beginning period for acquiring AP as semantic memory process based on active practice with human voice or musical instrument comes certainly later, i.e. after the critical period described in the early-learning theory of AP development. 


\section{APEPA METHOD DESCRIPTION}

\subsection{Methodological introduction.}

APEPA method (authorship of M. Dymnikowa with psychology education in SWPS University of Social Sciences and Humanities in Warsaw, music education in F. Chopin Music University in Warsaw and N. A. Rimsky-Korsakov Conservatory in Saint-Petersburg, with scientific agreement of music psychologist prof. V. I. Petrushin with professional music education in P. I. Tchaikovsky Moscow State Conservatory) is the 'absolute pitch ecological practical activity' program course of AP as cognitive psychological musical executive function, for possibility to develop it during psychological musical training on basis of semantic music memory and during learning the musical - pitch alphabet as musical language matter for practical utility. The method has been worked out during musical memory area scientific study and scientific practical activity with obtaining a $\mathrm{PhD}$ degree in psychology, in the range of cognitive neuropsychology (neuroscience) of music, music psychology, cognitive psychology and psychological diagnosis with music psychometric disciplines. The method was prepared after 4 post-graduate psychological courses in the frame of cognitive psychology, psychology of creativity, practical psychological diagnosis and clinical neuropsychology with neuropsychological diagnosis. The method was verified empirically on children aged from 8 to 13, realizing the intensive musical education with daily musical instrument activity till 2-2,5 hours in circadian schedule, with shorter and longer time of method realization. Independently method was empirically developed for the psychometric organization of tasks analysis with psychometric AP test preparing during the additional acquired experience of music psychometric scientific stage at the music-therapy laboratory in Institute of Psychiatry and Neurology (Warsaw) for qualitative music-therapy test validation under the music-therapist dr. E. Galinska [91, 92] supervision.

For neuropsychological background AP function is related to an optimized categorical perception for the auditory-related cortex processing level [129, 135, 183, 185, 208, 265, 273, 317]. The AP nature has proven as a two-component model established empirically by Zatorre, Beckett, Levitine and Rogers [173, 322, 324], described by three cognitive mechanisms. One concern the perceptual categorical perception. Two additional are cognitive and concern memory types - pitch memory as explicit memory and pitch labeling as associative implicit memory with activation of the dorsolateral prefrontal cortex [28, 29, 208, 322, 329] and fiber bundle linking the posterior supra-temporal area [181]. With taking into account that pitch memory is common function $[113,168]$ the most constituted and distinctive cue trait AP concern pitch labeling as the mnemonic association between pitch - tones' frequencies and its' name - labels [82, 245]. Here neuronal oscillations with theta frequency range around 4-7 HZ are: 1. Closely linked and reflected for mnemonic functions [310]; 2. Identified as a marker of associative memory functions [43, 46, 56, 150, 257] in the form of theta phase alignment between left auditory-related cortex and left dorsolateral prefrontal cortex, as electrophysiological brain mechanisms supporting absolute hearing behavior. Thus AP processing is primarily memory system with included executive functions of its applied ecological - practical activity based on natural cognitive learning availability.

Ecological activity concerns natural influence on the human body with the mind, human health, and human resources of optimal functioning by circadian rhythm of daily existence. So it is devoid of stimulants, steroids, artificial stimulation and time-shifting training, including artificial cognitive intelligence technologies. It includes natural native learning and natural stimulation of cognitive condition in circadian speed by cognitive professional activity, what concerns constant daily musical instrumental (or vocal) activity in training the music material and performing it at the concert level for an external audience. The natural cognitive learning, occurring in many circadian duties, allows obtaining and developing an executive function for any special behavior action that might be kept and automatized in mind activity level, with its natural widespread availability. Hence, ecological practical activity with the use AP, as semantic music memory or a semantic musical pitch alphabet might exist with its widespread resources in the field of musical professional activity. It may be available to obtain for various people motivated to obtain this psychological - musical cognitive executive function. Since the biological resources for innate mind presentations of phoneme letters and music pitch sounds are forming up in the human brain at the pregnancy level, with its crystallization in the infancy level of auditory memory maturation processing. Practical activity concerns the circadian duties for stable execution, especially conditioned by professional skills and functional rules. It especially belongs to language using, as constant lively need for optimal life existence. Music professional activity is conditioned by perceptual kinesthetic and mental cognitive duties on circadian field. Therefore cognitive process of the alphabet using occurring in a matter of linguistic language and music pitch language provides brain instrumental activity for optimal daily existence. It concerns the same mechanisms of natural-instinctive and innate cognitive learning in different semantic matters, where musical pitch alphabet is obligatorily needed only for professional musical activity's ergonomic optimization. The musical pitch alphabet has some similarities with linguistic letter alphabet and mathematical number alphabet. The main common and different attributes of its matter are described in the table 2. 


\subsection{Methodological definition.}

Musical Definition of Absolute Pitch: Aural identification the name - label with its chroma of accurate musical tone's pitch frequency (in equal-tempered tuning system) of specified musical timbre without its comparison to other external musical tone. In the light of the psychology of music - belonging to the musical art it is a narrow-specialized psychological-musical function of practical utility for professional musical activity.

APEPA scientific musical backgrounds: - organization of 1: equal-tempered tuning system; 2. language of musical tone pitch frequencies; 3. structural frequency of musical tone pitches (overtones, chromas) with its psycho-acoustic sounding specification (consonances, dissonances).

Psychological Definition of Absolute Pitch: Neural network layout of 12 long-term semantic memory traces for autonomic atomistic independent musical units (i.e. with no diatonic mutual relation) with: 1. Presentations of musical tone pitch frequencies' and its names; 2. Qualitative register types in octave chromas' units; 3. Specified musical timber of human voice or musical instrument. 4. Semantic memory resources based on categorical perception, categorical permanent memorizing with working memory span and mnemonic organization of semantic knowledge of musical tones. In the light of the psychology - where there is no classification of varieties of musical processes - it is a psychological process for the material of music and for the matter of musical sound.

Table 2. Features of the alphabet systems for matter of language, mathematics and music.

[M.Dymnikowa, E.A.Ogorodnikova]

\begin{tabular}{|c|c|c|c|}
\hline ALPHABET FEATURE & LANGUAGE MATTER & MATHEMATICS MATTER & MUSIC MATTER \\
\hline $\begin{array}{l}\text { preliminary aural stimulus } \\
\text { mind presentation }\end{array}$ & presence & absence & presence \\
\hline cultural stimulus content & presence (cultural) & absence (transcultural) & absence (transcultural) \\
\hline intonation component & presence & absence & presence \\
\hline $\begin{array}{c}\text { language notation } \\
\text { with reading system }\end{array}$ & $\begin{array}{c}\text { letter language } \\
\text { universal learning }\end{array}$ & $\begin{array}{c}\text { numeral language } \\
\text { universal-specific learning }\end{array}$ & $\begin{array}{c}\text { musical note language } \\
\text { specific learning }\end{array}$ \\
\hline $\begin{array}{l}\text { primary reproduce form } \\
\text { of initial aural stimulus }\end{array}$ & $\begin{array}{l}\text { kinesthetic spoken } \\
\text { articulation pronouncing }\end{array}$ & $\begin{array}{l}\text { visual manual extraction } \\
\text { on external items / toys }\end{array}$ & $\begin{array}{l}\text { kinesthetic extraction on } \\
\text { voice / music instrument }\end{array}$ \\
\hline aural natural learning & presence & absence & presence \\
\hline $\begin{array}{l}\text { order semantic } \\
\text { organization }\end{array}$ & $\begin{array}{c}\text { letter order } \\
\text { from } « \mathrm{~A} » \text { to } \ll \mathrm{Z} »\end{array}$ & $\begin{array}{l}\text { numeral order } \\
\text { from «0» to «9» }\end{array}$ & $\begin{array}{l}\text { equal tempered } \\
\text { tuning system }\end{array}$ \\
\hline semantic unit & letter (phoneme) & number & music tone \\
\hline $\begin{array}{c}\text { order scale }- \text { dependence } \\
\text { between stimulus }\end{array}$ & absence & $\begin{array}{c}\text { presence - in equal division } \\
1 ; 0.1 ; 0.01 ; 0.001 ; \text { etc. }\end{array}$ & $\begin{array}{l}\text { presence - in algorithm } \\
\text { of pitch frequencies }\end{array}$ \\
\hline units' rebound & absence & presence - in numeral form & presence - in overtones \\
\hline number of semantic units & $\approx \geq 25$ letters in languages & $10($ from $« 0 »$ to $« 9 »)$ & $\begin{array}{l}12 \text { music tones' names } \\
\text { (semitones in octave) }\end{array}$ \\
\hline $\begin{array}{l}\text { biological resources } \\
\text { for natural learning }\end{array}$ & presence & presence & presence \\
\hline education type of stimulus & obligatory basic primary & obligatory basic primary & additional professional \\
\hline similarity of content & type of letters & place in numeral notation & overtones, consonances \\
\hline $\begin{array}{l}\text { relation with naming } \\
\text { at perceptual level }\end{array}$ & automatic & automatic & $\begin{array}{l}\text { acquired in special } \\
\text { educational training }\end{array}$ \\
\hline semantic variability & in word & in numeral notation & in classical harmonic \\
\hline quality types of stimulus & big - small letters & absence & chromas of octaves \\
\hline double naming of stimulus & presence in written form & absence & enharmonic of 5 tones \\
\hline $\begin{array}{l}\text { receptor form of alphabet } \\
\text { using presentation }\end{array}$ & aural, visual written & aural, visual written & $\begin{array}{l}\text { visual written, kinesthetic } \\
\text { nusic instrument matter }\end{array}$ \\
\hline
\end{tabular}


APEPA scientific psychological backgrounds: - brain neuro-psychological bilateral organization of AP processing - the frequency (right-lateral, right hemisphere function) and the name - label (left-lateral, left hemisphere function) of musical sound.

Etiology of Absolute Pitch: Complex psychological - musical function on the basis of initial functions, such as music pitch hearing (audiation), music pitch memory, semantic language alphabet (i.e. language instrumental knowledge).

APEPA pedagogical exclusions: Absence of «wrong / non taught» reactions (task answers) and knowledge, with quality analyses of committed mistakes, with criterial diagnosis of «presence / absence» of function levels, with backward returning to the earlier training material until its complete mastering state, with providing opportunities for executive learning of all method technics without further realization until earlier level completion, with allowed amount of until $10 \%$ errors in each method exercise, with optimization customized for individual differences of each human including biological conditions of memory organization processing, with the possibility (probability) of losing the obtain function unless to stop using it on circadian activity in life.

Semantic Music Memory of Absolute Pitch Definition:

Order system:

1. Of twelve aural - linguistic semantic letter units for pitch frequencies of musical tones, for ordered scheme of frequencies in equal-tempered tuning system, with total acoustic pitch frequency space depended on the frame of musical instruments' (human voices') scale: 1.1. With 7 single - letter symbols from A to G; 1.2. With 5 double - letter enharmonic symbols (numbered auxiliaries) - i.e. black keys on clavier space system.

2. In mathematical order relation with a decimal fraction function with decimal values of qualitative number of chroma (i.e. octave's register) from possible 10 chromas' frequencies of equal-tempered tuning system's pitch scale, presented in the accurate musical instrument's scale space, in the scheme $\left[\ll A \leftrightarrow G \uparrow_{\sharp} \mid A \downarrow_{b} » \cdot \ll 0-9 »\right]$ with codes of: NAME - LABEL LETTER (FOR SINGLE UNITS); NUMBER (FOR DOUBLE UNITS); | REGISTER OCTAVE; CHROMA QUALITY NUMBER;

3. Of accurate musical timbre.

4. In mutual mathematical relation in equal-tempered tuning system with psycho-acoustical sounding similarities of musical pitch frequencies in consonance and dissonance characters.

5. Developed in the framework of stimulation the selective attention with the alignment of sensitivity and sharpness on each music pitch frequency of accurate music instrument (voice) scale by programming "mental-linguistic map of music pitch frequencies" during psychological - musical functional training, with including the organization of brain hemisphere specialization of AP function with types of committed left-right hemisphere mistakes for accurate 1 unit among 11 accompanied units.

Narrower frame:

Semantic Long-term working memory: 1. Sensory (visual, aural, kinesthetic,); 2. Declarative (i.e. knowledge of letter - labels of musical pitches) - procedural (executive); - developed during memory programming process of the "intelligent categorical aural musical pitch perception" basis of abstractive material (i.e. music) with mathematical tuning. Developing the cognitive behavioral reflex automatic habitual reaction on aural perception of music tone pitch frequencies, in the background of systems of musical intelligence, musical brain (mind), musical hearing, with broadcasting the semantic meaning and secondary presentation on musical notation and music instrument (voice) space location. Psychological - musical training etiology description is presented in table 3 with the semantic memory structure organization of AP musical content in schemes 5 and 6.

Wider frame: Executive function of musical tone pitch frequencies of equal tempered tuning system on 5 planes of executive musical knowledge: 1. Musical alphabet (i.e. letter - label code); 2. Musical notation with musical clef (such as treble (violin), bass, alto, tenor etc.); 3. Musical instrumental (vocal) language (i.e. location space in voice or music instrument range) without needed (independent from) music notation knowledge; 4. Musical harmony tuning (i.e. key identification of a musical piece in classical tonality language); 5. Musical internal hearing for preliminary work with musical notes' text of a musical piece without musical (vocal) instrument, with internal aural sounding presentation of musical notation. 6. Semantic music material organization into single and co-sound pitches' structural series, with grouping 12 name - labels' units of musical tones into two equal-tempered schemas (diminished 3 minor thirds or augmented 2 major thirds) according to working-memory span (total 3-4 elements in number of schemas and in single scheme), with closed focused or open extensive structures in melodic (single tones) or harmonic (co-sound tones) form. The contradictions of method use include aural central hearing loss disorders, memory illnesses, attention processing organic changes and pitch with timbre amusia syndromes. For stimulus presentation of method there is permitted natural sounding or electronic form of musical tone with its overtones sounding production. 
Table 3. Psychological - musical training etiology description.

[M.Dymnikowa, V.I.Petrushin]

\begin{tabular}{|c|c|}
\hline ETIOLOGY FEATURE & PSYCHOLOGICAL - MUSICAL TRAINING SPECIFICATION \\
\hline Function type & psychological - musical - executive \\
\hline Training properties & $\begin{array}{l}\text { development of function and practical skill } \\
\text { for circadian musical instrumental activity }\end{array}$ \\
\hline Trained memory function & $\begin{array}{l}\text { semantic long-term working memory of musical pitch frequencies } \\
\text { of concrete music timbre in the range of musical instrument (vocal) scale }\end{array}$ \\
\hline Practical utility & $\begin{array}{l}\text { development of new musical brain function } \\
\text { for musical performance practice }\end{array}$ \\
\hline Training specification with destination & $\begin{array}{l}\text { developmental neuropsychological musical aural } \\
\text { (for narrow population of professional music education) }\end{array}$ \\
\hline Type of trained function & rarely originally at innate level with possibility of common development \\
\hline Minimal period of training & $\begin{array}{l}\text { till } 2 \text { months with each day training till } 3 \text { hours } \\
\text { (double } 1,5 \mathrm{~h} \text { sessions in the morning and evening) }\end{array}$ \\
\hline Maximal period of training & $\begin{array}{l}\text { till } 2 \text { years with } 3 \text { times training per week for } 3 \text { hours } \\
\text { (triple } 1 \mathrm{~h} \text { sessions with the } 15-30 \text { minutes of internal break) }\end{array}$ \\
\hline Training effect stability & preservation for condition of circadian musical instrumental activity \\
\hline Alphabet training elements & presented in training content (structure, mnemonic semantic exercises) \\
\hline Interhemispheric cooperation training & $\begin{array}{l}\text { functional bilateralism of musical pitch processing (right hemisphere) and } \\
\text { musical name-label of musical pitch alphabet processing (left hemisphere) }\end{array}$ \\
\hline
\end{tabular}

Scheme 5. Semantic memory structure organization of absolute pitch musical content.

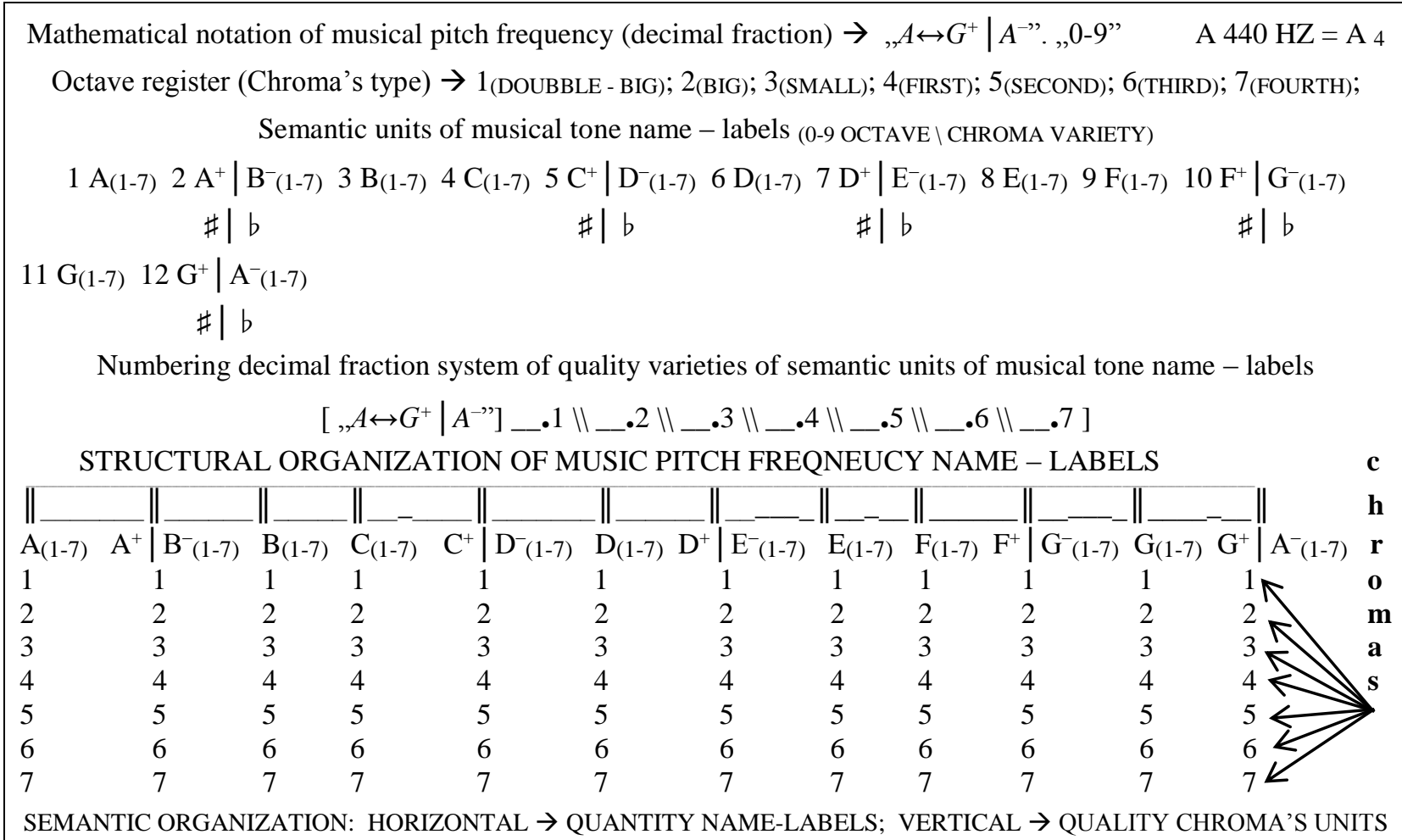


Scheme 6. Semantic memory organization of absolute pitch musical content with numeral tip.

\begin{tabular}{|c|c|c|c|}
\hline \multicolumn{3}{|c|}{ Absolute pitch function primary level } & Semantic identification of musical tone name - label (top) \\
\hline \multicolumn{3}{|c|}{ Absolute pitch function secondary level } & Semantic identification of musical tone name - label's chroma (down) \\
\hline $\begin{array}{l}\text { external } \\
\text { stimulus } \\
\text { of music } \\
\text { pitch } \\
\text { frequency }\end{array}$ & $\begin{array}{c}\text { mental } \\
\text { memory } \\
\text { map's } \\
\text { order } \\
\text { scheme }\end{array}$ & $\begin{array}{l}\text { music tone } \\
\text { name - label } \\
\text { quantitative } \\
\text { semantic unit }\end{array}$ & $\begin{array}{c}\text { music tone name - label qualitative (chroma) semantic unit } \\
\rightarrow \text { amount depended by vocal or musical instrument range scale }\end{array}$ \\
\hline & $\pi^{\mathbf{A}}$ & $\longrightarrow$ & $\rightarrow A\left\{a_{1} ; a_{2} ; a_{3} ; a_{4} ; a_{5} ; a_{6} ; a_{7} ;\right\}$ \\
\hline & 1 & $\mathrm{~A} \uparrow \# \backslash \mathrm{B} \downarrow b$ & $\rightarrow A \uparrow \backslash B \downarrow\left\{a \uparrow \backslash b \downarrow_{0} ; \rightarrow{ }_{-} 1 ;{ }_{2} ; ;_{-} 3 ;_{-} 4 ;_{-} 5 ;_{-} 6 ;_{-} 7\right\}$ \\
\hline & $\mathbf{B}$ & B - & $\rightarrow B\left\{b_{1} ; b_{2} ; b_{3} ; b_{4} ; b_{5} ; b_{6} ; b_{7} ;\right\}$ \\
\hline & $\mathbf{C}$ & $\mathrm{C} \quad-$ & $\rightarrow C\left\{c_{1} ; c_{2} ; c_{3} ; c_{4} ; c_{5} ; c_{6} ; c_{7} ;\right\}$ \\
\hline & 2 & $\mathrm{C} \uparrow \# \backslash \mathrm{D} \downarrow b$ & $\rightarrow C \uparrow \backslash D \downarrow\left\{c \uparrow \backslash d \downarrow_{0} ; \rightarrow{ }_{-1} ;{ }_{-2} ;{ }_{-3} ;{ }_{-4} ;{ }_{-} 5 ;{ }_{-} 6 ;{ }_{-} 7\right\}$ \\
\hline & $\mathbf{D}$ & $\mathrm{D} \longrightarrow$ & $\rightarrow D\left\{d_{1} ; d_{2} ; d_{3} ; d_{4} ; d_{5} ; d_{6} ; d_{7} ;\right\}$ \\
\hline & 3 & $\mathrm{D} \uparrow \# \backslash \mathrm{E} \downarrow b$ & $\rightarrow D \uparrow \backslash E \downarrow\left\{d \uparrow \backslash e \downarrow_{0} ; \rightarrow{ }_{-1} ; \__{-2} ; \__{3} ;{ }_{-4} ;{ }_{-} 5 ;_{-} 6 ;_{-} 7\right\}$ \\
\hline & $\mathbf{E}$ & $\mathrm{E} \longrightarrow$ & $\rightarrow E\left\{e_{1} ; e_{2} ; e_{3} ; e_{4} ; e_{5} ; e_{6} ; e_{7} ;\right\}$ \\
\hline & W $\mathbf{F}$ & $\mathrm{F}-$ & $\rightarrow F\left\{f_{1} ; f_{2} ; f_{3} ; f_{4} ; f_{5} ; f_{6} ; f_{7} ;\right\}$ \\
\hline & $\sqrt{ } 4$ & $\mathrm{~F} \uparrow \# \backslash \mathrm{G} \downarrow b$ & $\rightarrow F \uparrow \backslash G \downarrow\left\{f \uparrow \backslash g \downarrow_{0} ; \rightarrow{ }_{-} 1 ; \__{2} ; \__{3} ; \__{4} ;{ }_{-} 5 ; \__{6} ; \__{7} ;\right\}$ \\
\hline & $\mathbf{G}$ & $\mathrm{G}-$ & $\rightarrow G\left\{g_{1} ; g_{2} ; g_{3} ; g_{4} ; g_{5} ; g_{6} ; g_{7} ;\right\}$ \\
\hline & $\begin{array}{l}\mathrm{V} \\
\mathbf{5}\end{array}$ & $\mathrm{G} \uparrow \# \backslash \mathrm{A} \downarrow b$ & $\rightarrow G \uparrow \backslash A \downarrow\left\{g \uparrow \backslash a \downarrow_{0} ; \rightarrow{ }_{-1} ; \__{2} ;{ }_{-3} ;{ }_{-4} ;{ }_{-5} ;{ }_{-} 6 ;{ }_{-} ;\right\}$ \\
\hline
\end{tabular}

The memory programming process includes simultaneous connection of these hemispheric functions in completing the method tasks, with method's structure including all possible music tone name - label mistakes categorized by hemispheric belongings including the acoustic sounding specification of interval frequency ration between music tones with its reversal order by Helmholtz consonance - dissonance description (presented in table 4 with an example of «A» music tone name - label).

Neuropsychological organization of method's function includes both lateral processing engaged in method completion. The left hemisphere is processing semantic language functions, such as the alphabet, naming, syntax of language units. It contains linguistic litter, mathematical and musical languages contents. It produces the semantic knowledge for semantic memory content. In this hemisphere AP is the function of semantic language alphabetic memory. The right hemisphere is processing pitches frequency functions, with its timbre harmonics combination. It produces the availability of musical tone differentiation with its structural order memory, which is engaged in categorical musical pitch perception discrimination with its chroma's identification. In this hemisphere AP is the function of pitch frequency memory with its qualitative group of chromas for each of 12 musical tone - labels. Since chroma identification is conditioning the active AP function, while tone - label identification without its chroma type is conditioning the non-active (i.e. passive) AP function.

Perfect consonance errors are produced the close completed connection (scheme 7) that perform an impossibility to programming the mental memory map of music - tone name - labels since of transition through it's all components. That's the biggest disruption in AP semantic memory programming process. While second and seven dissonances produce the movement of created mental map to the up or down space for equal level, so group of music - tone name labels (or all of them) need to be re-programming on the condition of produced ordered scale with its' bias, so it isn't disruption for memory functioning statement of neural mental scheme. The rest of mistakes belong to condition of no forming up the mental memory map. It can be minimized through preserving the order of programming memory by grouping the name-labels with equal tempered distance (space) in octave range, i.e. placing into diminished chord with three minor thirds or augmented chord with two major thirds (table 5) by including working memory span principle for the personal decision of each individual human realizing the method. 
Table 4. Hemispheric music - tone name - label mistakes classification.

[M. Dymnikowa, E. A. Ogorodnikova]

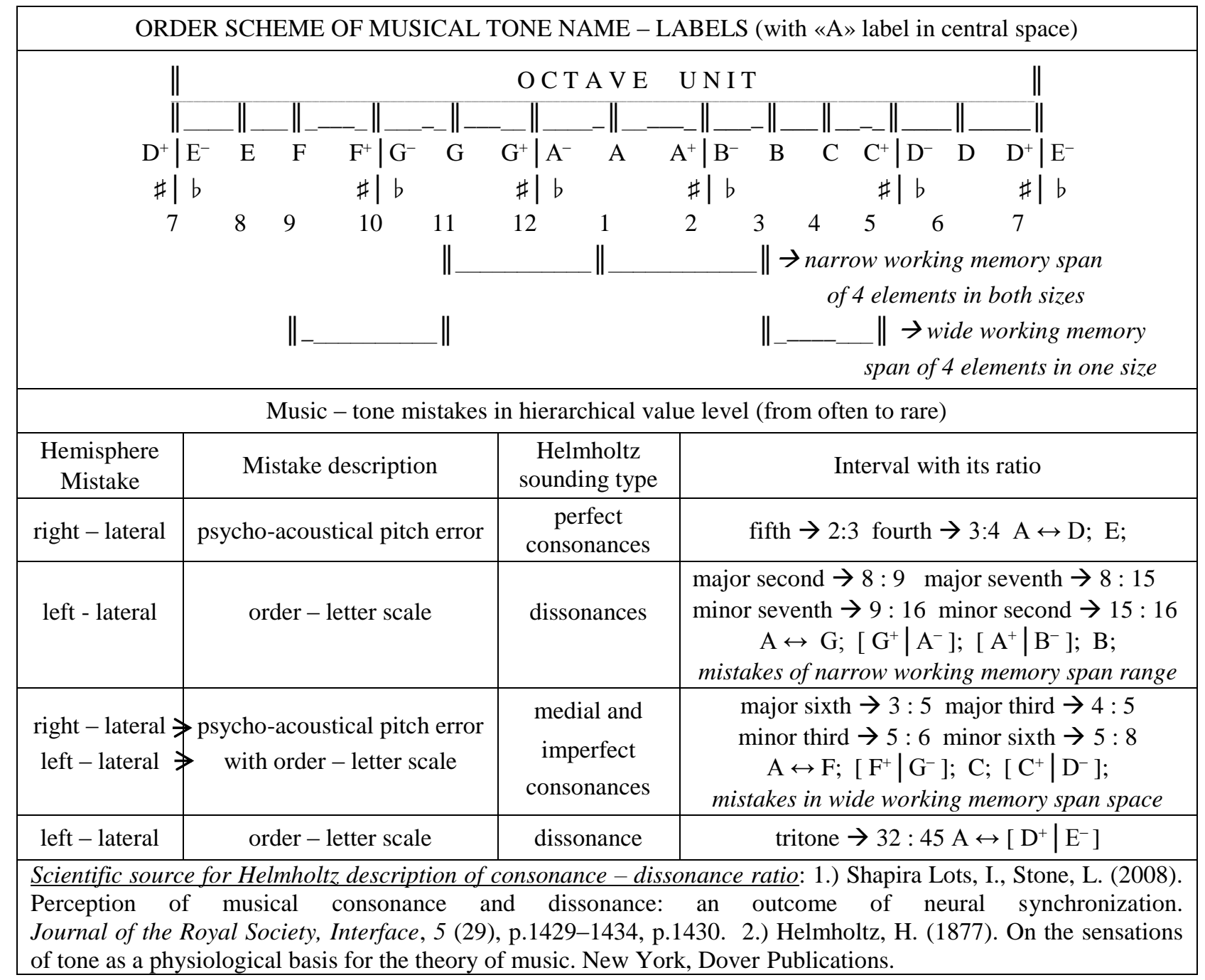

Scheme 7. Closed circuit of complementary perfect consonance errors.

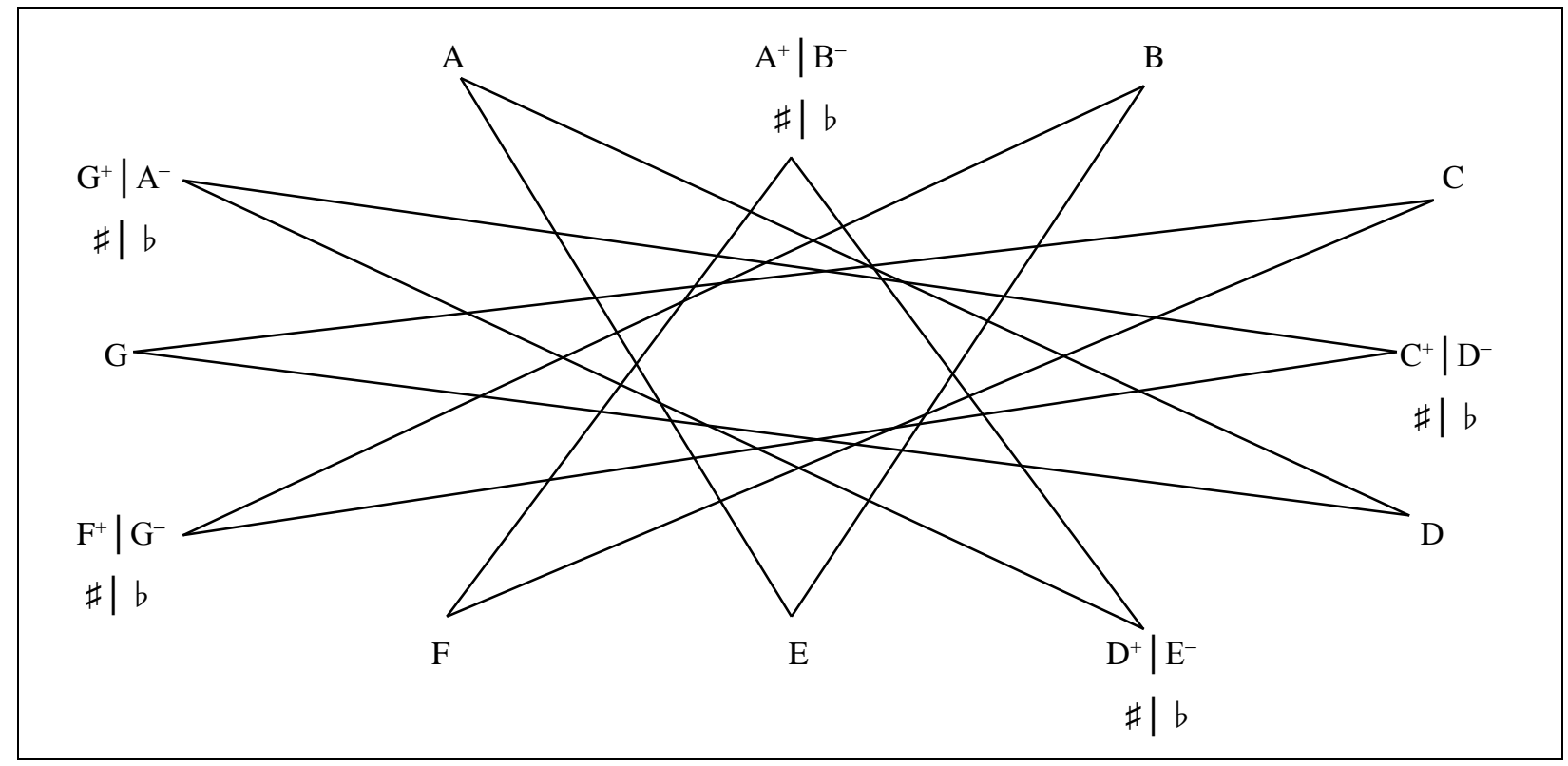


Table 5. Music - tone name - labels grouping layouts with working memory span principle

(3-4 structural units with 3-4 selected elements)

\begin{tabular}{|c|c|}
\hline \multicolumn{2}{|c|}{ Grouping layouts of equal tempered chord space in octave range } \\
\hline diminished chord with three minor thirds & augmented chord with two major thirds \\
\hline $\begin{array}{r}\mathrm{A} \leftrightarrow \mathrm{C} \leftrightarrow \mathrm{D}^{+}\left|\mathrm{E}^{-} \leftrightarrow \mathrm{F}^{+}\right| \mathrm{G}^{-} \\
\# \mid b\end{array}$ & $\begin{array}{c}\mathrm{A} \leftrightarrow \mathrm{C}^{+} \mid \mathrm{D}^{-} \leftrightarrow \mathrm{F} \\
\# \mid b\end{array}$ \\
\hline $\begin{array}{c}\mathrm{A}^{+}\left|\mathrm{B}^{-} \leftrightarrow \mathrm{C}^{+}\right| \mathrm{D}^{-} \leftrightarrow \mathrm{E} \leftrightarrow \mathrm{G} \\
\#|b \quad \#| b\end{array}$ & $\begin{array}{c}\mathrm{A}^{+}\left|\mathrm{B}^{-} \leftrightarrow \mathrm{D} \leftrightarrow \mathrm{F}^{+}\right| \mathrm{G}^{-} \\
\# \mid b\end{array}$ \\
\hline \multirow{2}{*}{$\begin{array}{r}\mathrm{B} \leftrightarrow \mathrm{D} \leftrightarrow \mathrm{F} \leftrightarrow \mathrm{G}^{+} \mid \mathrm{A} \\
\# \mid b\end{array}$} & $\begin{array}{c}\mathrm{B} \leftrightarrow \mathrm{D}^{+} \mid \mathrm{E}^{-} \leftrightarrow \mathrm{G} \\
\# \mid b\end{array}$ \\
\hline & $\begin{array}{r}\mathrm{C} \leftrightarrow \mathrm{E} \leftrightarrow \mathrm{G}^{+} \mid \mathrm{A} \\
\# \mid b\end{array}$ \\
\hline
\end{tabular}

The memory programming process requires mental resources of knowledge of wrong and correct memory presentation for each selected musical tone name - label. Recognition of proper label at the automatized level is possible by selective processing during analyses of all income aural stimuli from external acoustical space with comparing them to internal neuronal memory presentations obtained and produced the past aural experience. Therefore it needs to equip the brain with the experience of all possible comparative pairs with putting aside its sensory aural impressions in the auditory cortex and hippocampus for future automatic processing the income aural stimuli with proper recognition reaction of music tone name - label identification with its qualitative chroma description.

The structure of AP processing includes: 1. Income (external) level with pitch-frequency perception in the condition of attention processing, with engaged thinking operations and past experience with knowledge of musical pitches kept in memory data. 2. Outcome (internal) level of activation of long term working memory for music pitch frequencies, and of memory traces for accurate pitch-frequency of specific timbre sounding. So programming that function, as semantic music memory, includes necessity time reservation for thinking analysis at each level of completing the memory tasks for specific partial functions of memory processing.

The mental memory representation is conditioned by: 1. Interhemispheric cooperation of functional bilateralism state (i.e. bilateral processing of the left hemisphere for the name, of the right hemispheric for the pitch-frequency). 2. Partly cooperation of the primary auditory cortex for a specific music pitch frequency - with differential tonotopic organization of cell memory for chroma variants, with necessity of separable programming the music memory pitch frequencies. The stimulus can be identified as the same or different in relation to another stimulus that was previously remembered, in conditions of having the neural connection with memory presentation, and having the identification with its presentation as wrong (other) or correct (original).

The recognition with identification of a wrong stimulus example, as corrected with original accurate stimulus, does certify about the absence of forming up the mental memory presentation for the original accurate stimulus (i.e. left-hemispheric mistakes), or about the semantic similarity between attributes or properties of wrong and accurate stimulus (i.e. right-hemispheric mistakes). Therefore in AP processing weaker left-hemispheric organization cases the disorders of musical tone name - label identification, while weaker right-hemispheric organization cases the disorders of musical tone chroma identification. Perception of the wrong stimulus, on the background of memory for original accurate stimulus, does product output from memory by impression analysis, during the processing of: 1. Identification of perceived stimulus as false, on the background of mental memory neuronal network for original stimulus perceptual experience. 2. Comparison to original accurate stimulus on the background of: 2.1.Semantic acoustical structural similarity for pitch tuning or for ordered letter - scheme of musical tones. 2.2. Absence of mental memory presentation of original accurate stimulus of accurate musical pitch frequency. 
Spatial analysis of two music pitch frequencies (as higher, lower, the same) in structural order and in ratio to the twelve semitone scale in octave order, with the comparison of higher / lower pitch frequencies to one (same) octave register - for comparison of two pitch frequencies - is possible and accessible by the octave similarity principle and in the upheavals with the impression of sound in a different octave register. Including overtones' production of each pitch-frequency, with its one up direction for forming up the shades of basic musical tone - there is a necessity to programming the mental memory map with all qualitative chroma varieties at the beginning of memorizing the accurate musical tone name - label. Therefore spatial memory for musical pitch frequencies is created with principle of equal frequency pitch space, in the range of musical instrument (vocal) pitch scale. This principle (table 5) is also preserved in the method stage by grouping of memorized 3-4 music tones name labels that are equally distanced from each other in mutual relationship, i.e. the schemes of augmented or diminished pitch frequency structures, for the memory grouping preference of each individual human during the method realization.

\subsection{Methodological description.}

APEPA basic aim method: Developing (forming up, learning) the psychological - musical executive function, on the basis of semantic memory and of musical alphabet language. Developing the mental map of musical tone pitch frequencies' representation in the frame of structures of musical pitch language and semantic music memory.

APEPA accessibility resources - widespread with general availability for humans with preserved: 1. professional practical musical instrumental or vocal activity for musical performance; 2. biological resources of musical pitch and timbre hearing (audiation) presence as normal healthy state (in the case of pitch amusia existence).

Process activated in APEPA method: aural perception with visual perception of name - label notation (letter with chroma type) of musical tone's pitch frequency, aural and visual attention, semantic long-term working memory of musical tone's pitch frequency (musical pitch), musical knowledge (pitch name - labels' alphabet of musical tones with its musical notes' notation). Psychological executive function of semantic music memory for: 1. Professional musical performance practice; 2. Working with musical pieces and musical notes' text.

Specificity of APEPA method impact: Psychological (cognitive, behavioral) during natural learning on basis of developing: 1. Sensitivity and differentiation of musical tone pitch frequencies; 2. Categorical - semantic perception of musical tone with identification of 1 from 12 semitones name - labels and its chroma quality variety. 3. Aural sensitivity and sharpness on each of 12 semitone name - labels for prevention of confusion 1 music tone name label with 11 others including its mistakes' specification.

APEPA method description of use: The method might be used by people with circadian musical practice in daily activity, such as reading musical notes, practicing musical piece by vocal or the musical instrument with its memorizing, music peace performance. It can be realized independently by interested musicians (with audio recorded material) or by music teachers (with lively realization the method material from musical notes). The method material is reserved for the musical scale of accurate instrument or vocal range that concern daily practical musical activity, with additional complementary aural training of piano sound (for non-professional pianists) containing the $20 \%$ - $25 \%$ of main music timbre material (i.e. 1 piano exercise for 4 - 5 exercises in proper target music timbre). The requirements of biological resources' functions include musical pitch hearing, aural long-term memory, literal and numeral knowledge of units of linguistic and mathematical alphabets. Age requirements for method use concern critical age of cognitive school maturity (i.e. first classes of primary school level) and musical hearing stability with its crystallization function $(\approx 9$ year old), with taking into account the working - memory spam development till 11 - 12 years old (in differentiate of content realization before and after this age), with possibility to use the method till 40 age (beginning the stage of brain mental changes in working memory processing). The biological medical data of income organism statement taking into account might change the conditions of optimize the method realization. It concern of blood group, morphologic levels of hormones engaged into cognitive activity, sleep activity characteristics, eating style and metabolism of glucose during intensive mental activity, personal mental hygiene of daily activity according to the style of work, might change the conditions of optimizing the method realization. Stability of AP function obtained and developed by using the method is dependent by its active using daily, as long-term working memory processing i.e. dynamical statement (as it also concern the foreign language knowledge). Therefore any longer breaks might decrease or reduce the final out-come level after completed the method content. The diagnostic instrument for its function (i.e. AP test varieties for musical instrument's scale, with its content presented in paragraph 4.7), might be used many times (i.e. repeatedly), as during the method realization, as after its completion. The biological period that needed for long-term working memory stabilization for AP ranges approximately from 0,5 year for children age till 1,5 year for adult age. Internal breaks between partly sessions of 1 training session should be controlled by individual's present cognitive cognition with feedback information. 


\subsection{Methodological content of AP test varieties for musical instrument's scale.}

The complete realization of the method assumes the correct realization till $90 \%$ material (with possible backward to exercises till that level completion), with objective empiric psychological verification (presented in table 6) in personal individual checking by learning curve scheme and by «C» statistic index that is available by counting for $\geq 8$ attempts of specific exercise in the training session, of whole selective training session, or of all trials in 1 mnemonic technique from different sessions. The method might be controlled at each part of its realization, for every training exercise with counting the statistical level of correct \% completion. Therefore it allows overlooking the memory processing at the current time of method content realization. In case of mental fatigue syndromes during completion the tasks the training time should be reduced at the period of lower level of mental activity efficiency. It is especially important at the time period for other duties in life schedule, including the concert preparation and other personal affairs. The content structure of method include principles of tonotopic auditory cortex organization of music pitch processing, psycho-acoustic specifications of musical tone pitch frequencies sounding, with techniques of memory processing diagnosis, correction, improvement and development presented and realized in cognitive psychological and neuro-psychological diagnostic and clinical tests, with its respecting at the conscious practical programming memory process activated in the method, with including the dual level of AP content processing.

Time-series analysis $[99,120,143,188,286]$ is a desirable quantitative method for assistance and analysis of behavioral data, it is based on auto-regressive integrated moving average. This method can be used for small data sets to evaluate objectively the effects of psychological training influences or psychotherapy treatment in dependent time-series data. This methodological proposal came from Young [318] with evidence of normal distribution existence for time series containing above 25 values, with possibility to use «C» statistic (table 6 ) containing only 8 serial values, what is critical for short training and treatment condition. The critical values for statistical significance importance of improvement by the psychological influence and intervention for amount from 8 to 25 series for $p=0.01$ are defined by Tyron and Young (scientific source noted in table 6), with above 25 serial depended measurements at the level 310 for $\mathrm{p}=0.01$, and 1.64 for $\mathrm{p}=0.05$. All values above this level certify for the benefit of improvement statement. It is especially important during looking for better methods of psychological stimulation with correction, intervention, training-improvement, rehabilitation and developing the complex psychological functions.

Table 6. Statistical methodological verification of method efficiency function.

\begin{tabular}{|c|c|c|}
\hline \multicolumn{3}{|c|}{ «C»STATISTIC OF PSYCHOLOGIAL INFLUENCE EVALUATION IN DEF } \\
\hline \multirow{2}{*}{$\begin{array}{l}\text { Number of time }- \text { series }= \\
=\text { Number of series }-1\end{array}$} & $\mathrm{Z}$ - statistical significance & Function formula \\
\hline & $\mathrm{C}-\langle\mathrm{C} »$ statistic & \multirow{2}{*}{$\sum_{\mathrm{C}=1-}\left(\mathrm{X}_{\mathrm{I}}-\mathrm{X}_{\mathrm{I}+1}\right)^{2}$} \\
\hline $\mathrm{X}_{\mathrm{I}}-$ order serial number & $\mathrm{S}$ - standard error & \\
\hline $\mathrm{X}_{\mathrm{I}+1}-$ neighboring serial number & $\mathrm{N}-$ number of series & $\begin{array}{r}\mathrm{C}=1-\mathrm{X}\left(\mathrm{X}_{\mathrm{I}}-\mathrm{X}\right)^{2} \\
\end{array}$ \\
\hline $\mathrm{X}-$ mean average of all serial numbers & $\sum$ - total sum of serial calculations & \multirow{2}{*}{$\mathrm{S}=\sqrt{[\{\mathrm{N}+2\} /\{\mathrm{N}-1\} *\{\mathrm{~N}+1\}]}$} \\
\hline \multirow{2}{*}{\multicolumn{2}{|c|}{$\begin{array}{l}\text { Scientific source: Tyron, W. W. (1982). A simplified time-series analysis } \\
\text { for evaluation treatment interventions. Journal of Applied Behavioral Analysis, } \\
15, \text { no. } 3 \text {, Fall, p. } 423-429, \text { p. } 424 .\end{array}$}} & \\
\hline & & $\mathrm{Z}=\mathrm{C} / \mathrm{S}$ \\
\hline
\end{tabular}

This method allows making evaluation of changes due to psychological interventions, with its special usefulness in clinical and research practice, when it is needed to check the evidence of presence or absence of statistical importance of the influence effect. The behavioral learning curve might be obtained during frequency analysis of the correct stimulus' estimation of each task completion, from serial tasks, by divided this amount into the total number of stimulus in the task. Obtained \% frequency indices of the tasks' realization might be compared to each other on the order scale in accordance with the sequence of its completion. Each methodology task can be realized from 1 minute till 2 minutes. So the average completion of 10 - 15 tasks takes around half an hour that might be minimal diagnostic value of dynamic learning of tasks' realization. Therefore approximately 20 - 30 tasks might be realized during 1 hour training session. It might be representative for controlling the cognitive condition of mental activity efficiency. The time period of highest realization of the task's completion might inform about optimal duration of a single training session.

Total efficiency indices might be counted in statistical methodological principle by the data of the lowest and highest score of \% correct completion of the task probe in the training session, with comparison of these data with the mean value of all tasks' scores obtained in accurate session. If the mean value is near the lowest score, then it informs about the tendency of keeping the income level during the training session. When the initial level, as the lowest score, is higher from $50 \%$, then training sessions have controlled fixing rule. When the initial level is lower from $50 \%$, then the training session should be repeated further with mean value near or up from this indicator. 
When initial lowest level score is above $70 \%-75 \%$, then the training mechanism is completed and formed up, with possibility of its automatization during tasks completion, with no need to backward to it during further method completion. When the difference between the lowest and the highest score is till $10-15 \%$ then statistical difference will not be occurred by certificate of stable task completion. In case of lower scores till or around $50 \%$ it should be repeated further, while in case of level around $60-70 \%$ it might be passed at once task completion. The efficiency level of task completion is above $85 \%$ correct realization of correct stimulus' estimation, with optimal realization of above $90 \%$ correct completion. The tasks include also analysis of wrong stimulus to its estimation as correct pattern, so it is based on the memory programming process of wrong and correct answers. Regular monitoring of behavioral learning curve of each tasks completed in method might describe biological conditions and predispositions for AP mastering as psychological musical function at an optimal level. This can be viewed under the dynamic tendency of performing the methodological tasks, with the identification of possible periodic deterioration of cognitive work of a recurrent nature. Then it is possible to predict the arrival of such a period in advance in which it is advisable to reduce cognitive activity's effort for the duration of such reduced mental performance condition. In such a period, it is advisable to repeat the previous tasks, from which weaker results were obtained in completing the tasks at an earlier stage of realizing the method, which determines the conscious meta-memory regulation.

\subsection{Methodological assumptions for the aural tasks' realization.}

1. Each individual hearing task may last from 60 to 90 seconds. After this period, a break of 30 to 60 seconds is required.

2. In initial briefing mode, each auditory presentation must last up to 3 seconds according to the neuropsychological organization of the temporal hearing unit at the cerebral level [231, 232, 233, 234, 283, 284, 285], where after 3 seconds there must be a period of silence also up to 3 seconds. That is a total of 6 seconds for work with one stimulus. This means up to $10-15$ auditory stimuli as part of content of the single auditory exercise.

3. In advanced mode in shaping the of "behavioral automatism" condition as a response to auditory stimuli each auditory presentation must last until 1-1.5 seconds, with a silent period of $1 \mathrm{sec}$. up to 3 seconds (depending on the type of auditory task: 1. For perceptual, attention or memory functions; 2. With or without thinking process.) That is, from total 2 seconds up to 4.5 seconds to work with a single auditory stimulus. This means between 20 and 45 auditory stimuli as part of content of one auditory exercise.

4. Each methodical part of the training assumes the implementation of the control of diagnostic content for verification of the lack or presence of the purchase of a specific task function for AP. Task functions are conditioned by matter of music theory and the basis of semantic memory. Correct implementation of the control diagnostic content (at the level of $\geq 90 \%$ of diagnostic stimuli) is the basis for the implementation of the further part of the methodical tasks for AP. Implementation of control diagnostic content (at the level of $<90 \%$ of diagnostic stimuli) is the basis for the repeated implementation of the previous part of the methodical tasks for AP.

5. The essence of the method is to develop an alphabetic language system for AP as semantic memory map of musical pitch frequencies for a specific musical timbre within the available musical instrument scale. Learning the alphabet is not the knowledge in the sense of information understanding, but it is the habit of specific semantic units for using them on a regular basis in everyday life. Learning the alphabet is not a material to master in the pedagogical sense as a teaching (learning) program. It is a function of semantic memory enabling learning a specific semantic language (linguistic, mathematical, music, etc.).

6. The total number of methodical exercises for accurate musical timbre within the available scale of a musical instrument is conditioned by the scope of such a specific scale. Hence, the total amount of tasks of AP method may vary for individual musical instruments and requiring a different time for the practical realization of the method.

7. In the frame of learning of 12 units of musical tone alphabet, there are 2 ways of technical grouping of these units in the resources of direct working memory: 1. Grouping of 3 units of diminished chords with 4 tone units; 2. Grouping of 4 units of augmented chords with 3 tone units. The selection of the method realization at this stage belongs to the individual participant of the method. The decision about choosing the variant of the method realization should be made at the beginning of its using. The decision of individual person depend the order of working with specific musical tones names labels, so they should create logical systems of equal temporal tuning. Then during implementation of the method it is possible to respect the rules of aural mental map programming of semantic musical memory in the current order during semantic grouping of accurate musical tones, which are in specific equal temporal relation between each other. It concerns the major or minor thirds between two neighboring musical tones during method realization. 
8. The minimum duration of the method realization within 1 day should not be less than 1 hour practice (2 sessions for 30 minutes with an internal break up to 10 - 30 minutes according to preferences of individual participants). The maximum duration of the method within 1 day should not be larger than 2-3,5 hours of training for total morning and evening cycles. The duration of 3,5 hours is reserved for intensive mode of applying the method.

9. The original musical tone pitch-frequency pattern with its qualitative chroma varieties should be played in a method implementation by every $3-4$ tasks at the beginning stage, every 5 - 6 tasks in the middle level, every 7 - 10 tasks at the final period. Frequency of presenting the label pattern should be depended on the long-term memory statement of individual participant of method implementation, i.e. it's time to assimilate sufficiently this pattern that it will not need to remind the stimulated pattern. This condition is depended on individual differences of each participant completing the method. The whole time duration of original pattern stimulus scheme's sounding takes around 9 minutes (i.e. 9 pairs with 2 patterns in 10 parts - for 3 seconds aural presentation as «brain aural perceptual unit» i.e. $540 \mathrm{sec}$.)

[ Ordered sequence of original musical tone label presentation with correction including the range of music instrument (voice) scale $\left\{\mathrm{I}_{0}\right.$ symbol with $\mathrm{I}$ of name label and numeral octave - i.e. chroma $\}$ :

- 1 part: $\mathrm{I}_{0}-\mathrm{I}_{1} ; \mathrm{I}_{0}-\mathrm{I}_{2} ; \mathrm{I}_{0}-\mathrm{I}_{3} ; \mathrm{I}_{0}-\mathrm{I}_{4} ; \mathrm{I}_{0}-\mathrm{I}_{5} ; \mathrm{I}_{0}-\mathrm{I}_{6} ; \mathrm{I}_{0}-\mathrm{I}_{7} ; \mathrm{I}_{0}-\mathrm{I}_{8} ; \mathrm{I}_{0}-\mathrm{I}_{9} ; / /$

- 2 part: $\mathrm{I}_{1}-\mathrm{I}_{0} ; \mathrm{I}_{l}-\mathrm{I}_{2} ; \mathrm{I}_{l}-\mathrm{I}_{3} ; \mathrm{I}_{l}-\mathrm{I}_{4} ; \mathrm{I}_{1}-\mathrm{I}_{5} ; \mathrm{I}_{1}-\mathrm{I}_{6} ; \mathrm{I}_{l}-\mathrm{I}_{7} ; \mathrm{I}_{1}-\mathrm{I}_{8} ; \mathrm{I}_{l}-\mathrm{I}_{9} ; / /$

- 3 part: $\mathrm{I}_{2}-\mathrm{I}_{0} ; \mathrm{I}_{2}-\mathrm{I}_{1} ; \mathrm{I}_{2}-\mathrm{I}_{3} ; \mathrm{I}_{2}-\mathrm{I}_{4} ; \mathrm{I}_{2}-\mathrm{I}_{5} ; \mathrm{I}_{2}-\mathrm{I}_{6} ; \mathrm{I}_{2}-\mathrm{I}_{7} ; \mathrm{I}_{2}-\mathrm{I}_{8} ; \mathrm{I}_{2}-\mathrm{I}_{9} ; / /$

- 4 part: $\mathrm{I}_{3}-\mathrm{I}_{0} ; \mathrm{I}_{3}-\mathrm{I}_{1} ; \mathrm{I}_{3}-\mathrm{I}_{2} ; \mathrm{I}_{3}-\mathrm{I}_{4} ; \mathrm{I}_{3}-\mathrm{I}_{5} ; \mathrm{I}_{3}-\mathrm{I}_{6} ; \mathrm{I}_{3}-\mathrm{I}_{7} ; \mathrm{I}_{3}-\mathrm{I}_{8} ; \mathrm{I}_{3}-\mathrm{I}_{9} ; / /$

- 5 part: $\mathrm{I}_{4}-\mathrm{I}_{0} ; \mathrm{I}_{4}-\mathrm{I}_{1} ; \mathrm{I}_{4}-\mathrm{I}_{2} ; \mathrm{I}_{4}-\mathrm{I}_{3} ; \mathrm{I}_{4}-\mathrm{I}_{5} ; \mathrm{I}_{4}-\mathrm{I}_{6} ; \mathrm{I}_{4}-\mathrm{I}_{7} ; \mathrm{I}_{4}-\mathrm{I}_{8} ; \mathrm{I}_{4}-\mathrm{I}_{9} ; / /$

- 6 part: $\mathrm{I}_{5}-\mathrm{I}_{0} ; \mathrm{I}_{5}-\mathrm{I}_{1} ; \mathrm{I}_{5}-\mathrm{I}_{2} ; \mathrm{I}_{5}-\mathrm{I}_{3} ; \mathrm{I}_{5}-\mathrm{I}_{4} ; \mathrm{I}_{5}-\mathrm{I}_{6} ; \mathrm{I}_{5}-\mathrm{I}_{7} ; \mathrm{I}_{5}-\mathrm{I}_{8} ; \mathrm{I}_{5}-\mathrm{I}_{9} ; / /$

- 7 part: $\mathrm{I}_{6}-\mathrm{I}_{0} ; \mathrm{I}_{6}-\mathrm{I}_{1} ; \mathrm{I}_{6}-\mathrm{I}_{2} ; \mathrm{I}_{6}-\mathrm{I}_{3} ; \mathrm{I}_{6}-\mathrm{I}_{4} ; \mathrm{I}_{6}-\mathrm{I}_{5} ; \mathrm{I}_{6}-\mathrm{I}_{7} ; \mathrm{I}_{6}-\mathrm{I}_{8} ; \mathrm{I}_{6}-\mathrm{I}_{9} ; / /$

- 8 part: $\mathrm{I}_{7}-\mathrm{I}_{0} ; \mathrm{I}_{7}-\mathrm{I}_{1} ; \mathrm{I}_{7}-\mathrm{I}_{2} ; \mathrm{I}_{7}-\mathrm{I}_{3} ; \mathrm{I}_{7}-\mathrm{I}_{4} ; \mathrm{I}_{7}-\mathrm{I}_{5} ; \mathrm{I}_{7}-\mathrm{I}_{6} ; \mathrm{I}_{7}-\mathrm{I}_{8} ; \mathrm{I}_{7}-\mathrm{I}_{9} ; / /$

- 9 part: $\mathrm{I}_{8}-\mathrm{I}_{0} ; \mathrm{I}_{8}-\mathrm{I}_{1} ; \mathrm{I}_{8}-\mathrm{I}_{2} ; \mathrm{I}_{8}-\mathrm{I}_{3} ; \mathrm{I}_{8}-\mathrm{I}_{4} ; \mathrm{I}_{8}-\mathrm{I}_{5} ; \mathrm{I}_{8}-\mathrm{I}_{6} ; \mathrm{I}_{8}-\mathrm{I}_{7} ; \mathrm{I}_{8}-\mathrm{I}_{9} ; / /$

- 10 part: $\left.\mathrm{I}_{9}-\mathrm{I}_{0} ; \mathrm{I}_{9}-\mathrm{I}_{1} ; \mathrm{I}_{9}-\mathrm{I}_{2} ; \mathrm{I}_{9}-\mathrm{I}_{3} ; \mathrm{I}_{9}-\mathrm{I}_{4} ; \mathrm{I}_{9}-\mathrm{I}_{5} ; \mathrm{I}_{9}-\mathrm{I}_{6} ; \mathrm{I}_{9}-\mathrm{I}_{7} ; \mathrm{I}_{9}-\mathrm{I}_{8} ;\right]$.

10. Possible syndromes of individual participant faster fatigue might be occurred during one methodical session completion during the method implementation. Then it is recommended dividing the session for shorter time - duration with additional internal breaks, which should be quite regular for equal scope of method processing in a time context. It's the importance in the frame of circadian rhythms for brain mental memory activity functions. The regularity of breaks in the frame of methodical sessions ensures a cycle of stability of mind's absorbency for mastering methodical assumptions of AP as semantic memory.

11. For optimizing the method implementation the physiological indicators of blood morphology (just before the start of the method implementation) with blood type and clinical data from the diet nutrition metabolism of the individual participant should be taken into account. Medical specialists might recommend the optimal physiological reinforcement (with possible additional biological support) for the period of method implementation, for optimizing its influence on biological level. The importance of maintaining a regular sleep in circadian time during all period of method implementation is the case of its optimization with prolonged effect on brain memory mechanism processing.

12. During the method task completion, it is necessary to observe their dynamics of realization from the perspective of learning and mental fatigue curves, to determine constancy of periods of improvement or deterioration of the mental condition, selected, as permanent tendencies over several methodical sessions. Identifying the specificity of dynamic changes in the method implementation should be a cue to fit the cycle and form of tasks completion to the state of the body, i.e. the total length of the session should be fit to the learning curve (to the critical time period in which the learning ability begins to decrease) and to the mental fatigue curve (to the period of taking a break at the beginning moment of this mental statement, to optimize the methodological processes for the physiology of mental effort).

13. During the implementation of diagnostic control tasks the tendencies of different parts of the method should be observed. There is a tendency - probability to disclose specific inclinations for mistakes production or of mental fatigue for specific method tasks according to the types of programming memory techniques for aural tasks or for accurate musical pitch frequencies. For such methodical weaknesses, there is recommended to backward repeatedly for realized tasks in the later period of method implementation.

14. While observing any neurological and pain symptoms from the nervous system functioning during the method implementation, it is necessary to interrupt its realization for the time period of health regeneration. 
15. People who take drugs for chronic conditions with its influence on cognitive functions metabolism and brain statement, may have permanent mental disruptions during method implementation, there is needed to extend for them the time duration method completion.

\subsection{Methodological map of analysis of musical tone errors production.}

The qualitative content diagnosis of mistakes made during the method implementation in music - theory context might be useful for the identification of structural predispositions' varieties for their occurrence during programming the semantic music memory for AP. The structural hemispheric music - tone name - label mistakes classification presented in table 4, allow to making structural map of every individual human's diagnosis data, and to looking for different music - theory content in analysis of combination variety of all musical tone errors revealed in test. Determining the content of the structural unit for a combination of confused musical tones allows carrying out the additional repeated realization of method's tasks prepared for correcting the specific errors in the musical tones' identification processing.

The specification consists in finding optimal one (or maximum two) content structure of musical tones corresponding to the chosen mistaken musical tones in individual participant during the method implementation. It allows correcting consciously up to date the AP semantic music memory programming processing. The diagnostic analysis might be down in separating cases of effortless mistakes' production of un-recognized musical pitch tones' content into: 1. Consonance matter; 2. Dissonance matter;

3. Un-recognition of specified semitone label in different chroma's variants (i.e. in different octave ranges); 4. Un-recognition of specific chroma's variant (i.e. of couple different semitones of accurate octave range); 5. Grouping un-recognized pitch-tones of accurate harmonic structure (e.g. major, minor, diminished, augmented chords, or with double equal fourth / tritone / fifth form);

6. Grouping un-recognized pitch-tones in a sequence of major or minor seconds (i.e. equally spaced lower sensitivity of equal tempered tuning system) - with additional analysis of this effect presence in single or couple chroma's variants. 7. Location of un-recognized pitch-tones in selected diminished or augmented chord's structure in different chromas (i.e. octave ranges) as the evidence of the lower common sensitivity for accurate semitones' group of AP acquisition structured memory, what requires a separate correction training for pitch-tones belonged to such a group. 8. Frequency of mistakes production in the frame of attentional process difficulty in time resources of AP perception analysis (i.e. regularly mistakes for the duration of $15-20$ stimuli, e.g. every $2^{\text {nd }}, 3^{\text {rd }}, 4^{\text {th }}, 5^{\text {th }}$ or $6^{\text {th }}$ example in AP tasks, that are observed in partly neighboring tasks' content). That kind of mistakes requires to change the time speed of AP tasks realization with longer breaks after each selected task completion.

9. Amount of mistakes in each AP task during one training session converted to the percentage level scale, that allows obtaining the learning curve map with the possibility of monitoring and evaluating the time temporary content management of AP tasks for its' more utility usefulness. The diagnostic errors' analysis sheet presented in table 7 might be useful for putting all tasks' errors on one global structure. It might be prepared for selected AP tasks' group or for global calculated indicators from one part training session (i.e. separated by internal breaks). Each grill-field might contain a percentage or numeric value of corrected vs. uncorrected recognized musical pitch - tones in AP tasks.

Table 7. AP diagnostic errors' sheet.

\begin{tabular}{|c|c|c|c|c|c|c|c|c|c|c|c|c|}
\hline 7 & & & & & & & & & & & & \\
\hline 6 & & & & & & & & & & & & \\
\hline 5 & & & & & & & & & & & & \\
\hline 4 & & & & & & & & & & & & \\
\hline 3 & & & & & & & & & & & & \\
\hline 2 & & & & & & & & & & & & \\
\hline 1 & & & & & & & & & & & & \\
\hline $\begin{array}{l}\text { Chroma number } \uparrow \\
\text { Semitone label } \rightarrow\end{array}$ & A & $\begin{array}{l}\mathrm{A}^{+} \\
\mathrm{B}^{-}\end{array}$ & B & $\mathrm{C}$ & $\begin{array}{l}\mathrm{C}^{+} \\
\mathrm{D}^{-}\end{array}$ & $\mathrm{D}$ & $\begin{array}{l}D^{+} \\
E^{-}\end{array}$ & $\mathrm{E}$ & $\mathrm{F}$ & $\begin{array}{l}\mathrm{F}^{+} \\
\mathrm{G}^{-}\end{array}$ & $\mathrm{G}$ & $\begin{array}{l}\mathrm{G}^{+} \\
\mathrm{A}^{-}\end{array}$ \\
\hline
\end{tabular}

That collected sheets might be diagnostic evidence of AP acquisition processing for each participant, by including them in the analysis of $\mathrm{C}$ statistic indices of psychological influence evaluation in the dependent time series data from AP training tasks (described in table 6). 


\subsection{Methodological content with task completing tables.}

APEPA program includes material for single sounds and multiple 2-3 sounds ( 2 for intervals, 3 for chords) of pitch - frequencies presented by single - selected (i.e. melodic) and common (i.e. harmonic co-sound) forms. The multiple sounds can be presented in closed focused form (till $1-2$ octave ranges) or open extensive form (above 1 octave range). The algorithm of memory tasks structure and content for multiple sounds of intervals includes all possible varieties of mistakes' classification (table 4) with its combined combination forms. For chords it concerns such forms (with all possible configuration) as major, minor, diminished, augmented, with double equal fourth / tritone / fifth. The amount of memory tasks is depended on musical instrument (vocal) pitch-frequency scale, with basic principle to represent all possible aural sounding combinations in musical pitch space matter, for programming the memory experience for both true and false examples of accurate musical tone pitch name - label with its quality chroma form.

Combined tasks varieties forms include:

1 - «plane» identification of the accurate musical tone in closed focused form (till 1 - 2 octave ranges).

2 - «plane» identification of the accurate musical tone in open extensive form (above 1 octave range).

3 - «named» identification of the accurate musical tone in closed focused form (till 1 - 2 octave ranges).

4 - «named» identification of the accurate musical tone in open extensive form (above 1 octave range).

Including the neuropsychological data about time duration of brain aural perceptual unit of around 3 seconds, the method includes this principle of stimulus presentation in task completion, with additional variant of 1 second time-duration for forming up the mental memory presentation at the automatic reflex activation, as behavioral reaction on perceptual stimulus pattern processing. Both these forms include an additional factor of presence and absence of the distractor matter (i.e. tetrachord) for optimizes attentional processing, engaged in memory programming mechanisms. The distractor pattern (with time - duration presentation of 1 second, as perceptual influence on the intentional perceived pattern) has co-sound closed focused form of 4 musical tone pitches with equal major or minor second ratio without duplication of accurate musical tone name - label for memory programming processing, with possibility of closer or farther presence from the original pattern space location, with obligatory tritone presentation (in relation to accurate musical tone name) and quite equal amount of examples in the higher and lower space from accurate perceived stimulus pattern. The mental thinking processing, engaged in memory programming mechanisms during method implementation, with 3 second time - duration (i.e. equal for longer time sounding of the original stimulus pattern presentation) is taken into account for all task varieties' forms. It's especially importance is conditioned by scientific data and methodological principle with no limitation time for completing the psychological tests of thinking process engaged additionally long-term semantic memory processing.

In total time resources for singe stimulus pattern presentation in method structure it contains 4 different time amount for method task realization till 90 seconds duration (from shorter to longer):

1. With duration of 7 seconds [with distraction presence, 3 seconds of an original pattern sounding, 3 seconds for thinking analysis processing] - with till 12 - 13 stimulus patterns presented in 1 methodological task.

2. With duration of 6 seconds [without distraction presence, 3 seconds of an original pattern sounding, 3 seconds for thinking analysis processing] - with till 15 stimulus patterns presented in 1 methodological task. 3 . With duration of 5 seconds [with distraction presence, 1 second of an original pattern sounding, 3 seconds for thinking analysis processing] - with till 18 stimulus patterns presented in 1 methodological task.

4. With duration of 4 seconds [without distraction presence, 1 seconds of an original pattern sounding, 3 seconds for thinking analysis processing] - with till 22 stimulus patterns presented in 1 methodological task. The comparative function of working memory performance's evaluation (i.e. direct learning curve) for a different number of stimuli in time-duration of 90 seconds is presented in the table 8 .

Table 8. Comparative function of working memory performance's evaluation for 12 - 22 stimuli in 90 seconds.

\begin{tabular}{|c|c|c|c|}
\hline \multicolumn{4}{|c|}{ Number of stimuli $n \rightarrow$ Function formula with multiplier to union scale \% level of correctness } \\
\hline $12 \rightarrow n * 8.334$ & $15 \rightarrow n * 6.667$ & $18 \rightarrow n * 5.556$ & $21 \rightarrow n * 4.762$ \\
\hline $13 \rightarrow n * 7.693$ & $16 \rightarrow n * 6.25$ & $19 \rightarrow n * 5.264$ & \multirow{2}{*}{$22 \rightarrow n * 4.546$} \\
\hline $14 \rightarrow n * 7.143$ & $17 \rightarrow n * 5.883$ & $20 \rightarrow n * 5$ & \\
\hline
\end{tabular}

Programming memory techniques concern varieties of conditions of perceptual analysis processing, including the attention attributes' specification, with possible estimation, in task's presentation, of: 1. Each stimulus pattern with its true-false and chroma identification. 2. Every 2, 3, 4 stimulus pattern (tables $10-12$ in scheme 8). 3. Serial choice from the group of $3-4$ stimulus patterns, with presence or absence of prompt key. A prompt key concern the possible 4 varieties of feedback information: 1. In top / middle / down pattern. 2. In $1^{\text {st }}, 2^{\text {nd }}, 3^{\text {rd }}$ or $4^{\text {rd }}$ pattern. 3 . In $1-2$ of 3 patterns. 4. In $1-2-3$ of 4 patterns. 
Additional analysis includes the comparison of first and last $\left(3^{\text {rd }} / 4^{\text {th }}\right)$ stimulus pattern in the task (tables 13 - 14 in scheme 8), so these forms require an equal amount of stimulus in the task content. The tasks targeted for the backward integration of name - label form with its pitch sounding, prepared for all sounding material matter (single sounds and multiple 2-3 sounds), include presentation of written name - label form for estimation it as true or false in relation to perceived stimulus pattern. The factors of memory techniques with the time of stimulus pattern's presentation for completing the method's tasks are conditioned its big and rich material content as the method's background.

Combined prompt key tasks varieties forms: 1. With the function of «plane» or «named» identification of accurate musical tone, include information about location of accurate stimulus pattern: 1.1. In the down for 1 of 3 stimulus. 1.2. In the middle for 1 of 3 stimulus. 1.3. In the top for 1 of 3 stimulus. 2. With identification of the space location: in $1^{\text {st }}, 2^{\text {nd }}, 3^{\text {rd }}, 4^{\text {th }}$ pattern. 3 . With identification of the serial number with its chroma and space location: 3.1. For 1 of 3 or 4 stimulus. 3.2. For 2 of 3 or 4 stimulus. 3.3. For 3 of 4 stimulus.

Description of memory tasks' forms - organized into 7 training thematic specialized groups (tables' list in scheme 8).

\section{Tasks' forms of material with a single sound presentation}

1.1. Recognition of the numbers of octave registers (chromas) - an exercise on the material of the chromas of accurate musical tone (with no distractor presence) - Table 1 in scheme 8.

1.2. Estimation of a single imposed sound after distractor.

Table 2 in scheme 8 - determining whether the musical tone was correct or not.

Table 1 in scheme 8 - determining whether the musical tone was correct or not, on case of correct state with identification of its name label.

1.3. Estimation of written music tone name - label with sound perception.

Table 3 in scheme 8 - determining whether the written musical tone was correct to the aural perception or not, on material of the main chromas.

Table 3 in scheme 8 - determining whether the musical tone was correct or not, on case of correct state with its name label with foreign musical tones.

1.4. Serial recognition in group of 3 stimulus patterns with identification of music tone name (with possible promt key or obligator analysis of each pattern).

Table 4 in scheme 8 with possibility: - plane serial choice; - serial choice with identify the name - label (i.e. chroma).

1.5. Serial recognition in group of 4 stimulus patterns with identification music tone name (with possible promt key or obligator analysis of each pattern).

Table 6 in scheme 8 with possibility: - plane serial choice; - serial choice with identify the name - label (i.e. chroma).

1.6. Serial recognition in group of 3 stimulus patterns with Estimation of written music tone name - label with sound perception. Table 5 in scheme 8 . (with possible promt key or obligator analysis of each pattern with different amount of correct patterns). Determining in which example the written musical tone was correct to the aural perception, or estimation of each example in the group of stimulus patterns.

1.7. Recognition of accurate musical tone in the series of different single pitch - frequencies, with possibility of identification when it was presented, or with identification of its name - label (i.e. chroma). Table 7 in scheme 8 .

This form is also used in description the key tonality in series of major or minor chord with identification of when it was presented - Table 2 in scheme 8.

\section{Tasks' forms of material with 2 sound selected (melodic) presentation}

Recognition of accurate musical tone in the series of different double pitch - frequencies (presented in selected form), with possibility of identification when it was presented, or with identification of its name - label (i.e. chroma).

Table 7 and 9 in scheme 8 . In this task two chromas might be presented in 1 stimulus pattern of double pitch-frequencies.

The duration of each sound presentation is around 1-1,5 second. This task might be realized with promt key condition.

III. Tasks' forms of material with 3 sound selected (melodic) presentation

Recognition of accurate musical tone in the series of different tripple pitch - frequencies (presented in selected form), with possibility of identification when it was presented, or with identification of its name - label (i.e. chroma).

Table 8 in scheme 8 . In this task two chromas might be presented in 1 stimulus pattern of tripple pitch - frequencies.

The duration of each sound presentation is around 1-1,5 second. This task might be realized with promt key condition. 
Scheme 8. Task completing tables' list.

\begin{tabular}{|c|c|c|c|c|c|c|c|c|c|c|c|c|c|c|}
\hline \multicolumn{6}{|c|}{ Table № 1} & \multicolumn{9}{|c|}{ Table № 2} \\
\hline 1 & & 3 & & 5 & & 1 & 2 & 3 & 4 & & & & $N$ & $\ldots$ \\
\hline 2 & & 4 & & $N_{\ldots} \ldots$ & & + & + & + & + & & & & + & + \\
\hline \multicolumn{6}{|c|}{ Table № 3} & - & - & - & - & & & 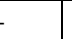 & - & - \\
\hline 1 & 2 & 3 & 4 & 5 & $N \ldots$ & \multicolumn{9}{|c|}{ Table № 4} \\
\hline note & note & note & note & note & note & \multicolumn{3}{|c|}{1} & \multicolumn{6}{|c|}{2} \\
\hline+ & + & + & + & + & + & \multicolumn{2}{|r|}{2} & 3 & 1 & & \multicolumn{2}{|c|}{2} & 3 & \\
\hline \multirow[t]{2}{*}{-} & - & - & - & - & - & & & & & & & & & \\
\hline & & & & & & \multicolumn{3}{|c|}{3} & \multicolumn{6}{|c|}{$N \ldots$} \\
\hline \multicolumn{6}{|c|}{ Table № 5} & 1 & \multirow[t]{2}{*}{2} & 3 & \multirow{2}{*}{\multicolumn{2}{|c|}{1}} & \multirow{2}{*}{\multicolumn{2}{|c|}{2}} & \multirow{2}{*}{\multicolumn{2}{|c|}{3}} \\
\hline \multicolumn{3}{|c|}{1} & \multicolumn{3}{|c|}{2} & & & & & & & & & \\
\hline 1 & 2 & 3 & 1 & 2 & 3 & & & Tabl & № 6 & & & & & \\
\hline note & note & note & note & note & note & & 1 & & & & & 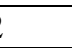 & & \\
\hline & 3 & & & $N \ldots$ & & 1 & 2 & 4 & 1 & & 2 & 3 & & 4 \\
\hline 1 & 2 & 3 & 1 & 2 & 3 & & & & & & & & & \\
\hline note & note & note & note & note & note & & 3 & & & & $N$ & & & \\
\hline & & $\mathrm{Tab}$ & № 7 & & & 1 & 2 & 4 & 1 & & 2 & 3 & & 4 \\
\hline 1 & 2 & 3 & 4 & 5 & $N \ldots$ & & & & & & & & & \\
\hline+ & + & + & + & + & + & & & Tabl & № 8 & & & & & \\
\hline- & - & - & - & - & - & 1 & 2 & 3 & 4 & & & & $N$ & $\ldots$ \\
\hline & & & & & & + & + & + & + & & & & + & + \\
\hline & & $\mathrm{Tab}$ & № 9 & & & - & - & - & - & & & & - & \\
\hline 1 & 2 & 3 & 4 & 5 & $N \ldots$ & top & top & top & to & & & & to & $\mathrm{p}$ \\
\hline+ & + & + & + & + & + & middle & middle & middle & mid & & $\operatorname{mic}$ & dle & mid & Idle \\
\hline- & - & - & - & - & - & down & down & down & dov & & & wn & dov & wn \\
\hline top & top & top & top & top & top & & able № 10 & - every & ${ }^{n d}$ sti & muli & esti & nation & & \\
\hline down & down & down & down & down & down & 1 & 2 & 3 & 4 & & & & 6 & \\
\hline Tal & le № 1 & - every & ${ }^{\mathrm{rd}}$ stimu & estima & & + & & + & & & & & & \\
\hline 1 & 2 & 3 & 4 & 5 & 6 & - & & - & & & & & & \\
\hline+ & & & + & & & & & & & & & & & \\
\hline- & & & - & & & & able № 12 & - every & ${ }^{\text {th }} \mathrm{sti}$ & nuli & estil & hation & & \\
\hline & & & & & & 1 & 2 & 4 & 5 & & 6 & 7 & & 8 \\
\hline Table & № 13 & irst and & hird sti & uli estil & ation & + & & & + & & & & & \\
\hline & 1 & & & $N \ldots$ & & - & & & - & & & & & \\
\hline 1 & 2 & 3 & 1 & 2 & 3 & & & & & & & & & \\
\hline+ & & + & + & & + & $\mathrm{Ta}$ & le № 14 - & first and & ourth & & uli e & stima & ion & \\
\hline- & & - & - & & - & & 1 & & & & $N$ & & & \\
\hline & & & & & & 1 & \begin{tabular}{l|l}
2 &
\end{tabular} & 4 & 1 & & 2 & 3 & & 4 \\
\hline & ble № & - four & ound se & al patte & & + & & + & + & & & & & + \\
\hline serial & ounds & 1 & 2 & 3 & 4 & - & & - & - & & & & & - \\
\hline & & + & + & + & + & & & & & & & & & \\
\hline $1^{\mathrm{st}} \mathrm{p}$ & ttern & - & - & - & - & & Гable № 1 & $5-$ three & ounc & seri & al pa & tterns & & \\
\hline & & & & & & & & & patte & & & $N \ldots$ & patt & ern \\
\hline serial & ounds & 1 & 2 & 3 & 4 & & l sounds & 1 & 2 & 3 & & 1 & 2 & 3 \\
\hline & & + & + & + & + & & & + & + & + & & + & + & + \\
\hline$N \ldots \mathrm{p}$ & attern & - & - & - & - & & & - & - & - & & - & - & - \\
\hline & & & & & & & & & & & & & & \\
\hline
\end{tabular}

\section{Tasks' forms of material with 2 sound common (harmonic) presentation}

Conditions the same as for part «II» with distraction presence only for variant of stimulus pattern duration for 3 seconds.

\section{$\underline{\text { V. Tasks' forms of material with } 3 \text { sound common (harmonic) presentation }}$}

Conditions the same as for part «III» with distraction presence only for variant of stimulus pattern duration for 3 seconds. 


\section{Tasks' forms for grouped material of 3-4 labels with selected (melodic) presentation}

6. 1. Estimation of a single imposed sound after distractor - Tables 15 and 16 in scheme 8 .

Terms of the task: - determining whether the musical tone was correct or not;

- determining whether the musical tone was correct or not, on case of correct state with identification of its name label.

6.2. Recognition of accurate musical tone in the series of 3 - 4 sounds (in selected and co-sound form) with its chroma identification, with analysis of each stimulus pattern [with closed focused form (till 1 - 2 octave ranges) or open extensive form (above 1 octave range)]. The duration of each sound presentation is around 1-1,5 second. Tables 4 and 6 in scheme 8. Conditions of tasks' forms: 1 - with only accurate musical tones; 2 - without distractors presence; 3 - with double form of sound duration ( 1 and 3 seconds). In this task two chromas of 1 from 3 - 4 accurate music tones might be presented in 1 stimulus pattern of 3 - 4 pitch - frequencies.

\section{Tasks' forms for grouped material of 3-4 labels with common (harmonic) presentation}

Conditions the same as for task 6.2. in part «VI».

\subsection{Methodological content of AP test varieties for string musical instruments' scale.}

The presented diagnostic material is included the single presentation of pitch-frequency from the string musical instrument's scale range (table 9), and might be used to narrower scale range of woodwinds and brass music instruments, with taking into account its' transposes function, i.e. the diagnostic pitch labels must be the same as at the sounding level. This also includes the double bass transposes to one octave down in the bass F clef, where the semitone label is preserved with numeral codes' changing.

The psychometric structure's content of AP includes three rules of reliable measurement on the music psychometry principles: 1 . All 12 semitone labels' presentation in every rank serial group, separated with the symbol ' $\mid$ ', (\# as,$+ b$ as - ) that might be used as a group of diagnostic pitch variants for other musical instruments' AP diagnosis. 2. Each group of 4 pitches has at least 1 element of consonance and dissonance relation between neighboring paired elements, with the $3^{\text {rd }}$ variable element. 3. Each pair of two elements is presented in a different octave range (i.e. chroma type) for excluding the relative pitch recognition of neighboring pitch tones.

Selected ranks of 12 elements from presented diagnostic content might be taken for other instrument range scale with changing the numeral labels to their accurate octave registers. For the aim of psychometric diagnostic stability of the diagnostic content, the presented material might be realized twice (i.e. repeatedly) during one diagnostic session trial. It might be presented from a different location-place of the material content. Including the dynamic statement of AP as long-term working memory functional role with its condition by circadian practical activity (an analogy of foreign language use), the partially revealed changes due to the different activity level of daily using this function in longitude period are characterized by its structural nature properties.

Table 9. String music instruments' pitch-frequency scale.

\begin{tabular}{|c|c|c|c|c|c|c|c|}
\hline Music instrument & piano & harpsichord & harp & violin & viola & cello & double bass \\
\hline Pitch frequency scale & $\mathrm{C}_{1} \leftrightarrow \mathrm{B}_{7}$ & $\mathrm{~F}_{1} \leftrightarrow \mathrm{F}_{6}$ & $\mathrm{C}_{2} \leftrightarrow \mathrm{G}_{7}$ & $\mathrm{G}_{3} \leftrightarrow \mathrm{G}_{7}$ & $\mathrm{C}_{3} \leftrightarrow \mathrm{D}_{6}$ & $\mathrm{C}_{2} \leftrightarrow \mathrm{A}_{5}$ & $\mathrm{E}_{1} \leftrightarrow \mathrm{B}_{3}$ \\
\hline Amount of musical tones & 83 & 61 & 68 & 49 & 39 & 45 & 32 \\
\hline $\begin{array}{c}\text { Total time duration } \\
\text { of AP test in minutes }\end{array}$ & $\begin{array}{c}\sim 8.3 \\
\text { minutes }\end{array}$ & $\begin{array}{c}\sim 6.1 \\
\text { minutes }\end{array}$ & $\begin{array}{c}\sim 6.8 \\
\text { minutes }\end{array}$ & $\begin{array}{c}\sim 5 \\
\text { minutes }\end{array}$ & $\begin{array}{c}\sim 4 \\
\text { minutes }\end{array}$ & $\begin{array}{c}\sim 4.5 \\
\text { minutes }\end{array}$ & $\begin{array}{c}\sim 3.5 \\
\text { minutes }\end{array}$ \\
\hline
\end{tabular}

MUSIC OCTAVE - LABEL EXPLANATION data source: http://pages.mtu.edu/ suits/notefreqs.html
$\mathrm{C}_{1} \leftrightarrow \mathrm{B}_{1} \rightarrow$ CONTRA octave with pitch frequency from $32.70 \mathrm{~Hz}$ to $61.74 \mathrm{~Hz}$.
$\mathrm{C}_{2} \leftrightarrow \mathrm{B}_{2} \rightarrow$ BIG octave with pitch frequency from $65.41 \mathrm{~Hz}$ to $123.47 \mathrm{~Hz}$.
$\mathrm{C}_{3} \leftrightarrow \mathrm{B}_{3} \rightarrow$ SMALL octave with pitch frequency from $130.81 \mathrm{~Hz}$ to $246.94 \mathrm{~Hz}$.
$\mathrm{C}_{4} \leftrightarrow \mathrm{B}_{4} \rightarrow 1^{S T}$ octave with pitch frequency from $261.63 \mathrm{~Hz}$ to $493.88 \mathrm{~Hz}$.
$\mathrm{C}_{5} \leftrightarrow \mathrm{B}_{5} \rightarrow 2^{N D}$ octave with pitch frequency from $523.25 \mathrm{~Hz}$ to $987.77 \mathrm{~Hz}$.
$\mathrm{C}_{6} \leftrightarrow \mathrm{B}_{6} \rightarrow 3^{R D}$ octave with pitch frequency from $1046.50 \mathrm{~Hz}$ to $1975.53 \mathrm{~Hz}$.
$\mathrm{C}_{7} \leftrightarrow \mathrm{B}_{7} \rightarrow 4^{T H}$ octave with pitch frequency from $2093 \mathrm{~Hz}$ to $3951.07 \mathrm{~Hz}$. 
The diagnostic material is valuable and psychometrically reliable for use with the matter of the natural sounding or electronic form of musical tone with its overtones sounding production. The time duration of each pattern's presentation is 3 seconds, in the case of that time range for output sensorial aural unit production on neuronal level in scientific evidences in neuropsychological studies about time perception for aural receptor [231, 232, 233, 234, 283, 284, 285], with additional time of 3 seconds reserved for thinking processing, which are not limited by speed in standardized psychological tests. Therefore totally diagnostic measurement of 10 pitch-frequencies belongs for 1-minute duration, with an average of whole diagnostic content around from 3.5 minutes (double bass) to 8.5 minutes (piano). Diagnostic notation includes semitone label with its chroma number (i.e. octave register unit).

AP TEST CONTENT FOR PIANO [scale $\mathrm{C}_{1}-\mathrm{B}_{7}$ ]

$$
\begin{aligned}
& \mathrm{G}^{+} / \mathrm{A}^{-}{ }_{2} ; \quad \mathrm{C}^{+} / \mathrm{D}_{4}^{-} ; \quad \mathrm{E}_{5} ; \quad \mathrm{F}_{3} ; \quad \mathrm{A}^{+} / \mathrm{B}_{1} ; \quad \mathrm{D}_{4} ; \quad \mathrm{A}_{6} ; \quad \mathrm{B}_{2} ; \quad \mathrm{C}_{5} ; \quad \mathrm{G}_{7} ; \quad \mathrm{D}^{+} / \mathrm{E}_{1}^{-} ; \mathrm{F}^{+} / \mathrm{G}_{4}^{-} ; \\
& \mathrm{F}_{7} ; \quad \mathrm{C}^{+} / \mathrm{D}^{-}{ }_{3} ; \quad \mathrm{E}_{1} ; \quad \mathrm{A}_{4} ; \quad \mathrm{D}^{+} / \mathrm{E}_{2}^{-} ; \quad \mathrm{C}_{3} ; \quad \mathrm{A}^{+} / \mathrm{B}^{-}{ }_{5} ; \quad \mathrm{B}_{6} ; \quad \mathrm{F}^{+} / \mathrm{G}^{-}{ }_{3} ; \quad \mathrm{D}_{1} ; \quad \mathrm{G}^{+} / \mathrm{A}^{-}{ }_{5} ; \quad \mathrm{G}_{1} ; \quad \\
& \mathrm{C}_{4} ; \quad \mathrm{F}_{2} ; \quad \mathrm{G}^{+} / \mathrm{A}^{-}{ }_{6} ; \quad \mathrm{A}_{3} ; \quad \mathrm{D}_{7} ; \quad \mathrm{F}^{+} / \mathrm{G}^{-}{ }_{6} ; \quad \mathrm{C}^{+} / \mathrm{D}^{-}{ }_{1} ; \quad \mathrm{E}_{4} ; \quad \mathrm{B}_{7} ; \quad \mathrm{G}_{3} ; \mathrm{A}^{+} / \mathrm{B}^{-}{ }_{7} ; \mathrm{D}^{+} / \mathrm{E}^{-}{ }_{5} ; \\
& \mathrm{D}_{2} ; \quad \mathrm{E}_{6} ; \quad \mathrm{B}_{1} ; \quad \mathrm{G}_{5} ; \quad \mathrm{F}^{+} / \mathrm{G}^{-}{ }_{2} ; \quad \mathrm{C}^{+} / \mathrm{D}^{-}{ }_{5} ; \quad \mathrm{A}^{+} / \mathrm{B}^{-}{ }_{2} ; \quad \mathrm{F}_{6} ; \quad \mathrm{D}^{+} / \mathrm{E}^{-}{ }_{7} ; \quad \mathrm{G}^{+} / \mathrm{A}^{-}{ }_{4} ; \mathrm{C}_{7} ; \mathrm{A}_{l} ; \mid \\
& \mathrm{E}_{3} ; \quad \mathrm{C}_{6} ; \quad \mathrm{G}_{2} ; \quad \mathrm{G}^{+} / \mathrm{A}^{-}{ }_{1} ; \quad \mathrm{D}^{+} / \mathrm{E}_{6}^{-} ; \quad \mathrm{D}_{3} ; \mathrm{A}^{+} / \mathrm{B}_{6}^{-} ; \quad \mathrm{F}_{1} ; \mathrm{B}_{5} ; \mathrm{C}^{+} / \mathrm{D}_{2}^{-} ; \quad \mathrm{F}^{+} / \mathrm{G}^{-}{ }_{7} ; \mathrm{A}_{5} ; \quad \\
& \mathrm{G}_{6} ; \quad \mathrm{C}_{2} ; \quad \mathrm{D}^{+} / \mathrm{E}^{-}{ }_{3} ; \quad \mathrm{F}^{+} / \mathrm{G}^{-}{ }_{1} ; \quad \mathrm{F}_{4} ; \quad \mathrm{C}^{+} / \mathrm{D}_{6}^{-} ; \quad \mathrm{A}_{2} ; \quad \mathrm{E}_{7} ; \quad \mathrm{A}^{+} / \mathrm{B}^{-}{ }_{4} ; \quad \mathrm{D}_{5} ; \quad \mathrm{G}^{+} / \mathrm{A}^{-}{ }_{7} ; \quad \mathrm{B}_{4} ; \\
& \mathrm{F}^{+} / \mathrm{G}^{-}{ }_{5} ; \quad \mathrm{A}_{7} ; \quad \mathrm{C}_{1} ; \quad \mathrm{F}_{5} ; \quad \mathrm{A}^{+} / \mathrm{B}^{-}{ }_{3} ; \quad \mathrm{D}^{+} / \mathrm{E}^{-}{ }_{4} ; \quad \mathrm{C}^{+} / \mathrm{D}^{-}{ }_{7} ; \quad \mathrm{G}^{+} / \mathrm{A}^{-}{ }_{3} ; \quad \mathrm{E}_{2} ; \quad \mathrm{G}_{4} ; \quad \mathrm{D}_{6} ; \quad \mathrm{B}_{3} ;
\end{aligned}
$$

AP TEST CONTENT FOR HARPSICHORD [scale $\mathrm{F}_{1}-\mathrm{F}_{6}$ ]

$$
\begin{aligned}
& \mathrm{D}^{+} / \mathrm{E}^{-}{ }_{2} ; \quad \mathrm{D}_{6} ; \quad \mathrm{A}^{+} / \mathrm{B}^{-}{ }_{5} ; \quad \mathrm{F}_{3} ; \quad \mathrm{B}_{4} ; \quad \mathrm{C}^{+} / \mathrm{D}^{-}{ }_{2} ; \quad \mathrm{F}^{+} / \mathrm{G}_{4}^{-} ; \quad \mathrm{A}_{3} ; \quad \mathrm{E}_{4} ; \quad \mathrm{C}_{6} ; \quad \mathrm{G}_{4} ; \mathrm{G}^{+} / \mathrm{A}^{-}{ }_{3} ; \\
& \mathrm{F}_{2} ; \quad \mathrm{C}^{+} / \mathrm{D}_{3}^{-} ; \quad \mathrm{D}^{+} / \mathrm{E}^{-}{ }_{5} ; \quad \mathrm{A}_{1} ; \quad \mathrm{E}_{6} ; \quad \mathrm{C}_{3} ; \quad \mathrm{A}^{+} / \mathrm{B}_{4}^{-} ; \quad \mathrm{F}_{6} ; \quad \mathrm{B}_{2} ; \quad \mathrm{F}^{+} / \mathrm{G}^{-}{ }_{1} ; \quad \mathrm{D}_{3} ; \mathrm{G}^{+} / \mathrm{A}^{-}{ }_{1} ; \quad \\
& \mathrm{G}_{2} ; \quad \mathrm{C}_{4} ; \quad \mathrm{F}_{1} ; \mathrm{G}^{+} / \mathrm{A}^{-}{ }_{2} ; \mathrm{A}_{4} ; \mathrm{D}_{2} ; \mathrm{F}^{+} / \mathrm{G}^{-}{ }_{5} ; \mathrm{C}^{+} / \mathrm{D}^{-}{ }_{6} ; \mathrm{E}_{5} ; \mathrm{B}_{3} ; \mathrm{G}_{1} ; \mathrm{A}^{+} / \mathrm{B}^{-}{ }_{3} ; \mathrm{D}^{+} / \mathrm{E}^{-}{ }_{6} ; \\
& \mathrm{D}_{4} ; \quad \mathrm{E}_{2} ; \quad \mathrm{B}_{1} ; \quad \mathrm{G}_{5} ; \quad \mathrm{F}^{+} / \mathrm{G}^{-}{ }_{3} ; \quad \mathrm{A}^{+} / \mathrm{B}^{-}{ }_{2} ; \quad \mathrm{F}_{4} ; \quad \mathrm{C}^{+} / \mathrm{D}^{-}{ }_{5} ; \mathrm{D}^{+} / \mathrm{E}^{-}{ }_{3} ; \quad \mathrm{G}^{+} / \mathrm{A}_{4}^{-} ; \mathrm{C}_{2} ; \mathrm{A}_{5} ; \\
& \mathrm{E}_{3} ; \quad \mathrm{C}_{5} ; \quad \mathrm{G}_{3} ; \quad \mathrm{G}^{+} / \mathrm{A}^{-}{ }_{5} ; \quad \mathrm{D}^{+} / \mathrm{E}_{4}^{-} ; \quad \mathrm{D}_{5} ; \quad \mathrm{A}^{+} / \mathrm{B}^{-}{ }_{1} ; \quad \mathrm{A}_{2} ; \quad \mathrm{B}_{5} ; \mathrm{C}^{+} / \mathrm{D}_{4}^{-} ; \mathrm{F}^{+} / \mathrm{G}_{2}^{-} ; \quad \mathrm{F}_{5} ; \quad
\end{aligned}
$$

\section{AP TEST CONTENT FOR HARP [scale $\mathrm{C}_{2}-\mathrm{G}_{7}$ ]}

$$
\begin{aligned}
& \mathrm{G}^{+} / \mathrm{A}^{-}{ }_{2} ; \mathrm{C}^{+} / \mathrm{D}_{6}^{-} ; \quad \mathrm{E}_{4} ; \quad \mathrm{F}_{7} ; \mathrm{A}^{+} / \mathrm{B}^{-}{ }_{2} ; \quad \mathrm{D}_{5} ; \mathrm{A}_{3} ; \mathrm{B}_{4} ; \mathrm{C}_{5} ; \mathrm{G}_{3} ; \mathrm{D}^{+} / \mathrm{E}_{7} ; \mathrm{F}^{+} / \mathrm{G}_{2}^{-} ; \\
& \mathrm{F}_{3} ; \quad \mathrm{C}^{+} / \mathrm{D}_{4}^{-} ; \quad \mathrm{E}_{6} ; \quad \mathrm{A}_{2} ; \quad \mathrm{D}^{+} / \mathrm{E}^{-} ; \quad \mathrm{C}_{2} ; \quad \mathrm{A}^{+} / \mathrm{B}^{-}{ }_{4} ; \quad \mathrm{B}_{3} ; \quad \mathrm{F}^{+} / \mathrm{G}_{6}^{-} ; \quad \mathrm{D}_{3} ; \quad \mathrm{G}^{+} / \mathrm{A}_{6}^{-} ; \mathrm{G}_{2} ; \quad \\
& \mathrm{C}_{4} ; \quad \mathrm{F}_{2} ; \quad \mathrm{G}^{+} / \mathrm{A}^{-}{ }_{3} ; \quad \mathrm{A}_{6} ; \quad \mathrm{D}_{2} ; \quad \mathrm{F}^{+} / \mathrm{G}^{-}{ }_{3} ; \quad \mathrm{C}^{+} / \mathrm{D}^{-}{ }_{2} ; \quad \mathrm{E}_{5} ; \quad \mathrm{B}_{2} ; \quad \mathrm{G}_{7} ; \mathrm{A}^{+} / \mathrm{B}^{-}{ }_{3} ; \mathrm{D}^{+} / \mathrm{E}_{6}^{-} ; \\
& \mathrm{D}_{4} ; \quad \mathrm{E}_{2} ; \quad \mathrm{B}_{6} ; \quad \mathrm{G}_{5} ; \quad \mathrm{F}^{+} / \mathrm{G}^{-}{ }_{4} ; \mathrm{C}^{+} / \mathrm{D}^{-}{ }_{7} ; \mathrm{A}^{+} / \mathrm{B}^{-}{ }_{5} ; \quad \mathrm{F}_{6} ; \mathrm{D}^{+} / \mathrm{E}^{-}{ }_{3} ; \mathrm{G}^{+} / \mathrm{A}_{4}^{-} ; \mathrm{C}_{3} ; \mathrm{A}_{5} ; \\
& \mathrm{E}_{3} ; \quad \mathrm{C}_{7} ; \quad \mathrm{G}_{6} ; \quad \mathrm{G}^{+} / \mathrm{A}^{-}{ }_{5} ; \quad \mathrm{D}^{+} / \mathrm{E}_{4}^{-} ; \quad \mathrm{D}_{7} ; \quad \mathrm{A}^{+} / \mathrm{B}_{6}^{-} ; \quad \mathrm{F}_{4} ; \quad \mathrm{B}_{5} ; \mathrm{C}^{+} / \mathrm{D}^{-}{ }_{3} ; \mathrm{F}^{+} / \mathrm{G}^{-}{ }_{7} ; \mathrm{A}_{4} ; \quad \\
& \mathrm{D}^{+} / \mathrm{E}^{-}{ }_{2} ; \quad \mathrm{D}_{6} ; \quad \mathrm{G}_{4} ; \quad \mathrm{E}_{7} ; \mathrm{F}^{+} / \mathrm{G}^{-}{ }_{5} ; \quad \mathrm{C}_{6} ; \quad \mathrm{F}_{5} ; \mathrm{C}^{+} / \mathrm{D}^{-}{ }_{5} ;
\end{aligned}
$$

AP TEST CONTENT FOR VIOLIN [scale $\mathrm{G}_{3}-\mathrm{G}_{7}$ ]

$$
\begin{aligned}
& \mathrm{F}_{5} ; \quad \mathrm{C}^{+} / \mathrm{D}_{4}^{-} ; \quad \mathrm{E}_{7} ; \quad \mathrm{A}_{4} ; \quad \mathrm{D}^{+} / \mathrm{E}^{-}{ }_{5} ; \quad \mathrm{C}_{4} ; \quad \mathrm{G}_{3} ; \quad \mathrm{A}^{+} / \mathrm{B}^{-}{ }_{6} ; \quad \mathrm{B}_{5} ; \quad \mathrm{F}^{+} / \mathrm{G}_{6}^{-} ; \quad \mathrm{D}_{7} ; \mathrm{G}^{+} / \mathrm{A}_{4}^{-} ; \\
& \mathrm{D}_{6} ; \quad \mathrm{E}_{4} ; \quad \mathrm{B}_{3} ; \quad \mathrm{G}_{7} ; \quad \mathrm{F}^{+} / \mathrm{G}_{4}^{-} ; \quad \mathrm{C}^{+} / \mathrm{D}_{6}^{-} ; \quad \mathrm{A}^{+} / \mathrm{B}^{-}{ }_{3} ; \quad \mathrm{F}_{4} ; \quad \mathrm{G}^{+} / \mathrm{A}_{6}^{-} ; \mathrm{D}^{+} / \mathrm{E}^{-}{ }_{7} ; \mathrm{C}_{6} ; \mathrm{A}_{3} ; \quad \\
& \mathrm{E}_{5} ; \quad \mathrm{C}_{7} ; \quad \mathrm{G}_{5} ; \quad \mathrm{D}^{+} / \mathrm{E}^{-}{ }_{6} ; \quad \mathrm{G}^{+} / \mathrm{A}^{-}{ }_{3} ; \mathrm{D}_{5} ; \quad \mathrm{A}^{+} / \mathrm{B}^{-}{ }_{4} ; \quad \mathrm{F}_{6} ; \mathrm{B}_{4} ; \mathrm{C}^{+} / \mathrm{D}^{-}{ }_{5} ; \quad \mathrm{F}^{+} / \mathrm{G}^{-}{ }_{7} ; \mathrm{A}_{5} ; \quad \\
& \mathrm{G}_{6} ; \mathrm{D}^{+} / \mathrm{E}_{4}^{-} ; \mathrm{F}^{+} / \mathrm{G}^{-}{ }_{5} ; \mathrm{B}_{6} ; \mathrm{F}_{7} ; \mathrm{D}_{4} ; \mathrm{A}_{6} ; \mathrm{C}_{5} ; \mathrm{C}^{+} / \mathrm{D}^{-}{ }_{7} ; \mathrm{G}^{+} / \mathrm{A}^{-}{ }_{5} ; \mathrm{E}_{6} ; \mathrm{A}^{+} / \mathrm{B}^{-}{ }_{5} ; \mathrm{G}_{4} ;
\end{aligned}
$$


AP TEST CONTENT FOR VIOLA [scale $\mathrm{C}_{3}-\mathrm{D}_{6}$ ]

$$
\begin{aligned}
& \mathrm{D}_{4} ; \quad \mathrm{E}_{3} ; \quad \mathrm{B}_{5} ; \quad \mathrm{G}_{3} ; \quad \mathrm{F}^{+} / \mathrm{G}_{4}^{-} ; \quad \mathrm{C}^{+} / \mathrm{D}^{-}{ }_{6} ; \quad \mathrm{A}^{+} / \mathrm{B}^{-}{ }_{3} ; \quad \mathrm{G}^{+} / \mathrm{A}^{-}{ }_{5} ; \mathrm{F}_{3} ; \mathrm{D}^{+} / \mathrm{E}^{-}{ }_{3} ; \mathrm{C}_{4} ; \mathrm{A}_{5} ; \mathrm{D}_{3} ; \\
& \mathrm{G}_{5} ; \mathrm{D}^{+} / \mathrm{E}^{-}{ }_{4} ; \mathrm{F}^{+} / \mathrm{G}^{-}{ }_{5} ; \mathrm{B}_{3} ; \mathrm{F}_{5} ; \mathrm{D}_{6} ; \mathrm{A}_{4} ; \mathrm{C}_{5} ; \mathrm{C}^{+} / \mathrm{D}^{-}{ }_{4} ; \mathrm{G}^{+} / \mathrm{A}^{-}{ }_{3} ; \mathrm{E}_{5} ; \mathrm{A}^{+} / \mathrm{B}_{4}^{-} ; \mathrm{C}^{+} / \mathrm{D}^{-}{ }_{3} ; \\
& \mathrm{F}_{4} ; \quad \mathrm{C}^{+} / \mathrm{D}^{-}{ }_{5} ; \quad \mathrm{E}_{4} ; \quad \mathrm{A}_{3} ; \quad \mathrm{D}^{+} / \mathrm{E}^{-}{ }_{5} ; \quad \mathrm{C}_{6} ; \quad \mathrm{G}_{4} ; \quad \mathrm{A}^{+} / \mathrm{B}^{-}{ }_{5} ; \mathrm{B}_{4} ; \quad \mathrm{F}^{+} / \mathrm{G}^{-}{ }_{3} ; \mathrm{D}_{5} ; \mathrm{G}^{+} / \mathrm{A}_{4}^{-} ; \mathrm{C}_{3} ; \quad
\end{aligned}
$$

AP TEST CONTENT FOR CELLO [scale $\left.\mathrm{C}_{2}-\mathrm{A}_{5}\right]$

$$
\begin{aligned}
& \mathrm{E}_{2} ; \mathrm{C}_{5} ; \mathrm{G}_{3} ; \mathrm{D}^{+} / \mathrm{E}^{-}{ }_{5} ; \mathrm{G}^{+} / \mathrm{A}^{-}{ }_{2} ; \mathrm{D}_{4} ; \mathrm{A}^{+} / \mathrm{B}^{-}{ }_{2} ; \mathrm{F}_{4} ; \mathrm{B}_{2} ; \mathrm{C}^{+} / \mathrm{D}^{-}{ }_{4} ; \mathrm{F}^{+} / \mathrm{G}^{-}{ }_{3} ; \mathrm{A}_{5} ; \\
& \mathrm{F}_{2} ; \mathrm{C}^{+} / \mathrm{D}^{-}{ }_{5} ; \mathrm{E}_{3} ; \mathrm{A}_{2} ; \mathrm{D}^{+} / \mathrm{E}^{-}{ }_{4} ; \mathrm{C}_{2} ; \mathrm{G}_{5} ; \mathrm{A}^{+} / \mathrm{B}^{-}{ }_{4} ; \mathrm{B}_{3} ; \mathrm{F}^{+} / \mathrm{G}^{-}{ }_{5} ; \mathrm{D}_{2} ; \mathrm{G}^{+} / \mathrm{A}_{4}^{-} ; \\
& \mathrm{D}^{+} / \mathrm{E}^{-}{ }_{3} ; \mathrm{F}^{+} / \mathrm{G}_{2}^{-} ; \mathrm{B}_{4} ; \mathrm{F}_{3} ; \mathrm{D}_{5} ; \mathrm{G}_{4} ; \mathrm{A}_{3} ; \mathrm{C}_{4} ; \mathrm{C}^{+} / \mathrm{D}^{-}{ }_{3} ; \mathrm{G}^{+} / \mathrm{A}^{-}{ }_{5} ; \mathrm{E}_{4} ; \mathrm{A}^{+} / \mathrm{B}_{3}^{-} ; \\
& \mathrm{D}_{3} ; \quad \mathrm{E}_{5} ; \quad \mathrm{G}_{2} ; \quad \mathrm{F}^{+} / \mathrm{G}^{-}{ }_{4} ; \quad \mathrm{C}^{+} / \mathrm{D}_{2}^{-} ; \quad \mathrm{G}^{+} / \mathrm{A}^{-}{ }_{3} ; \quad \mathrm{F}_{5} ; \quad \mathrm{D}^{+} / \mathrm{E}^{-}{ }_{2} ; \quad \mathrm{C}_{3} ; \quad \mathrm{A}_{4} ; \quad \text { । }
\end{aligned}
$$

AP TEST CONTENT FOR DOUBLE BASS [scale $\mathrm{E}_{1}-\mathrm{B}_{3}$ ]

[ Transposes to one octave down in the bass F clef, so the original labels' scale is noted $E_{0}-B_{2}$ ]

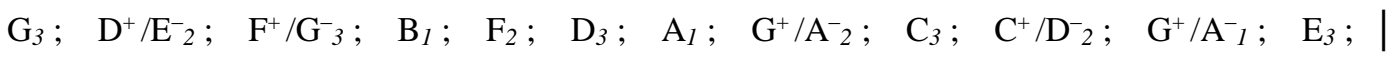

$$
\begin{aligned}
& \mathrm{A}^{+} / \mathrm{B}^{-}{ }_{1} ; \quad \mathrm{B}_{2} ; \quad \mathrm{F}_{1} ; \quad \mathrm{C}^{+} / \mathrm{D}^{-}{ }_{3} ; \mathrm{A}^{+} / \mathrm{B}^{-}{ }_{2} ; \mathrm{E}_{1} ; \quad \mathrm{A}_{2} ; \quad \mathrm{D}^{+} / \mathrm{E}^{-}{ }_{3} ; \mathrm{C}_{2} ; \mathrm{G}_{1} ; \mathrm{A}^{+} / \mathrm{B}^{-}{ }_{3} ; \mathrm{F}^{+} / \mathrm{G}^{-}{ }_{1} ; \\
& \mathrm{B}_{3} ; \quad \mathrm{D}_{2} ; \quad \mathrm{G}^{+} / \mathrm{A}_{3}^{-} ; \quad \mathrm{E}_{2} ; \quad \mathrm{A}_{3} ; \quad \mathrm{G}_{2} ; \quad \mathrm{F}_{3} ; \mathrm{F}^{+} / \mathrm{G}_{2}^{-} ;
\end{aligned}
$$

\subsection{The direction of future optimization of AP acquisition technology during empirical studies of AP nature}

Neuroscientific evidence of cognitive and executive functions with neurobiological studies about the metabolic background of memory processes, especially of such neurotransmitters as acetylcholine, dopamine, norepinephrine, glutamate and glycine, allow looking for memory development optimization during empirical measurement with including the: 1. Regulation by the nutrition adapted to the circadian rhythms of memory processing. 2. Stages and role of memory during the sleep stage, with the possibility of targeted directional management of memory resources before falling asleep and after waking up. The mnemonic techniques known in cognitive psychology for semantic material processing with its executive using during circadian cognitive activity might be improved or more effectively adapted to AP processing mechanisms with taking into account neurobiological backgrounds of principles of memory functioning. Additionally, contemporary methods of cognitive functions' behavioral neurorehabilitation (of non-expensive practical costs) with the separation of stimulation and regenerative compensatory rehabilitation for the separate components of human's cognitive sphere's processes, are bringing and delivering a new look for the diagnostic - training approach of human's cognitive control regulation. Separate scientific searching for saving the time resources for memory functions' development should be done in empirical memory studies' mechanisms, with taking into account the nature of memorizing and forgetting on the biological basis, observed during the human's learning the alphabet of any new linguistic system, to which AP has belonged certainly as music language. 


\section{REFERENCES}

[1] Abraham, O. (1901). Das absolute Tonbewusstsein. Psychologisch-musikalische studie. Sammelbände der internationalen musikgesellschaft, 3, p.1-86.

[2] Adams, W. (2006). The mysteries of perfect pitch. http://www.psychologytoday.com/articles/200607/the-mysteriesperfect-pitch (access on March 31 ${ }^{\text {st }}$ 2019).

[3] Amiez, C., Kostopoulos, P., Champod, A. S., Petrides, M. (2006). Local morphology predicts functional organization of the dorsal premotor region in the human brain. Journal of neuroscience, March, 26 (10), p.2724-2731.

[4] Amunts, K., Schlaug, G., Jancke, L., Steinmetz, H., Schleicher, A., Dabringhaus, A., Zilles, K. (1997). Motor cortex and hand motor skills: Structural compliance in the human brain. Human brain mapping, 5 (3), p.206-215.

[5] ANSI (1999). American National Psychoacoustic terminology. S3.20. ed. New York, American national standards institute. $67 \mathrm{p}$.

[6] Anvari, S. H., Trainor, L. J., Woodside, J., Levy, B. A. (2002). Relations among musical skills, phonological processing, and early reading ability in prescholl children. Journal of experimental child psychology, October, 83 (2), p.111-130.

[7] Arlinger, S., Lunner, T., Lyxell, B., Pichora-Fuller, M. K. (2009). The emergence of cognitive hearing science. Scandinavian journal of psychology, 50 (5), p.371-384.

[8] Auzou, P., Eustache, F., Etevenon, P., Platel, H., Rioux, P., Lambert, J., Lechevalier, B., Zarifian, E., Baron, J. C. (1995). Topographic EEG activations during timbre and pitch discrimination tasks using musical sounds. Neuropsychologia, January, 33 (1), p.25-37.

[9] Ayotte, J., Hyde., K., Peretz, I. (2002). Congenital amusia: a group study of adults afflicted with a music-specific disorder. Brain: a journal of neurology, February, 125 (2), p.238-251.

[10] Bachem, A. (1937). Various types of absolute pitch. Journal of the acoustical society of America, October, 9, p.146-151.

[11]Bachem, A. (1954). Time factors in relative and absolute pitch determination. Journal of the acoustical society of America, September, 26 (5), p.751 - 753.

[12] Baddeley, A. D. (1986). Working memory. ed. Oxford Clarendon Press. 289 p.

[13] Baddeley, A. D. (1992). Working memory. Science, January, 255(5044), p.556-559.

[14] Baddeley, A. D. (1998). Recent developments in working memory. Current opinion in neurobiology, April, 8 (2), p.234-238.

[15] Baddeley, A. D. (2002). The psychology of memory. In: A. D. Baddeley, B. A. Wilson, M. D. Kopelman. (eds.). Handbook of Memory Disorders. ed. Hove, Psychology Press. p.3-15.

[16] Baddeley, A. D., Hitch, G. (1974). Working memory. Psychology of learning and motivation, vol.8. p.47-89.

[17] Baddeley, A. D., Hitch, G. J. (1974). Working Memory. In: G. A. Bower (ed.). Recent advances in learning and motivation. vol.8. ed. New York Academic Press, p.47-90.

[18] Baharloo, S., Johnston, P. A., Service, S. K., Gitschier, J., Freimer, N. B. (1998). Absolute pitch: an approach for identification of genetic and nongenetic components. American journal of human genetics, February, 62 (2), p. 224-231.

[19] Baharloo, S., Service, S. K., Risch, N., Gitschier, J., Freimer, N. B. (2000). Familial aggregation of absolute pitch. American journal of human genetics, 67 (3), p.755-758.

[20]Bahr, N. (1998). Pitch discrimination skill: a cognitive perspective. Paper presented at the Annual conference of the Australian Association for Research in Education, Adelaide. 21p.

[21] Bahr, N. (2005). Diversity of accuracy profiles for absolute pitch recognition. Psychology of music, 33 (1), p.58-93.

[22] Bahr, N., Christensen, C. A., Bahr, M. (2005). Diversity of accuracy profiles for absolute pitch recognition. Psychology of music, 33 (1), p.58-93.

[23] Balari, S., Lorenzo, G. (2009). Computational phenotypes: Where the theory of computation meets evo-devo. Biolinguistics, 3(1), p.2-60.

[24]Barwick, J., Valentine, E., West, R., Wilding, J. (1989). Relations between reading and musical abilities. British journal of educational psychology, June, 59 (2), p.253-257.

[25] Belin, P., Zatorre, R. J., Lafaille, P., Ahad, P., Pike, B. (2000). Voice-selective areas in human auditory cortex. Nature, January, 403 (6767), p.309-312.

[26] Bendor, D, Wang, X (2005). The neuronal representation of pitch in primate auditory cortex. Nature, August, 436 (7054), p.1161-1165.

[27] Bergmann, H. C., Rijpkema, M., Fernandez, G., Kessels, R.P. (2012). Distinct neural correlates of associative working memory and long-term memory encoding in the medial temporal lobe. Neuroimage, November, 63 (2), p.989-997. 
[28] Bermudez, P., Zatorre, R. J. (2005). Conditional associative memory for musical stimuli in nonmusicians: implications for absolute pitch. The journal of neuroscience, August, 25 (34), p.7718-7723.

[29] Bermudez, P., Zatorre, R. J. (2009). The absolute pitch mind continues to reveal itself. Journal of biology, August, 8, art. 75, 4 p.

[30] Bermudez, P., Zatorre, R. J. (2009). A distribution of absolute pitch ability as revealed by computerized testing. Music perception, 27 (2), p.89-101.

[31] Bever, T. G., Chiarello, R. J. (1974). Cerebral dominance in musicians and nonmusicians. Science, August, 185 (4150), p.537-539.

[32] Bianki, W. L. (1985). Animal brain asymmetry. ed. Leningrad, Nauka. 296 p. [original title: Asimmetria mozga ziwotnyh.]

[33] Bidelman, G. M., Gandour, J. T., Krishnan, A. (2011). Musicians and tone-language speakers share enhanced brainstem encoding but not perceptual benefits for musical pitch. Brain and cognition, October, 77 (1), p.1-10.

[34] Binder, J. R., Rao, S. M., Hammeke, T. A., Yetkin, F. Z., Jesmanowicz, A., Bandettini, P. A., Wong, E. C., Estkowski, L. D., Goldstein, M. D., Haughton, V. M., Hyde, J. S. (1994). Functional magnetic resonance imaging of human auditory cortex. Annals of neurology, June, 35 (6), p.662-672.

[35] Bliss, T. V., Lomo, T. (1973). Long-lasting potentiation of synaptic transmission in the dentate area of the anaesthetized rabbit following stimulation of the perforant path. Journal of physiology, July, 232 (2), p.331-356.

[36] Boettiger, C. A., D'Esposito, M. (2005). Frontal networks for learning and executing arbitrary stimulus-response associations. Journal of neuroscience, March, 25 (10), p.2723-2732.

[37] Brady, P. T. (1970). Fixed-scale mechanism of absolute pitch. Journal of the acoustical society of America, 48, p.883-887.

[38] Broadbent, D. E. (1971). Decision and stress. ed. London, England, Academic Press. 522 p.

[39] Brown, M. W., Aggleton, J. P. (2001). Recognition memory: what are the roles of the perirhinal cortex and hippocampus? Nature reviews. Neuroscience, January, 2 (1), p.51-61.

[40] Brown, W., Cammuso, K., Sachs, H., Winklosky, B., Mullane, J., Bernier, R., Svenson, S., Arin, D., Rosen-Sheidley, Folstein, S. (2003). Autism-related language, personality and cognition in people with absolute pitch: results of a preliminary study. Journal of autism and developmental disorders, 33 (2), p.163-166.

[41] Buonomano, D. V., Merzenich, M. M. (1998). Cortical plasticity: from synapses to maps. Annual review of neuroscience, 21, p.149-186.

[42] Burns, E. M., Campbell, S. L. (1994). Frequency and frequency-ratio resolution by possessors of absolute and relative pitch: examples of categorical perception. Journal of the acoustical society of America, November, 96, p.2704 - 2719.

[43] Caplan, J. B., Madsen, J. R., Raghavachari, S., Kahana, M. J. (2001). Distinct patterns of brain oscillations underlie two basic parameters of human maze learning. Journal of neurophysiology, July, 86 (1), p.368-380.

[44] Chan, A. S., Ho, Y. C., Cheung, M. C. (1998). Music training improves verbal memory. Nature, November, 396 (6707), p.128.

[45] Chase, W. G., Ericsson, K. A. (1982). Skill and working memory. In: G.H. Bower (ed.). The psychology of learning and motivation. vol.16. ed. New York Academic Press. p.1-58.

[46] Chen, J., Dastjerdi, M., Foster, B. L., LaRocque, K. F., Rauschecker, A. M., Parvizi, J., Wagner, A. D. (2013). Human hippocampal increases in low-frequency power during associative prediction violations. Neuropsychologia, October, 51 (12), p.2344-2351.

[47] Chin, C. S. (2003). The development of absolute pitch: a theory concerning the roles of musical training at an early developmental age and individual cognitive style. Psychology of music, 31, p.155-171.

[48] Cooper-Kahn, J., Dietzel, L. (2019). What is executive functioning? http://www.ldonline.org/article/29122

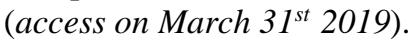

[49] Coulmas, F. (1989). The writing systems of the world. ed. Oxford, Basil Blackwell publishers ltd. 302 p.

[50] Cowan, N. A. (1998). Visual and auditory working memory capacity. Trends in cognitive sciences, 2 (3), p.77.

[51] Cowan, N. A. (1999). An embedded - processes model of working memory. In: A. Miyake, P. Shah (ed.). Models of working memory: Mechanisms of active maintenance and executive control. Ed. Cambridge, Cambridge University Press, p.62-101.

[52] Cowan, N. A. (2001). The magical number 4 in short - term memory: a reconsideration of mental storage capacity. Behavioral and brain sciences, February, 24 (1). p.87-185.

[53] Cowan, N. A. (2005). Working memory capacity. Essays in Cognitive Psychology. ed. Psychology Press, Taylor and Francis Group, New York, LLC. 246 p.

[54] Cowan, N. A. (2008). What are the differences between long -term, short -term, and working memory? Progress in brain research, vol.169. p.323-338.

Asian Online Journals (www.ajouronline.com) 
[55] Cowan, N. A., Morey, C. C., AuBuchon, A. M., Zwilling, C. E., Gilchrist, A. L. (2010). Seven - year - olds allocate attention like adults unless working memory is overloaded. Developmental science, 13 (1), p.120-133.

[56] Crespo-Garcia, M., Cantero, J. L., Atienza, M. (2012). Effects of semantic relatedness on age-related associative memory deficits: the role of theta oscillations. Neuroimage, 61 (4), p.1235-1248.

[57] Crowne, D. P., Dawson, K. A., Richardson, C. M. (1989). Unilateral periarcuate and posterior parietal lesions impair conditional position discrimination learning in the monkey. Neuropsychologia, 27 (9), p.1119-1127.

[58] Daniels, P. T., Bright, W. (1996). The world's writing systems. ed. Oxford University Press. 968 p.

[59] Davies, J. B. (1978). The psychology of music. ed. Stanford University Press. 240 p.

[60] Dehaene-Lambertz, G., Dehaene, S., Hertz-Pannier, L. (2002). Functional neuroimaging of speech perception in infants. Science, December, 298 (5600), p.2013-2015.

[61] Deutsch, D. (1970). Tones and numbers: specificity of interference in immediate memory. Science, June, 168 (3939), p.1604-1605.

[62] Deutsch, D. (1991). The tritone paradox: an influence of language on music perception. Music perception, July, 8 (4), p.335-347.

[63] Deutsch, D. (2002). The puzzle of absolute pitch. Journal of American psychological society, 11 (6), p.200-204.

[64] Deutsch, D. (2006). Absolute pitch, structural acoustics, ASA history, and more. Acoustics today, October, 2 (4), p.17.

[65] Deutsch, D. (2013). Absolute pitch.In: D.Deutsch (ed.). The psychology of music. ed. San Diego, CA, Elsevier, p.141-182.

[66] Deutsch, D. (2013). Psychology of music. ed. San Diego, CA, Elsevier. 786 p.

[67] Deutsch, D., Dooley, K. (2013). Absolute pitch is associated with a large auditory digit span: a clue to its genesis. Journal of the acoustical society of America, April, 133 (4), p.1859-1861.

[68] Deutsch, D., Henthorn, T., Dolson, M. (2004). Absolute pitch, speech, and tonal language: some experiments and a proposed framework. Music perception, 21 (3), p.339-356.

[69] Deutsch, D., Henthorn, T., Marvin, E., Xu, H. (2006). Absolute pitch among American and Chinese conservatory studies: prevalence differences, and evidences for a speech-related critical period. Journal of the acoustical society of America, February, 119 (2), p.719-722.

[70] Diamond, A. (2013). Executive functions. Annual review of psychology, vol.64, p.135-168.

[71] Dobbins, I. G., Rice, H. J., Wagner, A. D., Schacter, D. L. (2003). Memory orientation and success: separable neurocognitive components underlying episodic recognition. Neuropsychologia, 41 (3), p.318-333.

[72] Dohn, A., Garza-Villarreal, E. A., Riisgaard, R. L., Wallentin, M., Vuust, P. (2014). Musical activity tunes up absolute pitch ability. Music Perception, 31 (4), p.359-371.

[73] Drayna, D., Manichaikul, A., de Lange, M., Snieder, H., Spector, T. (2001). Genetic correlates of musical pitch recognition in humans. Science, March, 291 (5510), p.1969-1972.

[74] Dymnikowa, M. (2019). Analysis of sight-reading musical psychological process as an executive function. [original title: Analiz muzykalnogo psihologiceskogo processa ctenia s lista kak ispolnitelnoj funkcii.] The scientific method, 27 (1), p.3-9. http://scientific-met.com/wp-content/uploads/2019/04/SMT_27.pdf

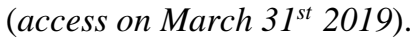

[75] Easterbrook, J. A. (1959). The effect of emotion on cue utilization and the organization of behavior. Psychological review, 66, p.183-201.

[76] Eguchi, K. (1991). Zettai onkan program. Ed. Tokyo, Japan, Zen-on Gakufu Shuppan.

[77] Eichenbaum, H. (2000). A cortical-hippocampal system for declarative memory. Nature reviews. Neuroscience, October, 1 (1), p.41-50.

[78] Eimas, P. D. (1975). Auditory and phonetic coding of the cues for speech: discrimination of the /r-1/ distinction by young infants. Perception and psychophysics, 18 (5), p.341-347.

[79] Eimas, P. D., Siquel, E. R., Juszczyk, P., Vigorito, J. (1971). Speech perception in infants. Science, January, 171 (3968), p.303-306.

[80] Elbert, T., Pantev, C., Wienbruch, C., Rockstroh, B., Taub, E. (1995). Increased cortical representation of the fingers of the left hand in string players. Science, October, 270 (5234), p.305-307.

[81] Eldridge, L. L., Knowlton, B. J., Furmanski, C. S., Bookheimer, S. Y., Engel, S. A. (2000). Remembering episodes: a selective role for the hippocampus during retrieval. Nature neuroscience, November, 3 (11), p.1149-1152.

[82] Elmer, S., Sollberger, S., Meyer, M., Jancke, L. (2013). An empirical reevaluation of absolute pitch: behavioral and electrophysiological measurements. Journal of cognitive neuroscience, October, 25 (10), p.1736-1753.

[83] Ergorul, C., Eichenbaum, H. (2004). The hippocampus and memory for "what," "where," and "when". Learning and memory, July, 11 (4), p.397-405.

[84] Ericsson, K. A., Kintsch, W. (1995). Long-term working memory. Psychological Review, April, 102 (2), p.211-245.

[85] Eysenck, M. W., Calvo, M. G. (1992). Anxiety and performance: The processing efficiency theory. Cognition and emotion, 6, p.409-434.

Asian Online Journals (www.ajouronline.com) 
[86] Fernald, A. (1989). Intonation and communicative intent in mothers' speech to infants: is the melody the message? Child development, December, 60 (6), p.1497-1510.

[87] Frankland, P. W., Bontempi, B. (2005). The organization of recent and remote memories. Nature reviews. Neuroscience, February, 6 (2), p.119-130.

[88] Friederici, A. D. (ed.). (1998). Language comprehension: a biological perspective. ed. Springer - Verlag Berlin Heidelberg. 314 p.

[89] Friederici, A. D., Meyer, M., von Cramon, D. Y. (2000). Auditory language comprehension: an event-related fMRI study on the processing of syntactic and lexical information. Brain and language, December, 75 (3), P.289-300.

[90] Fuster, J. M. (2002). Physiology of executive function: the perception-action cycle. In: D. T. Stuss, R. T. Knight (eds.). Principles of frontal lobe function. ed. New York, Oxford University Press, p.96-109.

[91] Galinska, E. (1989). La musicotherapie cognitive: le portrait musical du patient. La Revue de Musicothérapie, January, 1, p.33-63.

[92] Galinska, E. (2008). Music as a carrier of human traits: the musical identity test (MIT). Przeglad psychologiczny, $51(4), \mathrm{p} .423-441$

[93] Gardner, H. (1983). Frames of mind: the theory of multiple intelligences. ed. New York, Basic books. 440 p.

[94] Gardner, H. (1985). The mind's new science: A history of the cognitive revolution. ed. New York, Basic Books. $423 \mathrm{p}$.

[95] Gardner, H. (1999). Intelligence reframed: multiple intelligences for the $21^{\text {st }}$ century. ed. New York, Basic Books. $292 \mathrm{p}$.

[96] Gardner, H., Hatch, T. (1989). Multiple intelligences go to school: Educational implications of the theory of multiple intelligences. Educational researcher, 18 (8), p.4-10.

[97] Gardner, H., Kornhaber, M. L., Wake, W. K. (1996). Intelligence: multiple perspectives. ed. Harcourt Brace College Publishers. $351 \mathrm{p}$.

[98] Gazzaniga, M. S., Ivry, R. B., Mangun, G. R. (2013). Cognitive neuroscience: the biology of mind ed. New York, London, W.W. Norton and company. 752p.

[99] Glass, G. V., Willson, V. L., Gottman, J. M. (2008). Design and analysis of time-series experiments. ed. Information Age Publishing. 264 p.

[100] Gobet, F. (1998). Expert memory: a comparison of four theories. Cognition, 66 (2), p.115-152.

[101] Goldberg, E., Costa, L. D. (1981). Hemisphere differences in the acquisition and use of descriptive systems. Brain and language, September, 14 (1), p.144-173.

[102] Gordon, E. E. (1965). Musical aptitude profile. ed. Boston, MA, Houghton Mifflin Company (1965), GIA Music (2005), $162 \mathrm{p}$.

[103] Gordon, E. E. (1967). The Musical Aptitude Profile. Music educators journal, 53 (6), p.52-54.

[104] Gordon, E. E. (1988). Learning sequences in music: skill, content, and patterns. ed. Chicago, G. I. A. Publications. $354 \mathrm{p}$.

[105] Gordon, E. E. (1997). Learning sequences in music: skill, content and patterns. A music learning theory. ed. Chicago, G. I. A. Publications. 397 p.

[106] Gordon, E. E. (2006). Nature, source, measurement and evaluation of musical aptitudes. Polish psychological forum, 11 (2), p.227-237.

[107] Gordon, E. E. (2007). Learning sequences in music: a contemporary learning theory. ed. Chicago, G. I. A. Publications. 448 p.

[108] Gregersen, P. K., Kowalsky, E., Kohn, N., Marvin, E. W. (1999). Absolute pitch: prevalence, ethnic variation, and estimation of the genetic component. American journal of medical genetics, September, 65 (3), p.911-913.

[109] Gregersen, P. K., Kowalsky, E., Kohn, N., Marvin, E. W. (2000). Early childhood music education and predisposition to absolute pitch: teasing apart genes and environment. American journal of medical genetics, January, 98 (3), p.280-282.

[110] Griffiths, T. D., Warren, J. D. (2002). The planum temporale as a computational hub. Trends in neurosciences, July, 25 (7), p.348-353.

[111] Griusser, P., Zelke, A., Cinda, T. (1995). Functional asymmetry of the brain and its importance for art, aesthetic perception and artistic creation. In: I. Rebcler, B. Hercberger, D. Epstain. Beauty and the brain. Biological aspects of aesthetics. ed. Moscow, Mir. Chapter 11, p.265-299. [original title: Funkcionalnaja asimmetria mozga i eje znacenie dla iskusstwa, esteticeskogo wospritaia i hudozestwennogo tworcestwa. In: Krasota i mozg. Biologiceskie aspekty estetiki.]

[112] Guida, A., Gobet, F., Tardieu, H., Nicolas, S. (2012). How chunks, long-term working memory and templates offer a cognitive explanation for neuroimaging data on expertise acquisition: a two-stage framework. Brain and cognition, August, 79 (3), p.221-244.

[113] Halpern, A. R. (1989). Memory for absolute pitch of familiar songs. Memory and cognition, September, 17 (5), p.572-581.

Asian Online Journals (www.ajouronline.com $)$ 
[114] Halsband, U., Freund, H. J. (1990). Premotor cortex and conditional motor learning in man. Brain, February, 113 (1), p.207-222.

[115] Halsband, U., Passingham, R. E. (1985). Premotor cortex and the conditions for movement in monkeys (Macaca fascicularis). Behavioural Brain Research, December, 18 (3), p.269-277.

[116] Hantz, E. C., Crummer, G. C., Wayman, J. W., Walton, J. P., Frisina, R. D. (1992). Effects of musical training and absolute pitch on the neural processing of melodic intervals: a P3 event-related potential study. Music perception, Fall, 10 (1), p.25-42.

[117] Hantz, E. C., Kreilick, K. G., Braveman, A. L., Swartz, K. P. (1995). Effects of musical training and absolute pitch on a pitch memory task an event-related-potential study. Psychomusicology: a journal of research in music cognition, 14 (1-2), p.53-76.

[118] Hantz, E. C., Kreilick, K. G., Kananen, W., Swartz, K. P. (1997). Neural responses to melodic and harmonic closure: an event-related-potential study. Music perception, 15 (1), p.69-98.

[119] Harris, C. A. (1926). Can I develop absolute pitch? The etude, 44, p.721-722.

[120] Hartmann, D. P., Gottman, J. M., Jones, R. R., Gardner, W., Kazdin, A. E., Vaught, R. (1980). Interrupted time-series analysis and its application to behavioral data. Journal of applied behavior analysis, 13, p.543-559.

[121] Hauser, M. D., McDermott, J. (2003). The evolution of the music faculty: a comparative perspective. Nature neuroscience, July, 6 (7), p.663-668.

[122] Hay, A. (2009). Stability and accuracy of long-term memory for musical pitch. BA thesis. ed., Edith Cowan University, 31 p. https://ro.ecu.edu.au/theses_hons/1207/ (access on March 31 $1^{\text {st }}$ 2019).

[123] Headley, D. B., Pare, D. (2013). In sync: gamma oscillations and emotional memory. Frontiers in behavioral neuroscience, November, vol.7, art.170, 12 p.

[124] Heald, Sh. L. M., Van Hedger, S. C., Nusbaum, H. C. (2017). Understanding sound: auditory skill acquisition. Psychology of learning and motivation, vol.67, p.53-93.

[125] Heath, S., McMahon, K., Nickels, L., Angwin, A., MacDonald, A., van Hees, S., Johnson, K., Copland, D. (2012). The neural correlates of picture naming facilitated by auditory repetition. BMC Neuroscience, vol.13, art.21, 13 p.

[126] Heiervang, E., Hugdahl, K., Steinmetz, H., Smievoll, I. A., Stevenson, J., Lund, A., Ersland, L., Lundervold, A.,. (2000). Planum temporale, planum parietale, and dichotic listening in dyslexia. Neuropsychologia, 38 (13), p.1704-1713.

[127] Heilman, K. M., Van Den Abell, T. (1980). Right hemisphere dominance for attention: the mechanisms underlying hemispheres asymmetries of innatention (neglect). Neurology, March, 30 (3), p.327-330.

[128] Helmholtz, H. F., Ellis, A. J. (1885). On the sensations of tone as a physiological basis for the theory of music. $2^{\text {nd }}$ ed. London, New York, Longmans, Green and co. 576 p. Reprint: 2012. Series Cambridge library collection music. $3^{\text {rd }}$ ed. Cambridge University Press.

[129] Hirata, Y., Kuriki, S., Pantev, C. (1999). Musicians with absolute pitch show distinct neural activities in the auditory cortex. Neuroreport, April, 10 (5), p.999-1002.

[130] Hirose, H., Kubota, M., Kimura, I., Ohsawa, M., Yumoto, M., Sakakihara, Y. (2002). People with absolute pitch process tones with producing P300. Neuroscience letters, September, 330 (3), p.247-250.

[131] Hirose, H., Kubota, M., Kimura, I., Yumoto, M., Sakakihara, Y. (2004). N100m in adults possessing absolute pitch. Neuroreport, June, 15 (9), p.1383-1386.

[132] Hirshhorn, M., Grady, C., Rosenbaum, R. S., Winocur, G., Moscovitch, M. (2012). Brain regions involved in the retrieval of spatial and episodic details associated with a familiar environment: an fMRI study. Neuropsychologia, November, 50 (13), p.3094-3106.

[133] Ho, Y. C., Cheung, M. C., Chan, A. S. (2003). Music training improves verbal but not visual memory: cross-sectional and longitudinal explorations in children. Neuropsychology, July, 17 (3), p.439-450.

[134] Huang, Z., Zhang, J. X., Yang, Z., Dong, G., Wu, J., Chan, A. S., Weng, X. (2010). Verbal memory retrieval engages visual cortex in musicians. Neuroscience, June, 168 (1), p.179-189.

[135] Itoh, K., Suwazono, S., Arao, H., Miyazaki, K., Nakada, T. (2005). Electrophysiological correlates of absolute pitch and relative pitch. Cerebral cortex, June, 15 (6), p.760-769.

[136] Ivry, R. B., Robertson, L. C. (1998). The two sides of perception. ed. Cambridge, MA, MIT Press. 315 p.

[137] Jackendoff, R., Lerdahl, F. (2006). The capacity for music: What is it, and what's special about it? Cognition, May, $100(1)$, p.33-72.

[138] Jamison, H. L., Watkins, K. E., Bishop, D. V., Matthews, P. M. (2006). Hemispheric specialization for processing auditory nonspeech stimuli. Cerebral cortex, September, 16 (9), p.1266-1275.

[139] Jancke, L.,Wustenberg, T.,Scheich, H., Heinze, H. J. (2002).Phonetic perception and the temporal cortex. Neuroimage, 15, p.733-746.

[140] Jefferies, L. N., Smilek, D., Eich, E., Enns, J. T. (2008). Emotional valence and arousal interact in attentional control. Psychological science, 19, p.290-295.

Asian Online Journals (www.ajouronline.com) 
[141] Johnsrude, I. S., Penhune, V. B., Zatorre, R. J. (2000). Functional specificity in the right human auditory cortex for perceiving pitch direction. Brain: a journal of neurology, January, 123 (1), p.155-163.

[142] Jones, S. J., Longe, O., Vaz Pato, M. (1998). Auditory evoked potentials to abrupt pitch and timbre change of complex tones: electrophysiological evidence of 'streaming'? Electroencephalography and clinical neurophysiology, March, 108 (2), p.131-142.

[143] Jones, R. R., Vaught, R. S., Weinrott, M. (1977). Time-series analysis in operant research. Journal of applied behavior analysis, 10, p.151-166.

[144] Just, M. A., Carpenter, P. A., Keller, T. A., Eddy, W. F., Thulborn, K. R. (1996). Brain activation modulated by sentence comprehension. Science, October, 274 (5284), p.114-116.

[145] Justus, K. (1988). Musical pitch identification by absolute pitch possessors. Perception and psychophysics, December, 44 (6), p.501-512.

[146] Justus, T. C., Bharucha, J. J. (2002). Music perception and cognition. In: H. Pashler, S. Yantis (eds.). Steven's handbook of experimental psychology: sensation and perception. ed. Hoboken, NJ, US, John Wiley and Sons Inc.p.453-492.

[147] Justus, T., Hutsler, J. J. (2005). Fundamental issues in the evolutionary psychology of music: assessing innateness and domain-specificity. Music perception, 23 (1), p.1-27.

[148] Juszczyk, P. W., Krumhansl, C. L. (1993). Pitch and rhythmic patterns affecting infants' sensitivity to musical phrase structure. Journal of experimental psychology. Human perception and performance, June, 19 (3), p.627-640.

[149] Kaas, J. H., Hackett, T. A., Tramo, M. J. (1999). Auditory processing in primate cerebral cortex. Current opinion in neurobiology, April, 9 (2), p.164-170.

[150] Kahana, M. J., Sekuler, R., Caplan, J. B., Kirschen, M., Madsen, J. R. (1999). Human theta oscillations exhibit task dependence during virtual maze navigation. Nature, June, 399 (6738), p.781-784.

[151] Kane, M. J., Hambrick, D. Z., Conway, A. R. A. (2005). Working memory capacity and fluid intelligence are strongly related constructs: comment on Ackerman, Beier, and Boyle. Psychological bulletin, 131 (1), p.66-71.

[152] Keenan, J. P., Thangaraj, V., Halpern, A. R., Schlaug, G. (2001). Absolute pitch and planum temporale. Neuroimage, December, 14 (6), p.1402-1408.

[153] Kelahan, A. M., Doetsch, G. S. (1984). Time-dependent changes in the functional organization of somatosensory cerebral cortex following digit amputation in adult raccoons. Somatosensory research, 2 (1), p.49-81.

[154] Klein, M., Coles, M. G., Donchin, E. (1984). People with absolute pitch process tones without producing a P300. Science, March, 223 (4642), p.1306-1309.

[155] Koelsch, S. (2005). Neural substrates of processing syntax and semantics in music. Current opinion in neurobiology, April, 15 (2), p. 207-212.

[156] Koelsch, S., Siebel, W. A. (2005). Towards a neural basis of music perception. Trends in cognitive sciences, December, 9 (12), p.578-584.

[157] Korsakowa, N. K., Moskowicute, L. I., Simernickaja, E. G. (1979). About functional interaction of the brain hemispheres in memory processes. In: Memory and trace processes. Abstracts of the 4 all-union conference. ed. Pusino, p.163-164. [original title: O funkcionalnom wzaimodeistwii polusharij mozga w procesah pamiati. In: Pamiat' i sledowye processy.Tezisy dokladow IV wsesojuznoj konferencii.]

[158] Kuhl, P. K. (1986). Theoretical contributions of tests on animals to the special-mechanisms debate in speech. Experimental biology, 45 (3), p.233-265.

[159] Kuhl, P. K. (1991). Perception, cognition and the ontogenetic and phylogenetic emergence of human speech. In: S. E. Brauth, W. S. Hall, R. J. Dooling (eds.). Plasticity of development, ed. Cambridge, MA, MIT Press. p.73-106.

[160] Kuhl, P. K. (2007). Cracking the speech code: how infants learn language. Acoustical science and technology, 28 (2), p.71-83.

[161] Kuhl, P. K., Conboy, B. T., Coffey-Corina, S., Padden, D., Rivera-Gaxiola, M., Nelson, T. (2007). Developmental phonetic perception: native language magnet theory expanded (NLM-e). Philosophical transactions of the Royal society B. Biol. Sci.,363 (1493), p.979-1000.

[162] Kuhnis, J., Elmer, S., Meyer, M., Jancke, L. (2013). The encoding of vowels and temporal speech cues in the auditory cortex of professional musicians: an EEG study. Neuropsychologia, July, 51 (8), p.1608-1618.

[163] Kurata, K., Tsuji, T., Naraki, S., Seino, M., Abe, Y. (2000). Activation of the dorsal premotor cortex and pre-supplementary motor area of humans during an auditory conditional motor task. Journal of neurophysiology, September, 84 (3), p.1667-1672.

[164] Langers, D. R. M., Krumbholz, K., Bowtell, R. W., Hall, D. A. (2014). Neuroimaging paradigms for tonotopic mapping (I): The influence of sound stimulus type. Neuroimage, October, 100, p.650-662.

[165] Larsen, J. P., Hoien, T., Lundberg, I., Odegaard, H. (1990). MRI evaluation of the size and asymmetry of the planum temporale in adolescents with developmental dyslexia. Brain and language, August, 39 (2), p.289-301. 
[166] Lepage, M., Brodeur, M., Bourgouin, P. (2003). Prefrontal cortex contribution to associative recognition memory in humans: an event-related functional magnetic resonance imaging study. Neuroscience letters, July, 346 (1-2),p.73-76.

[167] Leushina, L. I., Newskaja, A. A., Pawlowskaja, M. B. (1982). Asymmetry of the cerebral hemispheres in terms of identifying visual images. In: G. W. Gershuni (ed.). Sensory systems. Vision. ed. Leningrad, Nauka. p.76-92. [original title: Asimmetria polusarij golownogo mozga s tocki zrenija opoznanija zritelnyh obrazow. In: Sensornye sistemy. Zrenie.]

[168] Levitin, D. J. (1994). Absolute memory for musical pitch: evidence from the production of learned melodies. Perception and psychophysics, 56 (4), p.414-423.

[169] Levitin, D. J. (1996). Mechanisms of memory for musical attributes. Ph.D. Dissertation, University of Oregon, Eugene, Oregon, U.S.A. Dissertation Abstracts International, 57(07B), 4755. (University Microfilms No. AAG9638097).

[170] Levitin, D. J. (1999). Absolute pitch: self-reference and human memory. International journal of computing and anticipatory systems, $4, \mathrm{p} .255-266$.

[171] Levitin, D. J. (2004). Absolute pitch: self-reference and memory. (L'oreille absolue: Autoréférencement et mémoire) L'Annee psychologique, 104 (1), p.103-120.

[172] Levitin, D. J., Menon, V. (2003). Musical structure is processed in "language" areas of the brain: a possible role for Brodmann area 47 in temporal coherence. Neuroimage, December, 20 (4), p.2142-2152.

[173] Levitin, D. J., Rogers, S. E. (2005). Absolute pitch: perception, coding, and controversies. Trends in cognitive sciences, January, 9 (1), p.26-33.

[174] Levitin, D. J., Zatorre, R. J. (2003). On the nature of early music training and absolute pitch: a reply to Brown, Sachs, Cammuso, and Folstein. Music perception, Fall, 21 (1), p.105-110.

[175] Lewandowsky, S., Yang, L. X., Newell, B. R., Kalish, M. L. (2012). Working memory does not dissociate between different perceptual categorization tasks. Journal of experimental psychology: learning, memory, and cognition, 38 (4), p.881-904.

[176] Lezak, M. D. (2004). Neuropsychological assessment. $4^{\text {th }}$ ed. New York, Oxford University Press. 1016 p.

[177] Liegeois-Chauvel, C., Peretz, I., Babai, M., Laguitton, V., Chauvel, P. (1998). Contribution of different cortical areas in the temporal lobes to music processing. Brain, October, 121 (10), p.1853-1867.

[178] Loring, D. W. (1999). Dictionary of neuropsychology. ed. New York, Oxford University Press. 193 p.

[179] Loui, P., Li, H. C., Schlaug, G. (2011). White matter integrity in right hemisphere predicts pitch-related grammar learning. Neuroimage, March, 55 (2), p.500-507.

[180] Makovski, T. (2019). Preparing for distraction: Attention is enhanced prior to the presentation of distractors. Journal of experimental psychology: general, 148 (2), p.221-236.

[181] Makris, N., Kennedy, D. N., McInerney, S., Sorensen, A. G., Wang, R., Caviness, V. S., Pandya, D. N. (2005). Segmentation of subcomponents within the superior longitudinal fascicle in humans: a quantitative, in vivo, DT-MRI study. Cerebral cortex, June, 15 (6), p.854-869.

[182] Massaro, D. W (1972). Perceptual images, processing time, and perceptual units in auditory perception. Psychological review, 79 (2), p.124-145.

[183] Matsuda, A., Hara, K., Watanabe, S., Matsuura, M., Ohta, K., Matsushima, E. (2013). Pre-attentive auditory processing of non-scale pitch in absolute pitch possessors. Neuroscience letters, August, 548, p.155-158.

[184] Maye, J., Werker, J. F., Gerken, L. (2002). Infant sensitivity to distributional information can affect phonetic discrimination. Cognition, January, 82 (3), B101-B111.

[185] Meyer, M., Elmer, S., Ringli, M., Oechslin, M. S., Baumann, S., Jancke, L. (2011). Long-term exposure to music enhances the sensitivity of the auditory system in children. European journal of neuroscience, September, 34 (5), p. 755-765.

[186] Mazoyer, B. M., Tzourio, N.Frak, V., Syrota, A., Murayama, N., Levrier, O., Salamon, G., Dehaene, S., Cohen, L., Mehler, J. (1993). The cortical representation of speech. Journal of cognitive neuroscience, Fall, 5 (4), p.467-479.

[187] Mazzucchi, A., Marchini, C., Budai, R., Parma, M. (1982). A case of receptive amusia with prominent timbre perception defect. Journal of neurology, neurosurgery and psychiatry, July, 45 (7), p.644-647.

[188] McCain, L. J., McCleary, R. (1979). The statistical analysis of the simple interrupted time-series quasi-experiment. In: T. D. Cook., D. T. Campbell, (eds.). Quasi-experimentation: design and analysis issues for field settings. Chicago, ed. Rand-Mc-Nally, p.233-293.

[189] McLachlan, N., and Sarah, W. (2010). The central role of recognition in auditory perception: a neurobiological model. Psychological review, January, 117 (1), p.175-196.

[190] Mehler, J., Dupoux, E., Nazzi, T., Dehaene-Lambertz, G. (1996). Coping with linguistic diversity: the infant's viewpoint. In: J. L. Morgan, K. Demuth (eds.). Signal to syntax: bootstrapping from speech to grammar in early acquisition. ed. Hillsdale, NJ, US, Lawrence Erlbaum Associates Inc. p.101-116.

[191] Meltzer, J. A., Constable, R. T. (2005). Activation of human hippocampal formation reflects success in both encoding and cued recall of paired associates. Neuroimage, January, 24 (2), p.384-397.

Asian Online Journals (www.ajouronline.com) 
[192] Merzenich, M. M., Nelson, R. J., Stryker, M. P., Cynader, M. S., Schoppmann, A., Zook, J. M. (1984). Somatosensory cortical map changes following digit amputation in adult monkeys. Journal of comparative neurology, April, 224 (4), p.591-605.

[193] Meyer, M., Baumann, S., Jancke, L. (2006). Electrical brain imaging reveals spatio-temporal dynamics of timbre perception in humans. Neuroimage, October, 32 (4), p.1510-1523.

[194] Meyer, M., Friederici, A. D., von Cramon, D. Y. (2000). Neurocognition of auditory sentence comprehension: event related fMRI reveals sensitivity to syntactic violations and task demands. Brain research, January, 9 (1), p.19-33.

[195] Milner, B. (1962). Laterality effects in audition. In: V. B. Mountcastle (ed.). Interhemispheric relations and cerebral dominance. ed. Baltimore, Md. Johns Hopkins University Press. p.177-195.

[196] Miyazaki, K. (1989).Absolute pitch identification:Effects of timbre and pitch region.Music Perception,7(1), p.1-14.

[197] Miyazaki, K. (2000). Interaction in musical-pitch naming and syllable naming: an experiment on a Stroop-like effect in hearing. In: T. Nakada (ed.). Integrated human brain science: theory, method, application (music). ed. Amsterdam, Elsevier. p.415-423.

[198] Miyazaki, K., Ogawa, Y. (2006). Learning absolute pitch by children: a cross-sectional study. Music perception, 24 (1), p.63-78.

[199] Morrison, A. B., Chein, J. M. (2011). Does working memory training work? The promise and challenges cognition by training working memory. Psychonomic bulletin and review, 18 (1), p.46-60.

[200] Mummery, C. J., Ashburner, J., Scott, S. K., Wise, R. J. (1999). Functional neuroimaging of speech perception in six normal and two aphasic subjects. Journal of the acoustical society of America, July, 106 (1), p.449-457.

[201] Munte, T. F., Altenmuller, E., Jancke, L. (2002). The musician's brain as a model of neuroplasticity. Nature reviews. Neuroscience, June, 3 (6), p.473-478.

[202] Munte, T. F., Nager, W., Beiss, T., Schroeder, C., Altenmuller, E. (2003). Specialization of the specialized: electrophysiological investigations in professional musicians. Annals of the New York academy of sciences, November, 999, p.131-139.

[203] Nazzi, T., Bertoncini, J., Mehler, J. 1998. Language discrimination in newborns: Toward an understanding of the role of rythm. Journal of experimental psychology: human perception and performance, June, 24 (3), p.756-766.

[204] Norman, D. A., Shallice, T. (1986). Attention to action: willed and automatic control of behavior. In: R. Davidson, R. Schwartz, D. Shapiro. (eds.). Consciousness and self-regulation: advances in research and theory, volume IV. ed. New York, Plenum Press. p.1-18.

[205] Nusbaum, H, C., Morin, T. M. (1992). Paying attention to differences among talkers. In: Y. Tohkura, Y. Sagisaka, E. Vatikiotis-Bateson (eds.). Speech perception, production and linguistic structure. ed. Tokyo, OHM publishing company, p.113-134.

[206] Oakes, W. E (1951). An alternative interpretation of "absolute pitch." Transactions of the Kansas academy of sciences, 54, p.396-406.

[207] Oechslin, M. S., Meyer, M., Jancke, L. (2010). Absolute pitch - functional evidence of speech relevant auditory acuity. Cerebral cortex, February, 20 (2), p.447-455.

[208] Ohnishi, T., Matsuda, H., Asada, T., Aruga, M., Hirakata, M., Nishikawa, M., Katoh, A., Imabayashi, E. (2001). Functional anatomy of musical perception in musicians. Cerebral cortex, August, 11 (8), p.754-760.

[209] Olivers, C. N., Nieuwenhuis, S. (2005). The beneficial effect of concurrent task-irrelevant mental activity on temporal attention. Psychological science, 16, p.265-269.

[210] Oskina, S. E., Parnes, D. G. (2005). Musical hearing: theory and method of development and improvement. ed. Moscow, AST. 78 p. [original title: Muzykalnyj sluh: teoria i metodika razwitia i sowershenstwowania.]

[211] Overy, K. (2003). Dyslexia and music. From timing deficits to musical intervention. Annals of the New York academy of sciences, November, 999, p.497-505.

[212] Owen, A. M., Milner, B., Petrides, M., Evans, A. C. (1996). Memory for object features versus memory for object location: a positron-emission tomography study of encoding and retrieval processes. Proceedings of the national academy of sciences of the United States of America, August, 93 (17), p.9212-9217.

[213] Pantev, C., Engelien, A., Candia, V., Elbert, T. (2001). Representational cortex in musicians. Plastic alterations in response to musical practice. Annals of the New York academy of sciences, June, 930, p.300-314.

[214] Pantev, C., Roberts, L. E., Schulz, M., Engelien, A., Ross, B. (2001). Timbre-specific enhancement of auditory cortical representations in musicians. Neuroreport, January, 12 (1), p.169-174.

[215] Papousek, H. (1996). Musicality in infancy research: biological and cultural origins of early musicality. In: I. Deliege., J. A. Sloboda. (eds.) Musical beginnings. ed. Oxford University Press. p.37-55.

[216] Parncutt, R., Levitin, D. J. (2001). Absolute pitch. In: S. Sadie (ed.) New Grove dictionary of music and musicians. ed. New York, St. Martin's Press. p.37-39.

Asian Online Journals (www.ajouronline.com) 
[217] Patel, A. D. (2003). Language, music, syntax and the brain. Nature neuroscience, July, 6 (7), p. 674-681.

[218] Patel, A. D. 2010. Music, language, and the brain. ed. New York, Oxford University Press. 526 p.

[219] Pauws, S. (2003). Effects of song familiarity, singing training, and recent song exposure on the singing of melodies. 8 p. https://jscholarship.library.jhu.edu/handle/1774.2/11 (access on March 31 ${ }^{\text {st }} 2019$ ).

[220] Pechmann, T., Mohr, G. (1992).Interference in memory for tonal pitch: implications for a working-memory model. Memory and cognition, 20 (3), p.314-320.

[221] Penfield, W., Milner, B. (1958). Memory deficit produced by bilateral lesions in the hippocampal zone. A.M.A.Archives of neurology and psychiatry, May, 79 (5). p.475-497.

[222] Perani, D., Saccuman, M. C., Scifo, P., Spada, D., Andreolli, G., Rovelli, R., Baldoli, C., Koelsch, S. (2010). Functional specializations for music processing in the human newborn brain. Proceedings of the national academy of sciences of the United States of America, March, 107 (10), p.4758-4763.

[223] Peretz, I., Zatorre, R, J. (2005). Brain organization for music processing. Annual review of psychology, 56, p.89-114.

[224] Pessoa, L., Padmala, S., Kenzer, A., Bauer, A. (2012). Interactions between cognition and emotion during response inhibition. Emotion, 12, p.192-197.

[225] Petrides, M. (1985). Deficits in non-spatial conditional associative learning after periarcuate lesions in the monkey. Behavioural brain research, August, 16 (2-3), p.95-101.

[226] Petrides, M. (1990). Nonspatial conditional learning impaired in patients with unilateral frontal but not unilateral temporal lobe excisions. Neuropsychologia, 28 (2), p.137-149.

[227] Petrides, M. (1985). Deficits on conditional associative-learning tasks after frontal- and temporal-lobe lesions in man. Neuropsychologia, 23 (5), p.601-614.

[228] Petrides, M., Alivisatos, B., Evans, A. C., Meyer, E. (1993). Dissociation of human mid-dorsolateral from posterior dorsolateral frontal cortex in memory processing. Proceedings of the national academy of sciences of the United States of America, February, 90 (3), p.873-877.

[229] Petrides, M., Alivisatos, B., Meyer, E., Evans, A. C. (1993). Functional activation of the human frontal cortex during the performance of verbal working memory tasks. Proceedings of the national academy of sciences of the United States of America, February, 90 (3), p.878-882.

[230] Podbros, L. Z., Stamm, J. S., Denaro, F. J. (1980). Associative function of the arcuate segment of the monkey's prefrontal cortex. Physiology and behavior, January 24 (1), p.103-109.

[231] Poeppel, D. (1996). A critical review of PET studies of phonological processing. Brain and language, December, 55 (3), p.317-385.

[232] Poppel, E. (1994). Temporal mechanisms in perception. International review of neurobiology, 37, p.185-207.

[233] Poppel, E. (1997). A hierarchical model of temporal perception. Trends in cognitive sciences, May, 1 (2), p.56-61.

[234] Poppel, E. (2004). Lost in time: a historical frame, elementary processing units and the 3-second-window. Acta neurobiologiae experimentalis, 64 (3), p.295-301.

[235] Profita, J., Bidder, T. G., Optiz, J. M., Reynolds, J. F. (1988). Perfect pitch. American journal of medical genetics, April, 29 (4), p.763-771.

[236] Rabbitt, P. (1997). Methodology of frontal and executive function. ed. Hove, UK, Psychology Press. 264 p.

[237] Ragert, P., Schmidt, A., Altenmuller, E., Dinse, H. R. (2004). Superior tactile performance and learning in professional pianists: evidence for meta-plasticity in musicians. European journal of neuroscience, January, 19 (2), p.473-478.

[238] Rakowski, A. (1993). Categorical perception in absolute pitch. Archives of Acoustics, 18 (4), p. 515-523.

[239] Rakowski, A., Morawska-Bungeler, M. (1987). In search for the criteria of absolute pitch. Archives of acoustics, 12, p.75-87.

[240] Rakowski, A., Miyazaki, K. (2007). Absolute pitch: common traits in music and language. Archives of acoustics, 32 (1), p.5-16.

[241] Rama, P., Relander-Syrjanen, K., Carlson, S., Salonen, O., Kujala, T. (2012). Attention and semantic processing during speech: An fMRI study. Brain and language. August, 122 (2), p.114-119.

[242] Ramus, F., Nespor, M., Mehler, J. (1999). Correlates of linguistic rhythm in the speech signal. Cognition, December, 73 (3), p.265-292.

[243] Revesz, G. (1913). Zur grundlagen der tonpsychologie. Ed. Germany, Leipzig Veit.

[244] Robertson, D., Irvine, D. R. (1989). Plasticity of frequency organization in auditory cortex of guinea pigs with partial unilateral deafness. Journal of comparative neurology, April, 282 (3), p.456-471.

[245] Rogenmoser, L., Elmer, S., Jancke, L. (2014). Absolute pitch: evidence for early cognitive facilitation during passive listening as revealed by reduced $\mathrm{P} 3 \mathrm{a}$ amplitudes. Journal of cognitive neuroscience, March, 27 (3), p.623-637.

[246] Rotenberg, V. S., Arshavsky, V. V. (1995): The "entropy" of right hemisphere activity and the restorative capacity of image thinking. Journal of mental imagery, 19, p.151-160.

Asian Online Journals (www.ajouronline.com) 
[247] Ronnberg, J., Lunner, Th., Zekveld, A., Sorqvist, P., Danielsson, H., Lyxell, B., Dahlstrom, O., Signoret, C., Stenfelt, S., Pichora-Fuller, M. K., Rudner, M. (2013). The ease of language understanding (ELU) model: theoretical, empirical, and clinical advances. Frontiers in systems neuroscience, July, vol.7, art.31, 17 p.

[248] Ross, D., Olson, I., Marks, L., Gore, J. (2004). A nonmusical paradigm for identifying absolute pitch possessors. Journal of the acoustical society of America, October, 116 (3), p.1793-1799.

[249] Ross, D. A., Olson, I. R., Gore, J. C. (2006). Absolute pitch does not depend on early musical training. Annals of the New York academy of sciences, November, 999, p.522-526.

[250] Saffran, J. R, Aslin, R. N., Newport, E. L. (1996). Statistical learning by 8-month old infants. Science, December, 274 (5294), p.1926-1928.

[251] Sakakibara. A. (2014). A longitudinal study of the process of acquiring absolute pitch: a practical report of training with the 'chord identification method'. Psychology of music, 42 (1), p.86-111.

[252] Sakurai, Y. (2002). Coding of auditory temporal and pitch information by hippocampal individual cells and cell assemblies in the rat. Neuroscience, 115 (4), p.1153-1163.

[253] Salame, P., Baddeley, A. D. (1989). Effects of background music on phonological short-term memory. Quarterly journal of experimental psychology: a human experimental psychology, 41A, p. 107-122.

[254] Samson, S. (2003). Neuropsychological studies of musical timbre. Annals of the New York academy of sciences, November, 999 (1), p.144-151.

[255] Samson, S., Zatorre, R. J. (1988). Melodic and harmonic discrimination following unilateral cerebral excision. Brain and cognition, June, 7 (3), p.348-360.

[256] Samson, S., Zatorre, R. J. (1994). Contribution of the right temporal lobe to musical timbre discrimination. Neuropsychologia, February, 32 (2), p.231-240.

[257] Sauseng, P., Klimesch, W., Schabus, M., Doppelmayr, M. (2005). Fronto-parietal EEG coherence in theta and upper alpha reflect central executive functions of working memory. International journal of psychophysiology, August, 57 (2), p.97-103.

[258] Schellenberg, E. G., Trehub, S. E. (2003). Good pitch memory is widespread. Psychological science, May, 14 (3), p.262-266.

[259] Schendel, Z. A, Palmer, C. (2007). Suppression effects on musical and verbal memory. Memory and cognition, 35 (4), p.640-650.

[260] Schlaug, G. (2001). The brain of musicians. A model for functional and structural adaptation. Annals of the New York academy of sciences, June, 930, p.281-299.

[261] Schlaug, G., Jancke, L., Huang, Y., Steinmetz, H. (1995). In vivo evidence of structural brain asymmetry in musicians. Science, 267 (5198), p.699-701.

[262] Schlosser, M. J., Aoyagi, N., Fulbright, R. K., Gore, J. C., McCarthy, G. (1998). Functional MRI studies of auditory comprehension. Human brain mapping, 6 (1), p.1-13.

[263] Schonwiesner, M., Rubsamen, R., von Cramon, D. Y. (2005). Hemispheric asymmetry for spectral and temporal processing in the human antero-lateral auditory belt cortex. European journal of neuroscience, September, 22 (6), p.1521-1528.

[264] Schreiner, C. E., Read, H. L., Sutter, M. L. (2000). Modular organization of frequency integration in primary auditory cortex. Annual review of neuroscience, 23, p.501-529.

[265] Schulze, K., Gaab, N., Schlaug, G. (2009). Perceiving pitch absolutely: comparing absolute and relative pitch possessors in a pitch memory task. BMC neuroscience, August,10, art. 106, 13 p.

[266] Seachore, C. E. (1919). The psychology of musical talent. ed. Boston, Silver Burdett Company. 310 p.

[267] Semenowic, A. W. (2018). Introduction to neuropsychology of childhood. $6^{\text {th }}$ ed. Moscow, Genesis. 319 p. [original title: Wwedenie w neiropsihologiu detskogo wozrasta.]

[268] Sergeant, D. (1969). Experimental investigation of absolute pitch. Journal of research in music education, 17, p.135-143.

[269] Sergeant, D., Roche, S. (1973). Perceptual shifts in the auditory information processing of young children. Psychology of music, 1 (2), p.39-48.

[270] Shallice, T. Burgess, P. (1996). The domain of supervisory processes and the temporal organization of behavior. Philosophical transactions of the Royal society of London, 351, p.1405-1412.

[271] Shallice, T. (1982). Specific impairments of planning. Philosophical transactions of the Royal society of London, 298, p.199-209.

[272] Shaywitz, B. A., Shaywitz, S. E., Pugh, K. R., Constable, R. T., Skudlarski, P., Fulbright, R. K., Bronen, R. A., Fletcher, J. M., Shankweiler, D. P., Katz, L., Gore, J. C. (1995). Sex differences in the functional organization of the brain for language. Nature, February, 373 (6515). p.607-609.

[273] Siegel, J. A. (1974). Sensory and verbal coding strategies in subjects with absolute pitch. Journal of experimental psychology, July, 103 (1), p.37-44.

[274] Siegel, J. A., Siegel, W. (1977). Absolute identification of notes and intervals by musicians. Perception and Psychophysics, 21 (2), p.143-152.

Asian Online Journals (www.ajouronline.com) 
[275] Sinai, A., Pratt, H. (2003). High-resolution time course of hemispheric dominance revealed by low-resolution electromagnetic tomography. Clinical neurophysiology, July, 114 (7), p.1181-1188.

[276] Stamm, J. S. (1973). Functional dissociation between the inferior and arcuate segments of dorsolateral prefrontal cortex in the monkey. Neuropsychologia, May, 11 (2), p.181-190.

[277] Stanley, J. M., Hughes, J. E. (1997). Evaluation of an early intervention music curriculum for enhancing prereading / writing skills. Music therapy perspectives, 15, p.79-85.

[278] Stumpf, C. (1882, 1890). Tonpsychology, vol.1 (1882), vol.2 (1890), ed. Hirzel, Leipzig.

[279] Stuss, D. T., Benson, D. F. (1986). The frontal lobes. ed. New York, Raven Press. 303 p.

[280] Stuss, D. T., Knight, R. T. (2002). Principles of frontal lobe function.ed.New York, Oxford University Press.800 p.

[281] Sussman, T. J., Heller, W., Miller, G. A., Mohanty, A. (2013). Emotional distractors can enhance attention. Psychological science, 24 (11), p.2322-2328.

[282] Suzuki, W. A., Clayton, N. S. (2000). The hippocampus and memory: a comparative and ethological perspective. Current opinion in neurobiology, December, 10 (6), p.768-773.

[283] Szelag, E. (1997). Temporal integration of the brain as studied with the metronome paradigm. In: H. Atmanspacher, E. Ruhnau (ed.). Time, temporality, now. Part.II. Experiencing time and concepts of time in an interdisciplinary perspective. Copyright Springer-Verlag Berlin Heidelberg. p.121-131.

[284] Szelag, E., von Steinbuchel, N., Reiser, M., Langen, E. G., Poppel, E. (1996). Temporal constraints in processing of nonverbal rhythmic patterns. Acta neurobiologiae experimentalis, 56 (1), p.215-225.

[285] Szelag, E., Kanabus, M., Kolodziejczyk, I., Kowalska, J., Szuchnik, J. (2004). Individual differences in temporal information processing in humans. Acta neurobiologiae experimentalis, 64 (3), p.349-366.

[286] Tyron, W. W. (1982). A simplified time-series analysis for evaluation treatment interventions. Journal of applied behavioral analysis, Fall, 15 (3), p.423-429.

[287] Takeuchi, A. H., Hulse, S. H. (1991). Absolute-pitch judgments of black- and white-key pitches. Music perception, 9, p.27-46.

[288] Takeuchi, A. H., Hulse, S. H. (1993). Absolute pitch. Psychological bulletin, March, 113 (2), p.345-361.

[289] Talavage, T. M., Sereno, M. I., Melcher, J. R., Ledden, P. J., Rosen, B. R., Dale, A. M. (2004). Tonotopic organization in human auditory cortex revealed by progressions of frequency sensitivity. Journal of neurophysiology, March, 91 (3), p.1282-1296.

[290] Teki, S., Kumar, S., von Kriegstein, K., Stewart, L., Lyness, C., Moore, B. C., Capleton, B., Griffiths, T. D.(2012). Navigating the auditory scene: an expert role for the hippocampus. Journal of neuroscience, August, 32 (35), p.12251-12257.

[291] Terhardt, E., Ward, W. D. (1982). Recognition of musical key: exploratory study. Journal of the acoustical society of America, July, 72 (1), p.26-33.

[292] Terhardt, E., Seewann, M. (1983). Aural key identification and its relationship to absolute pitch. Music perception, 1, p.63-84.

[293] Tervaniemi, M., Hugdahl, K. (2003). Lateralization of auditory-cortex functions. Brain research reviews, 43 (3), January, p.231-246.

[294] Trainor, L. J., Shahin, A., Roberts, L. E. (2003). Effects of musical training on the auditory cortex in children. Annals of the New York academy of sciences, November, 999, p.506-513.

[295] Trainor, L. J., Trehub, S. E. (1992). A comparison of infants' and adults' sensitivity to western musical structure. Journal of experimental psychology. Human perception and performance, May, 18 (2), p.394-402.

[296] Tramo, M. J., Cariani, P. A., Delgutte, B., Braida, L. D. (2001). Neurobiological foundations for the theory of harmony in western tonal music. Annals of the New York academy of sciences, June, 930, p.92-116.

[297] Tramo, J. M., Cariani, P. A., Delgutte, B., Braida, L. D. (2003). Neurobiology of harmony perception. In: I. Peretz, R. J. Zatorre. The cognitive neuroscience of music. ed. New York, Oxford University Press. p.126-151.

[298] Tramo, M. J., Shah, G. D., Braida, L. D. (2002). Functional role of auditory cortex in frequency processing and pitch perception. Journal of Neurophysiology, January, 87 (1), p.122-139.

[299] Trehub, S. (2003). Absolute and relative pitch processing in tone learning tasks. Developmental science, 6 (1), p.44-45.

[300] Trehub, S. E., Schellenberg, E. G., Hill, D. S. (1997). The origins of music perception and cognition: a developmental perspective. In: I. Deliege, J. Sloboda (eds.) Perception and cognition of music. ed. Hove, England, Psychology Press, Erlbaum UK Taylor and Francis. p.103-128.

[301] Van Hedger, S. C., Heald, Sh. L. M., Nusbaum, H. C. (2018). Absolute pitch can be learned by some adults. 22 p. https://www.researchgate.net/profile/Shannon_Heald/publication/325208629_Absolute_pitch_can_be_learned_ by_some_adults/links/5bc12772299bf1004c5e4bd4/Absolute-pitch-can-be-learned-by-some-adults.pdf

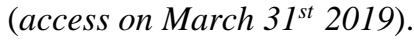

[302] Van Hedger, S. C., Heald, Sh. L. M., Nusbaum, H. C. (2018). Long-term pitch memory for music recordings is related to auditory working memory precision. Quarterly journal of experimental psychology, April, 71 (4),p.879-891.

Asian Online Journals (www.ajouronline.com) 177 
[303] Van Hedger, S. C., Heald, Sh. L. M., Koch, R., Nusbaum, H. C. (2015). Auditory working memory predicts individual differences in absolute pitch learning. Cognition, July, 140, p.95-110.

[304] Van Strien, N. M., Cappaert, N. L., Witter, M. P. (2009). The anatomy of memory: an interactive overview of the parahippocampal-hippocampal network. Nature reviews. Neuroscience, April, 10 (4), p.272-282.

[305] Vanzella, P., Schellenberg, E. G. (2010). Absolute pitch: effects of timbre on note-naming ability. PloSOne, November, 5 (11), e15449. 7 p.

[306] Vitouch, O. (2003). Absolutist models of absolute pitch are absolutely misleading. Music perception, Fall, 21 (1), p.111-117.

[307] Wagner, A. D., Schacter, D. L., Rotte, M., Koutstaal, W., Maril, A., Dale, A. M., Rosen, B. R., Buckner, R. L. (1998). Building memories: remembering and forgetting of verbal experiences as predicted by brain activity. Science, August, 281 (5380), p.1188-1191.

[308] Ward, W. D. (1963). Absolute pitch: Part I. Sound: its uses and control, 2(3), p.14-21; 2 (4), p.33-41.

[309] Ward, W. D. (1999). Absolute Pitch. In: D. Deutsch (ed.). The psychology of music. ed. San Diego, CA, Academic Press. p.265-298.

[310] Ward, L. M. (2003). Synchronous neural oscillations and cognitive processes. Trends in cognitive sciences, December, 7 (12), p.553-559.

[311] Ward, W. D., Burns, E. M. (1982). Absolute Pitch. In: D. Deutsch (ed.). The psychology of music. ed. San Diego, CA, Academic Press. p.431-451.

[312] Warren, J. D., Uppenkamp, S., Patterson, R. D., Griffiths, T. D. (2003). Separating pitch chroma and pitch height in the human brain. Proceedings of the national academy of sciences of the United States of America, August, 100 (17), p.10038-10042.

[313] Watt, H. J. (1917). The psychology of sound. ed. London and New York, Cambridge University Press. 241 p.

[314] Wilson, S. J., Lusher, D., Martin, C. L., Rayner, G., McLachlan, N. (2012). Intersecting factors lead to absolute pitch acquisition that is maintained in a 'fixed do' environment. Music Perception, 29 (3), p.285-296.

[315] Wing, R. A. (1941) A factorial study of musical tests. British journal of psychology, April, 31 (4), p.341-355.

[316] Wong, P. C., Uppunda, A. K., Parrish, T. B., Dhar, S. (2008). Cortical mechanisms of speech perception in noise. Journal of speech language and hearing research, August, 51 (4), p.1026-1041.

[317] Wu, C., Kirk, I. J., Hamm, J. P., Lim, V. K. (2008). The neural networks involved in pitch labeling of absolute pitch musicians. Neuroreport, May, 19 (8), p.851-854.

[318] Young, L. C. (1941). On randomness in ordered sequences. Annals of mathematical statistics, 12, p.293-300.

[319] Zaehle, T., Jancke, L., Meyer, M. (2007). Electrical brain imaging evidences left auditory cortex involvement in speech and non-speech discrimination based on temporal features. Behavioral and brain functions, December, 3 (63), $11 \mathrm{p}$.

[320] Zakay, D., Roziner, I., Ben-Arzi, S. (1984). On the nature of absolute pitch. Archiv fur psychologie, 136 (2), p.163-166.

[321] Zatorre, R. J. (1985). Discrimination and recognition of tonal melodies after unilateral cerebral excisions. Neuropsychologia, 23 (1), p.31-41.

[322] Zatorre, R. J. (2003). Absolute pitch: a model for understanding the influence of genes and development on neural and cognitive function. Nature neuroscience, July, 6 (7), p.692-695.

[323] Zatorre, R. J. (2005). Neuroscience: finding the missing fundamental. Nature, August, 436 (7054), p.1093-1094.

[324] Zatorre, R. J., Beckett, C. (1989). Multiple coding strategies in the retention of musical tones by possessors of absolute pitch. Memory and cognition, September, 17 (5), p.582-589.

[325] Zatorre, R. J., Samson, S. (1991). Role of the right temporal neocortex in retention of pitch in auditory short-term memory. Brain, December, 144 (6), p.2403-2417.

[326] Zatorre, R. J., Evans, A. C., Meyer, E., Gjedde, A. (1992). Lateralization of phonetic and pitch discrimination in speech processing. Science, May, 256 (5058), p.846-849.

[327] Zatorre, R. J., Evans, A. C., Meyer, E. (1994). Neural mechanisms underlying melodic perception and memory for pitch. Journal of neuroscience, April, 14 (4), p.1908-1919.

[328] Zatorre, R. J., Halpern, A. R., Perry, D. W., Meyer, E., Evans, A. C. (1996). Hearing in the mind's ear: a PET investigation of musical imagery and perception. Journal of cognitive neuroscience, Winter, 8 (1), p. $29-46$.

[329] Zatorre, R. J., Perry, D. W., Beckett, C. A., Westbury, C. F., Evans, A. C. (1998). Functional anatomy of musical processing in listeners with absolute pitch and relative pitch. Proceedings of the national academy of sciences of the United States of America, 95 (6), p.3172-3177.

[330] Zatorre, R. J., Belin, P. (2001). Spectral and temporal processing in human auditory cortex. Cerebral cortex, October, 11 (10), p.946-953. 